Division

Chemical Technology

Division

Chemical Technology

Division

Chemical Technology

Division

Chemical Technology

Division

Chemical Technology

Division

Chemical Technology

\title{
A Survey of Decontamination Processes Applicable to DOE Nuclear Facilities
}

Division

Chemical Technology

Division

Chemical Technology

Division

Chemical Technology

Division

Chemical Technology

Division

chemical Technology

Division

Chemical Technology

Division

Chemical Technology

Division

Chemical Technology

Division

Chemical Technology

Division

Chemical Technology

Division

\section{RECEIVED \\ JAN 271998 \\ OOTI}

by L. Chen, D. B. Chamberlain, C. Conner, and G. F. Vandegrift

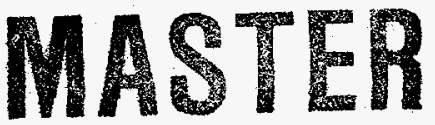

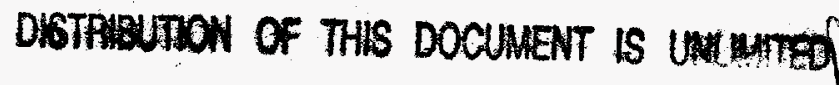

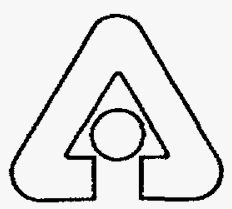

Argonne National Laboratory, Argonne, Illinois 60439 operated by The University of Chicago

for the United States Department of Energy under Contract W-31-109-Eng-38

Chemical Technology

Division

Chemical Technology

Division

Chemical Technology

Division

Chemical Technology

Division 
Argonne National I Laboratory, with facilities in the states of Illinois and Idaho, is owned by the United States government, and operated by The University of Chicago under the provisions of a contract with the Department of Energy.

\section{DISCLAIMER}

This report w'as prepared as an account of work sponsored by an agency of the United S ates Government. Neither the United States Government nor any agency thereof, nor any of their employees, makes any warranty, express or implied, or assumes any legal liability or responsibility for the accuracy, completenes:; or usefulness of any information, apparatus, product, or process disclose1, or represents that its use would not infringe privately owned rights. Reference herein to any specific commercial product, process, or service by trade name, trademark, manufacturer, or otherwise, does not necessarily sonstitute or imply its endorsement, recommendation, or favoring by the United States Government or any agency thereof. The views and opinions of authors expressed herein do not necessarily state or reflect those of the United States Government or any agency thereof.

Reproduced from the best available copy.

Available to DOE and DOE contractors from the

Office of Scientific and Technical Information

P.O. Box 62

Oak Ridge, TN 37831

Prices available from (423) 576-8401

Available to the public from the

National Technical Information Service

U.S. Department of Commerce

5285 Port Royal Road

Springfield, VA 22161 


\section{DISCLAIMER}

Portions of this document may be illegible electronic image products. Images are produced from the best available original document. 


\author{
ARGONNE NATIONAL LABORATORY \\ 9700 South Cass Avenue \\ Argonne, IL 60439
}

\title{
A SURVEY OF DECONTAMINATION PROCESSES APPLICABLE TO DOE NUCLEAR FACILITIES
}

by

L. Chen, D. B. Chamberlain, C. Conner, and G. F. Vandegrift

Chemical Technology Division

May 1997

Prepared for Westinghouse Hanford Company, Richland, WA, through Inter-DOE Work Order No. M5CHEO1. Funded by U.S. Department of Energy, Office of Technology Development (EM-50). 


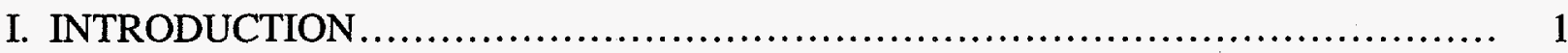

II. SUMMARY OF DECONTAMINATION TECHNIQUES............................ 3

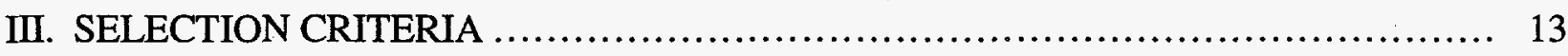

IV. CONSTITUENTS OF CONTAMINATED LAYERS.............................. 15

A. Contamination of Reactor Coolant Systems and Components................... 15

B. Contamination of Nuclear Fuel Cycle Facilities and Related Systems ............ 16

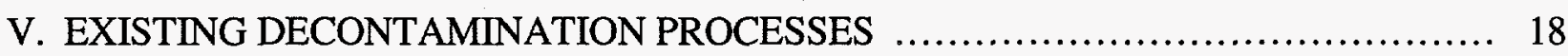

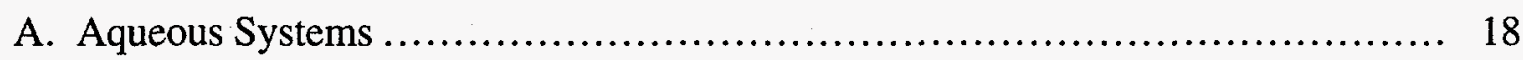

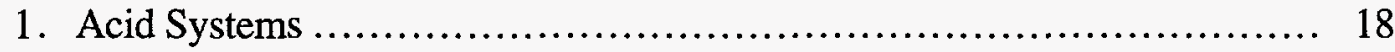

a. Hydrochloric Acid........................................... 20

b. Nitric Acid.................................................... 20

c. Sulfuric Acid................................................ 21

d. Phosphoric Acid .............................................. 22

e. Sulfamic Acid ........................................... 23

f. Nitric Acid plus Hydrofluoric Acid .............................. 23

g. Nitric plus Sulfuric Acids ................................... 25

h. Nitric Acid plus Hydrochloric Acid .............................. 25

i. Fluoroboric Acid ............................................. 25

j. Oxalic Acid........................................................ 27

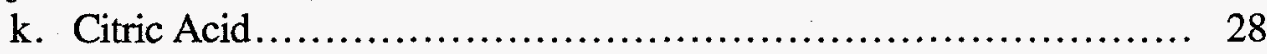

1. Mixed Organic Acids....................................... 28

2. Alkaline Permanganate Systems .................................... 29

a. Alkaline Permanganate (AP) ................................... 29

b. Alkaline Permanganate-Ammonium Citrate (APAC)............... 29

c. Alkaline Permanganate-Ammonium Citrate-EDTA (APACE) ........ 31

d. Alkaline Permanganate-Oxalic Acid (APOX) .................... 31

e. Alkaline Permanganate-Oxalic Acid-Citric Acid (AP-Citrox) ....... 32

f. Alkaline-Persulfate/Citrox ..................................... 33

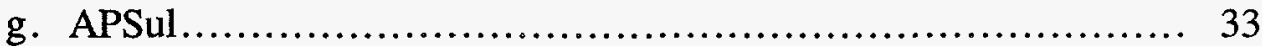

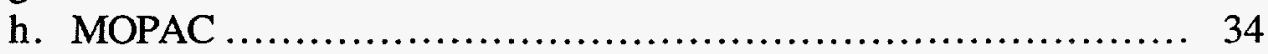

i. Nitric Acid-Potassium Permanganate (NP) ..................... 34 


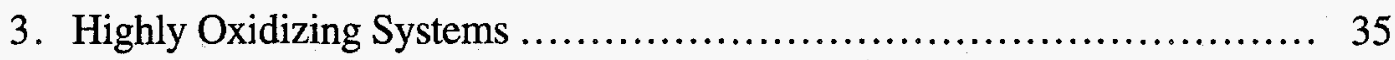

a. Cerium(IV) Process.......................................... 35

b. Ce(IV) with Fluoride Promoters............................ 37

c. Ag(II) Process ................................................ 38

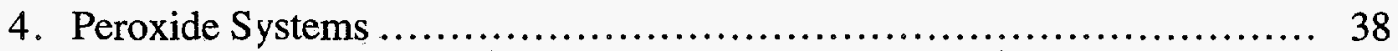

a. Hydrogen Peroxide-Oxalic Acid-Hydrothermic Acid (OPP)........ 39

b. Hyidrogen Peroxide-Oxalic Acid-Hydrofluoric Acid................ 39

c. Hydrogen Peroxide-Oxalic Acid-Citric Acid...................... 39

d. Hydrogen Peroxide-Oxalic Acid-Gluconic Acid (OPG) ............ 40

e. Hydrogen Peroxide-Sulfuric Acid............................. 41

f. Hydrogen Peroxide-Carbonate ................................ 41

g. Hydrogen Peroxide-Carbonate-EDTA ......................... 41

h. Alk:aline Tartrate Peroxide (ATP) ........................... 43

5. Miscellaneous Systems ............................................ 44

a. Proprietary Systems......................................... 44

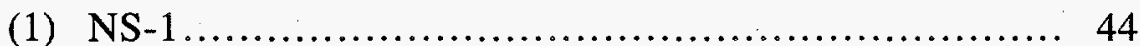

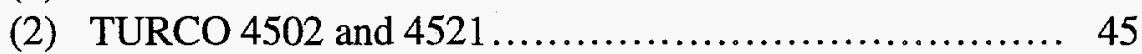

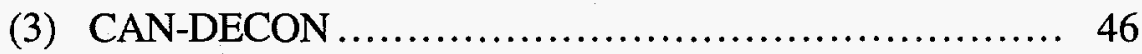

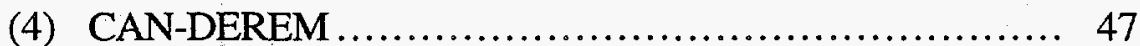

(5) LOMI ............................................. 48

(6) CORD ............................................. 49

(7) POD .................................................. 50

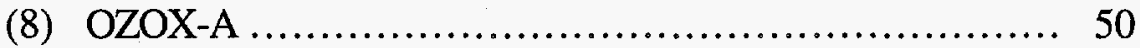

(9) ESI Solutions..................................... 50

b. Alkaline Reagents .......................................... 51

c. Acid Salts..................................................... 52

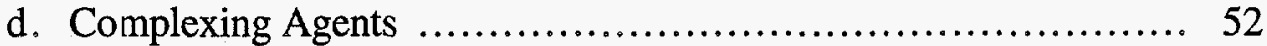

e. REDOX Agents............................................... 53

B. Electrochemical Processes...................................................... 54

1. Phosphoric Acid Electrolytes .................................... 55

2. Nitric Acid Electrolytes .......................................... 56

3. Sulfuric Azid Electrolytes ....................................... 57

4. Organic Azid Electrolytes......................................... 57 


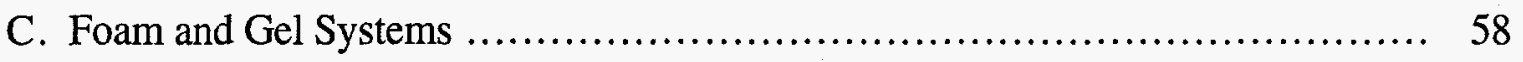

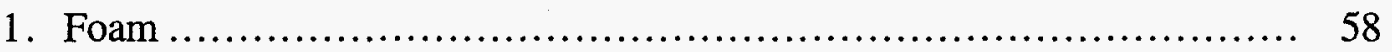

2. Gels ................................................................ 59

a. Glycerophthalic Gel .................................... 60

b. Glycerophosphoric Gel ..................................... 60

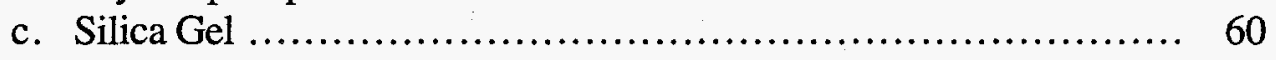

d. Diopside Gel ........................................... 60

e. Cerium(IV) Gel ........................................... 62

VI. RECOMMENDED DECONTAMINATION PROCESSES....................... 63

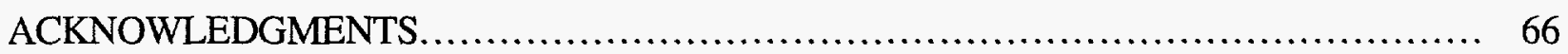

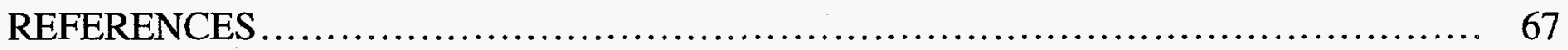




\section{LIST OF TABLES}

No.

Title

Page

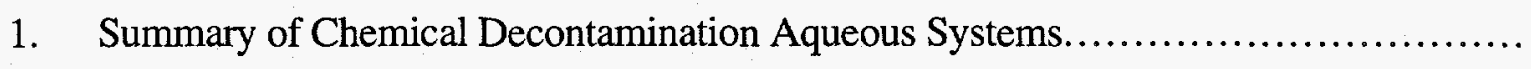

2. Recommended Decontamination Processes 


\section{LIST OF ACRONYMS}

AC (di)ammonium citrate

AECL Atomic Energy of Canada Limited

ANL Argonne National Laboratory

AP alkaline permanganate

APAC alkaline permanganate-diammonium citrate

APACE alkaline permanganate-diammonium citrate-EDTA

APOX alkaline permanganate-oxalic acid

APPR-1 Army Package Power Reactor

ATP alkaline tartrate peroxide

BNL Brookhaven National Laboratory

BWR boiling water reactor

CANDU PHW Canadian Deuterium-Uranium Pressurized Heavy Water Reactor

CEPOD catalyzed electrolytic plutonium oxide dissolution

CORD Chemical Oxidation Reaction Decontamination

$\mathrm{DF}$ decontamination factor

DOE U.S. Department of Energy

EDTA ethylenediaminetetraacetic acid

EM-50 DOE Office of Technology Development

HAPO Hanford Atomic Products Operation

IGA intergranular attack

ICPP Idaho Chemical Processing Plant

IRP Irradiation Rupture Prototype

LOMI low-oxidation-state metal ion

MOPAC modified APAC/APOX

NP nitric acid-potassium permanganate

OPG oxalic-peroxide-gluconic

OPP oxalate peroxide

ORNL Oak Ridge National Laboratory

PBC peroxide-bicarbonate-carbonate 
POD

PNL

PRTR

PWR

SIMCON

TTHA

WHC

WINCO
PWR oxidative decontamination

Pacific North west Laboratory

Plutonium Recycle Test Reactor

pressurized v/ater reactor

simulated contaminant

triethylenetet:aminehexaacetic acid

Westinghouse Hanford Company

Westinghouse Idaho Nuclear Company 


\title{
A SURVEY OF DECONTAMINATION PROCESSES APPLICABLE TO DOE NUCLEAR FACILITIES
}

\author{
by \\ L. Chen, D. B. Chamberlain, C. Conner, and G. F. Vandegrift
}

\begin{abstract}
The objective of this survey was to select an appropriate technology for in situ decontamination of equipment interiors as part of the decommissioning of U.S. Department of Energy nuclear facilities. This selection depends on knowledge of existing chemical decontamination methods.

This report provides an up-to-date review of chemical decontamination methods. According to available information, aqueous systems are probably the most universally used method for decontaminating and cleaning metal surfaces. We have subdivided the technologies, on the basis of the types of chemical solvents, into acid, alkaline permanganate, highly oxidizing, peroxide, and miscellaneous systems. Two miscellaneous chemical decontamination methods (electrochemical processes and foam and gel systems) are also described. A concise technical description of various processes is given, and the report also outlines technical considerations in the choice of technologies, including decontamination effectiveness, waste handing, fields of application, and the advantages and limitations in application.
\end{abstract} evaluation.

On the basis of this survey, six processes were identified for further

\section{INTRODUCTION}

Because of downsizing, many buildings and facilities throughout the U.S. Department of Energy (DOE) complex will be decommissioned and dismantled. As part of this decommissioning, some form of decontamination will be required. Selection of an appropriate decontamination technology depends on knowledge of the various available decontamination methods. The purpose of this document is to identify these techniques from a literature search.

In FY 1995, DOE's Office of Technology Development (EM-50) funded a program at Westinghouse Hanford Company (WHC) to develop a technology for in situ decontamination of the interior surfaces of nuclear facility equipment (TTP RL452003). This project is part of EM-50's Decontamination and Decommissioning focus area. In this program, technologies will be evaluated for their ability to (1) reduce equipment radioactive contamination levels sufficiently to allow either free release of the equipment or land disposal (below detection limits is desirable), 
(2) minimize residues generaled by the decontamination process, and (3) generate residues that are compatible with existing disposal technologies.

In support of this program, WHC provided funds to Argonne National Laboratory (ANL) through Inter-DOE Work Order No. M5CHE01. Tasks completed by ANL include surveys of the following: (1) decontamination requirements of the DOE complex, (2) applicable decontamination processes, and (3) handling of plutonium liquids in the DOE complex. Other tasks include laboratory and engineering evaluations of selected decontamination processes and exploration of waste disposal issues. Some of the laboratory evaluations were completed by the University of Illinois Nuclear Engineering Department. This report is the result of the literature survey of decontamination processes. Two related reports contain the results of the DOE surveys [CONNER-1995A, 1995B].

The two primary cate; ${ }^{\prime}$ ories of decontamination techniques are chemical and mechanical. Chemical decontamination uses solvents to dissolve either the base metal or the contamination film covering the base metal. Only chemical decontamination is surveyed in this report; strictly mechanical methods are not discussed.

The chemical technology for decontaminating nuclear reactors and accessory equipment was developed relatively recently compared with industrial cleaning, which was initiated in the mid-1920s when equipment and piping systems became too large to be disassembled and cleaned in chemical solvent tanks. Instead, these systems were cleaned by using solvents, which were inserted, circulated, and finally drained (along with contaminants) from the systems.

In our survey, the various decontamination processes are organized into three broad categories: aqueous systems, electrochemical processes, and foam and gel systems. The aqueous systems are further divided into those based on acids, alkaline permanganate (AP), $\mathrm{Ce}(\mathrm{IV})$ and related highly oxidizing speries, peroxides, and miscellaneous systems such as those using proprietary alkaline reagents. Numerous chemical formulations are possible, but without specific physical and chemical information pertaining to the species present on a particular type of surface, it is not possible to describe the specific chemical reactions that will occur during decontamination. Furthermore, the complete caemical formulations used most frequently are often not available because proprietary reagentsi are sold under a sales descriptor without complete technical information about the ingredients. The report includes a concise technical description of various processes and techniques being used or developed, and an evaluation of each process from the standpoints of typical deccntamination parameters, historical applications, advantages and disadvantages, and waste generation during decontamination.

Most of the information obtained for this survey relates to the decontamination and decommissioning of pressurized water reactors (PWRs) and boiling water reactors (BWRs), and the decontamination techniques were designed for removing the scale that forms in water systems at high temperatures and pressures. These types of scale might be very different from those encountered in a fuel reprocessing facility. In addition, many of the reactor systems are currently being operated; thus, the cleaning process must remove only the oxide scale (and activity) and not the base metal. The physical integrity of the equipment cannot be compromised in these situations. 
When the base metal must be protected, decontamination systems are usually less effective (i.e., decontamination factors are lower).

The survey also summarizes the pertinent information on decontamination processes used in the DOE weapons complex facilities. Some of these were designed to decontaminate equipment for reuse, and some were clearly developed for system decommissioning. However, for weaponscomplex facilities, there is generally no significant difference between the decontamination processes applied during the plant's service life and those applied during decommissioning.

\section{SUMMARY OF DECONTAMINATION TECHNIQUES}

The radioactive contamination in nuclear facilities varies in its form and composition and depends on the particular facility. The available information on decontamination experiences falls into two main categories. Most of the information in this survey comes from the first category, that is, experience in the decontamination of commercial power reactor (BWR and PWR) coolant systems and related components. These methods were designed for removing the scale that forms in water systems at high temperatures and pressures. The second category comprises decontamination processes for fuel fabrication and reprocessing facilities, including the DOE weapons complex.

In water-cooled reactors, two types of oxide form on the internal surfaces of reactor piping: (1) an adherent inner layer formed by in situ corrosion of the base metal and (2) a relatively loose outer layer formed by deposition or precipitation of crud from the coolant. The composition and form of these layers vary with the type of reactor. In PWRs, the inner layer is usually magnetite $\left(\mathrm{Fe}_{3} \mathrm{O}_{4}\right)$, which forms under the elevated temperature and reducing conditions of the coolant. Another constituent of the inner, adherent layer is $\mathrm{Cr}(\mathrm{III})$ oxide. The outer layer tends to be ironand nickel-rich, while the inner layer tends to be iron- and chromium-rich. The inner layer also has a relatively high level of activity compared with the outer layer and is more difficult to remove. In BWRs, the water chemistry is typically oxidizing; therefore, the most stable chromium ion is $\mathrm{Cr}(\mathrm{VI})$, which is soluble in water. As a result, the oxide layers usually contain less than $5 \%$ chromium. The layers generally consist of magnetite, hematite $\left(\mathrm{Fe}_{2} \mathrm{O}_{3}\right)$, and nickel ferrite. However, as the film grows, the supply of oxygen to the inner layer is reduced and, over the years, the layer converts to various forms of magnetite.

The difference in oxide layers requires the use of different decontamination procedures. Radioactive films in PWRs are more difficult to dissolve than those in BWRs because the insoluble trivalent chromium of the oxide layer has to be oxidized to the hexavalent state before the layer becomes amenable to dissolution by the decontamination solution. The oxide films in BWRs, however, are directly soluble in an appropriate acid.

The generation of scale on walls of piping and equipment in fuel reprocessing facilities results from various chemical processes and process conditions. The acid that is used in the dissolution and separation steps tends to inhibit the formation of an internal oxide layer; thus, deposition of radionuclides is limited. However, acid etching may cause erosion/corrosion at the metal grain boundaries. The depth of this contamination prevents decontamination solutions from 
being effective in removing the contaminants. This type of contamination can be very localized, such as around welds, but the low $\mathrm{pH}$ of the acidic solutions may contribute to diffusion of the contaminants into surface oxides. The use of tributylphosphate in PUREX-type systems leads to the generation of dibutyl phosphate and other radiolytic and acidic organic degradation products. These organics can form heav'y, pasty deposits in pipes and tanks, and these deposits are often very difficult to remove.

The chemical composition, structure, morphology, and adherence to the base metal are important features of contaminated layers that determine their resistance to chemical decontaminants. The more accurately the constituents of contamination layers are known, the easier it becomes to choose an efficient decontamination method. Although a considerable amount of pertinent data is available on the composition of contaminants in water-cooled reactors, there is little or no information on other facilities. Some general constituents have been identified, but detailed characterization has bien largely ignored.

Aqueous processes are probably the most universally used systems for the decontamination and cleaning of metal surfaces. Decontamination techniques use solvents, from dilute to concentrated, to dissolve either the contamination film covering the base metal or the base metal itself. Dissolution of the film; is intended to be nondestructive to the base metal and is generally used if the facility is to be operated again. Dissolution of the base metal is considered only for the decommissioning process, where the item will never be reused.

The mineral acids $\left(\mathrm{HCl}, \mathrm{HNO}_{3}, \mathrm{H}_{3} \mathrm{PO}_{4}\right.$, and $\left.\mathrm{H}_{2} \mathrm{SO}_{4}\right)$ are powerful scale solvents. These acids can be used by themselves in dilute or concentrated solutions, or in mixtures with other acids and other compounds. Their main purpose is to attack and dissolve metal oxide films; when the $\mathrm{pH}$ is lowered, the solubility or ion exchange capacity of the metal ions increases. More aggressive acids such as hydrofluoric arid (HF) and fluoroboric acid $\left(\mathrm{HBF}_{4}\right)$ will provide more effective decontamination; however, these acids can affect (dissolve) the base metal. Excessive corrosion will also deplete the reagent by complexing the fluoride, and thus create additional liquid waste. In most hydrofluoric acid systems, only a small amount is added to the other acids to accelerate dissolution of oxide layers.

Organic and complexing acids such as formic, acetic, citric, oxalic, and sulfamic acids, are much weaker; they are often used in combination with other chemicals. Weak acids are generally used on metal surfaces, such as steel, and act by dissolving the metal oxide film and complexing or solubilizing the metal ion. This complexing or chelating property gives organic acids an advantage over strong mineral acids.

Alkaline permanganate is an oxidizing agent used to condition chromium oxide films on stainless steel, Inconel, and Inicoloy [AYRES-1979]. Use of AP is normally the first step in a twoor multi-step process, intende 1 to oxidize the chromium oxide layer to yield soluble chromate ions. In the second (acid) stage, metals are dissolved and complexed by acidic reagents. Acidic reagents such as ammonium citrate (AC), ethylenediaminetetraacetic acid (EDTA), oxalic acid, and sulfamic acid have been successfully used in various applications to remove conditioned oxide films on stainless steel, carbon steel, and Inconel. Most of these processes were developed for application to both BWR and PWR nucle ar power plants. 
Highly oxidizing systems, such as $\mathrm{Ce}(\mathrm{IV})$ and $\mathrm{Ag}(\mathrm{II})$, were developed to replace nitrichydrofluoric acid mixtures in the dissolution of high-fired plutonium oxides. These systems are also effective in the decontamination of stainless steel piping and equipment.

A series of decontamination solutions were developed that contain hydrogen peroxide mixed with acids such as sulfuric, oxalic, or hydrofluoric acids, or with basic solutions such as carbonates. These solutions are effective because the peroxide oxidizes the oxide coatings, which are then dissolved by the acid. In contrast to AP treatments, these processes typically involve only one step. Careful control of the peroxide concentration is required because peroxide acts as a corrosion promoter at low concentrations and as a corrosion inhibitor at higher concentrations.

Many proprietary decontamination systems have been developed in the United States and abroad. These reagents are usually combinations of various chelators, oxidizers, reducing agents, inhibitors, and surfactants. Some commonly used reagents are classified as alkaline reagents, acid salts, complexing agents, and REDOX agents. None of these systems was selected for further evaluation.

Electrochemical decontamination can be used to remove a variety of radionuclides from metal surfaces, including americium, plutonium, uranium, radium, cobalt, strontium, and cesium that have been baked onto or ground into the metal surface. Electropolishing, as distinguished from electroetching, is a special case of electrochemical decontamination. It can be applied by immersing the contaminated components in a bath, or as an in situ technique for cleaning the inside of tanks, pumps, large pipes, and the outside of large components. Electropolishing is applicable to relatively complex shapes. High decontamination factors ${ }^{1}$ (DFs) are usually achieved by the removal of a few tens of micrometers of material, and the volumes of secondary waste solutions generated are typically low. The technique uses phosphoric acid as an electrolyte and a high current density to produce a smooth surface, which is desirable if the item decontaminated is to be reused. If the item is not to be reused, electrolytes such as nitric acid can be used at lower current densities. Other potential electrolytes are sulfuric or organic acids.

Use of reagents in the form of foams or gels can provide satisfactory DFs with small amounts of decontaminants. The volume of liquid waste generated with foam and gel methods is only 1 to $2 \%$ of that produced by using soaking procedures. Gelled solutions are also satisfactory for decontaminating hot spots or selected areas. Various chemical compounds or mixtures of chemicals have been developed as gels, foams, and pastes for application to facility or component surfaces.

A summary of the major decontamination systems described in this report is presented in Table 1. The table includes information on treatment procedures, typical decontamination parameters such as reagent concentrations, treatment temperatures and times, and typical DFs obtained. Some details are provided on waste treatment and particular applications where the system was used.

\footnotetext{
${ }^{1}$ The decontamination factor is the ratio of activity before treatment to activity after treatment.
} 
Table 1. Summary of Chemical Decontamination Aqueous Systems

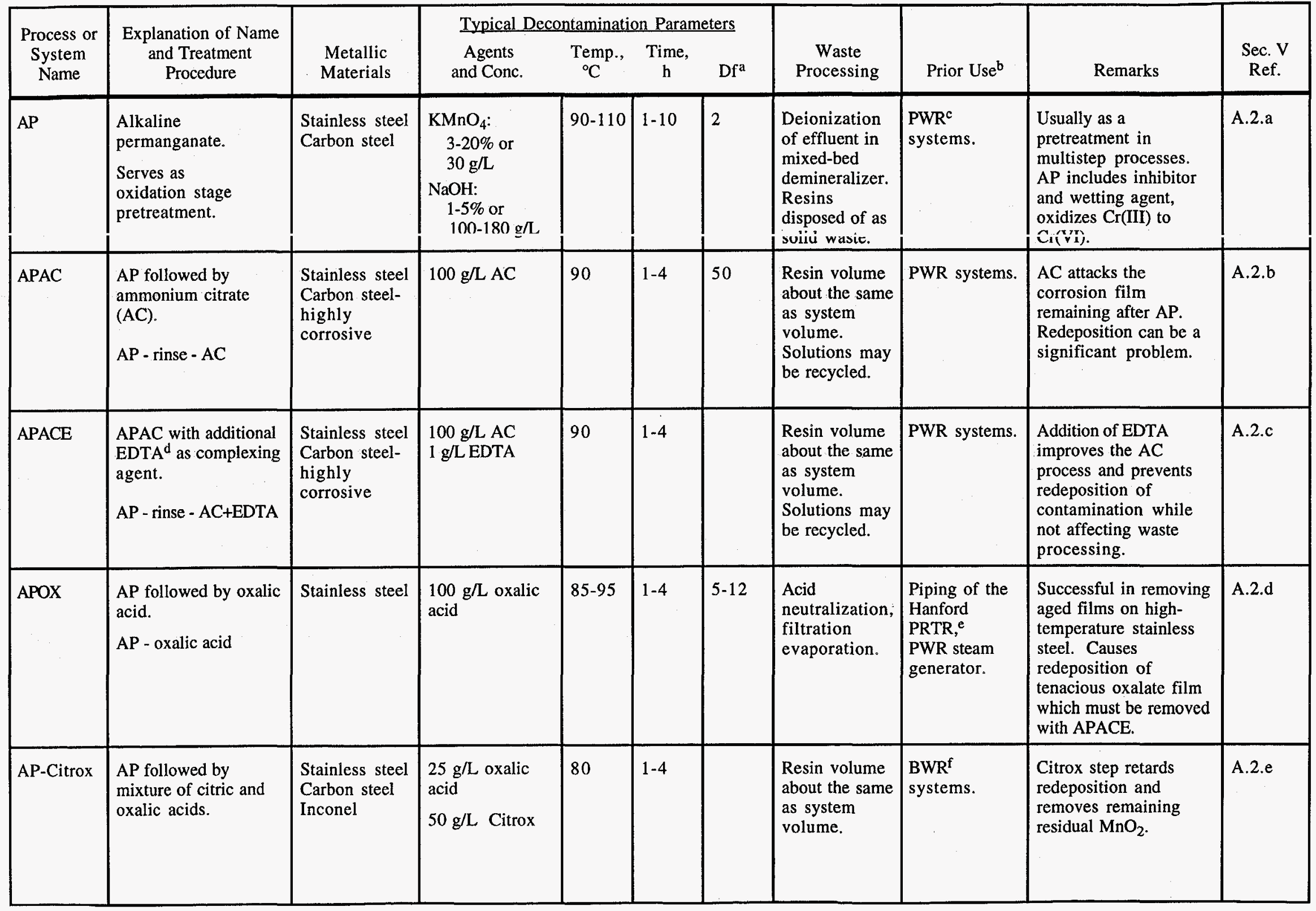


Table 1. (contd)

\begin{tabular}{|c|c|c|c|c|c|c|c|c|c|c|}
\hline $\begin{array}{l}\text { Process or } \\
\text { System } \\
\text { Name }\end{array}$ & $\begin{array}{l}\text { Explanation of Name } \\
\text { and Treatment } \\
\text { Procedure }\end{array}$ & $\begin{array}{l}\text { Metallic } \\
\text { Materials }\end{array}$ & $\begin{array}{l}\text { Typical Deco } \\
\text { Agents. } \\
\text { and Conc. }\end{array}$ & $\begin{array}{l}\text { nemp. } \\
{ }^{\circ} \mathrm{C}\end{array}$ & $\begin{array}{c}\text { Time } \\
\mathrm{h}\end{array}$ & ${ }_{\mathrm{Df}}^{\mathrm{a}}$ & $\begin{array}{c}\text { Waste } \\
\text { Processing }\end{array}$ & Prior Use $\mathrm{b}^{\mathrm{b}}$ & Remarks & $\begin{array}{l}\text { Sec. V } \\
\text { Ref. }\end{array}$ \\
\hline $\begin{array}{l}\text { Alkaline- } \\
\text { persulfate- } \\
\text { Citrox }\end{array}$ & $\begin{array}{l}\text { AP+persulfate } \\
\text { followed by } \\
\text { citrate+oxalate } \\
\text { (Citrox). }\end{array}$ & Stainless steel & $\begin{array}{l}0.2 \mathrm{M} \mathrm{K} \mathrm{S}_{2} \mathrm{O}_{8} \\
1 \underline{\mathrm{MNaOH}}\end{array}$ & 85 & 4 & $>10$ & & $\begin{array}{l}\text { CANDU PWRg } \\
\text { fueling } \\
\text { machines. }\end{array}$ & $\begin{array}{l}\text { Similar to } \\
\text { AP-Citrox; compared } \\
\text { to the AP based } \\
\text { process with no } \\
\text { obvious corrosion } \\
\text { attack. }\end{array}$ & A.2.f \\
\hline APSul & $\begin{array}{l}\text { AP followed by } \\
\text { sulfamic acid. } \\
\text { AP - rinse - sulfamic } \\
\text { acid }\end{array}$ & $\begin{array}{l}\text { Stainless steel } \\
\text { Carbon steel } \\
\text { Aluminum } \\
\text { alloys }\end{array}$ & $\begin{array}{l}90 \mathrm{~g} / \mathrm{L} \text { sulfamic } \\
\text { acid }\end{array}$ & $50-80$ & $1-4$ & 20 & $\begin{array}{l}\text { Resin volume } \\
\text { about the same } \\
\text { as system } \\
\text { volume. } \\
\text { Solutions may } \\
\text { be recycled. }\end{array}$ & & $\begin{array}{l}\text { Sulfamic acid step } \\
\text { prevents formation of } \\
\text { precipitates, thus } \\
\text { preventing } \\
\text { redeposition. }\end{array}$ & A.2.g \\
\hline $\begin{array}{l}\text { MOPAC } \\
\text { (APACl } \\
\text { APOX) }\end{array}$ & $\begin{array}{l}\text { AP followed by citric } \\
\text { and oxalic acid, EDTA, } \\
\text { Fe(III) inhibition. }\end{array}$ & Stainless steel & Proprietary & & & $10-200$ & $\begin{array}{l}\text { Evaporated and } \\
\text { combined with } \\
\text { boric acid. } \\
\text { Nuclides are } \\
\text { precipitated. }\end{array}$ & $\begin{array}{l}\text { Proprietary } \\
\text { development } \\
\text { of Kraftwerk } \\
\text { Union AG. } \\
\text { In situ } \\
\text { decontamina- } \\
\text { tion of BWR. }\end{array}$ & $\begin{array}{l}\text { Similar to APAC } \\
\text { process. }\end{array}$ & A. $2 . \mathrm{h}$ \\
\hline NP & $\begin{array}{l}\text { Nitric acid and } \\
\text { permanganate } \\
\text { pretreatment. }\end{array}$ & Stainless steel & $\begin{array}{l}0.5 \underline{\mathrm{M}} \mathrm{HNO}_{3} \\
0.05 \underline{\mathrm{M}} \mathrm{KMnO}_{4}\end{array}$ & $20-80$ & & $6-10$ & & $\begin{array}{l}\text { Reactor } \\
\text { decontamina- } \\
\text { tion. }\end{array}$ & $\begin{array}{l}\text { Similar application to } \\
\text { AP. Using NP instead } \\
\text { of AP results in a } \\
\text { significant waste } \\
\text { savings. }\end{array}$ & A.2.i \\
\hline $\begin{array}{l}\text { AP/LOMI } \\
\text { NP/LOMI }\end{array}$ & $\begin{array}{l}\text { AP or NP followed by } \\
\text { LOMI. }\end{array}$ & $\begin{array}{l}\text { Stainless steel } \\
\text { Inconel }\end{array}$ & $\begin{array}{l}2-4 \mathrm{E}-3 \mathrm{M} \mathrm{V}^{+2} \\
1-2 \mathrm{E}-3 \mathrm{M} \text { each of } \\
\text { picolinic acid, } \\
\text { formate ions, } \\
\text { and } \mathrm{NaOH}\end{array}$ & $80-90$ & $1-3$ & & & $\begin{array}{l}\text { BWR heat } \\
\text { exchanger and } \\
\text { piping. }\end{array}$ & $\begin{array}{l}\text { Low corrosion without } \\
\text { the use of inhibitor; } \\
\text { expensive; resin } \\
\text { radwaste is larger than } \\
\text { the Citrox and } \\
\text { CAN-DECON. }\end{array}$ & $\begin{array}{l}\text { A.5.a(5) } \\
\text { A. } 2 . \mathrm{j}\end{array}$ \\
\hline
\end{tabular}


Table 1. (contd)

\begin{tabular}{|c|c|c|c|c|c|c|c|c|c|c|}
\hline $\begin{array}{l}\text { Process or } \\
\text { System } \\
\text { Name }\end{array}$ & $\begin{array}{l}\text { Explanation of Name } \\
\text { and Treatment } \\
\text { Procedure }\end{array}$ & $\begin{array}{l}\text { Metallic } \\
\text { Materials }\end{array}$ & $\begin{array}{l}\text { Typical Dec } \\
\text { Agents } \\
\text { and Conc. }\end{array}$ & $\frac{\text { ntaminat }}{\text { Temp., }}$ & $\frac{\text { on Param }}{\mathrm{Time}}$ & $\stackrel{\text { eters }}{\text { Df }^{\mathrm{a}}}$ & $\begin{array}{c}\text { Waste } \\
\text { Processing }\end{array}$ & Prior Use ${ }^{b}$ & Remarks & $\begin{array}{l}\text { Sec. V } \\
\text { Ref. }\end{array}$ \\
\hline $\begin{array}{l}\text { AP' } \\
\text { CAN- } \\
\text { DECON }\end{array}$ & $\begin{array}{l}\text { AP followed by } \\
\text { CAN-DECON. } \\
\text { CAN-DECON is a } \\
\text { proprietary } \\
\text { development of } \\
\text { AECL. }\end{array}$ & $\begin{array}{l}\text { Stainless steel } \\
\text { Carbon steel }\end{array}$ & $\begin{array}{l}\text { Citric, oxalic } \\
\text { acids and EDTA. } \\
\text { CAN-DECON: } \\
1 \mathrm{~g} / \mathrm{L}\end{array}$ & 90 & 72 & $5-15$ & $\begin{array}{l}\text { Deionization } \\
\text { resulting in } \\
\text { solid waste } \\
\text { only as spent } \\
\text { resins. }\end{array}$ & $\begin{array}{l}\text { CANDUPHW } \\
\text { complete } \\
\text { reactor system } \\
\text { (including } \\
\text { fuel). } \\
\text { BWR systems. }\end{array}$ & $\begin{array}{l}\text { No system drainage } \\
\text { required. Generates } \\
\text { little liquid wastes; } \\
\text { allowed to use } \\
\text { existing waste } \\
\text { systems, low costs. } \\
\text { Lower DFs. }\end{array}$ & A.5.a(3) \\
\hline NS-1 & $\begin{array}{l}\text { Proprietary } \\
\text { development of Dow } \\
\text { Chemical Company }\end{array}$ & $\begin{array}{l}\text { Stainless steel } \\
\text { Carbon steel } \\
\text { Chromium- } \\
\text { molybdenum } \\
\text { alloys }\end{array}$ & $\begin{array}{l}\text { Complexing } \\
\text { agent and } \\
\text { inhibitor }\end{array}$ & 120 & 100 & $>100$ & $\begin{array}{l}\text { Four system } \\
\text { volumes, } \\
\text { evaporation. }\end{array}$ & BWR systems. & $\begin{array}{l}\text { High-concentration } \\
\text { process. }\end{array}$ & A.5.a(1) \\
\hline $\begin{array}{l}\text { TURCO } \\
4502\end{array}$ & $\begin{array}{l}\text { Proprietary agent } \\
\text { containing AP. }\end{array}$ & Stainless steel & & & & 5.5 & $\begin{array}{l}\mathrm{Al}\left(\mathrm{NO}_{3}\right)_{3} \text { must } \\
\text { be added to } \\
\text { prevent } \\
\text { agglomeration } \\
\text { of the calcine } \\
\text { bed. }\end{array}$ & & Similar to AP. & A.5.a(2) \\
\hline $\begin{array}{l}\text { CAN- } \\
\text { DEREM }\end{array}$ & $\begin{array}{l}\text { AP followed by CAN- } \\
\text { DEREM (2nd step). }\end{array}$ & Stainless steel & $\begin{array}{l}\text { AP: } 0.1 \mathrm{wt} \% \\
\text { CAN-DEREM: } \\
0.1 \mathrm{wt} \%\end{array}$ & $\begin{array}{l}\text { AP: } 95 \\
\text { step } 2 \\
120\end{array}$ & $\begin{array}{l}\text { AP: } 12 \\
\text { step } 2 \\
6-24\end{array}$ & $\begin{array}{l}6.2- \\
6.5\end{array}$ & & PWR systems. & $\begin{array}{l}\text { Modified } \\
\text { CAN-DECON. }\end{array}$ & A.5.a(4) \\
\hline CORD & $\begin{array}{l}\text { Oxidization by } \\
\text { permanganic acid, } \\
\text { then reduction by } \\
\text { organic acid, then } \\
\text { decontamination by } \\
\text { dicarboxylic acid. }\end{array}$ & Stainless steel & $\begin{array}{l}\text { Chemicals do } \\
\text { not exceed } \\
3 \mathrm{~g} / \mathrm{L}\end{array}$ & 95 & & $14-85$ & & $\begin{array}{l}\text { For BWR and } \\
\text { PWR oxide } \\
\text { films. }\end{array}$ & Modified OZOX. & A.5.a(6) \\
\hline
\end{tabular}


Table 1. (contd)

\begin{tabular}{|c|c|c|c|c|c|c|c|c|c|c|}
\hline $\begin{array}{l}\text { Process or } \\
\text { System } \\
\text { Name }\end{array}$ & $\begin{array}{l}\text { Explanation of Name } \\
\text { and Treatment } \\
\text { Procedure }\end{array}$ & $\begin{array}{l}\text { Metallic } \\
\text { Materials }\end{array}$ & $\begin{array}{l}\text { Typical Dec } \\
\text { Agents } \\
\text { and Conc. }\end{array}$ & $\begin{array}{l}\text { Temp. } \\
{ }^{\circ} \mathrm{C}\end{array}$ & $\frac{\text { ion Para }}{\mathrm{Time}}$ & neters & $\begin{array}{c}\text { Waste } \\
\text { Processing }\end{array}$ & Prior Use $^{b}$ & Remarks & $\begin{array}{l}\text { Sec. V } \\
\text { Ref. }\end{array}$ \\
\hline POD & NP followed by POD. & Stainless steel & $\begin{array}{l}\text { Mixture of NP, } \\
\text { NO, and Citrox. } \\
\text { NP: } 0.1 \% \\
\text { pH: } 2.5\end{array}$ & $85-95$ & $\begin{array}{l}\text { NP: } \\
5-24 \\
\text { POD: } \\
1 \mathrm{hr}\end{array}$ & $\begin{array}{l}4-25 \\
\text { Best } \\
\text { DF }>100\end{array}$ & & $\begin{array}{l}\text { Developed in } \\
\text { the United } \\
\text { Kingdom; } \\
\text { tested at BNL. }\end{array}$ & & A.5.a(7) \\
\hline OPP & $\begin{array}{l}\text { One-step } \\
\text { oxidizing agent. }\end{array}$ & $\begin{array}{l}\text { Stainless steel } \\
\text { Carbon steel } \\
\text { Inconel } \\
\text { Copper alloys- } \\
\text { highly } \\
\text { corrosive }\end{array}$ & $\begin{array}{l}2 \mathrm{~g} / \mathrm{L} \text { oxalic acid } \\
5 \mathrm{~g} / \mathrm{L} \mathrm{H}_{2} \mathrm{O}_{2}\end{array}$ & 80 & $1-4$ & $\begin{array}{l}20-100 \\
1000 \mathrm{for}^{j} \\
\text { ORNL }^{j}\end{array}$ & $\begin{array}{l}\text { Neutralization, } \\
\text { filtration, } \\
\text { evaporation. }\end{array}$ & $\begin{array}{l}\text { Decontami- } \\
\text { nation of } \\
\text { Gas-Cooled } \\
\text { Reactor, } \\
\text { ORNL. }\end{array}$ & $\begin{array}{l}\text { For failed fuel } \\
\text { cleanup, removed } \\
\text { uranium, uranium } \\
\text { oxides, and } \\
\text { plutonium films. }\end{array}$ & A. $4 . \mathrm{a}$ \\
\hline $\begin{array}{l}\text { Hydro- } \\
\text { chloric } \\
\text { acid }\end{array}$ & One-step process. & $\begin{array}{l}\text { Stainless steel } \\
\text { Carbon steel- } \\
\text { highly } \\
\text { corrosive }\end{array}$ & $100 \mathrm{~g} / \mathrm{L} \mathrm{HCL}$ & 70 & 2 & 10 & $\begin{array}{l}\text { Neutralization, } \\
\text { filtration, } \\
\text { evaporation. }\end{array}$ & $\begin{array}{l}\text { Decontami- } \\
\text { nation for } \\
\text { stainless steel, } \\
\text { purification } \\
\text { systems and } \\
\text { Cr-Mo main } \\
\text { steam system. }\end{array}$ & $\begin{array}{l}\text { Very aggressive, } \\
\text { corrosive to stainless } \\
\text { steel and carbon } \\
\text { steel. }\end{array}$ & A.1.a \\
\hline Nitric acid & One-step process. & $\begin{array}{l}\text { Stainless steel } \\
\text { Carbon steel- } \\
\text { highly } \\
\text { corrosive } \\
\text { Copper alloys- } \\
\text { highly } \\
\text { corrosive }\end{array}$ & $100 \mathrm{~g} / \mathrm{L} \mathrm{HNO}$ & 75 & 1 & 10 & $\begin{array}{l}\text { Neutralization, } \\
\text { filtration, } \\
\text { evaporation. }\end{array}$ & $\begin{array}{l}\text { Decontami- } \\
\text { nation of } \\
\text { reprocessing } \\
\text { plants. }\end{array}$ & $\begin{array}{l}\text { Addition of } 0.1 \% \\
\text { hydrofluoric acid } \\
\text { improves the DF. } \\
\text { Also used for Inconel. }\end{array}$ & A.1.b \\
\hline
\end{tabular}


Table 1. (contd)

\begin{tabular}{|c|c|c|c|c|c|c|c|c|c|c|}
\hline $\begin{array}{l}\text { Process or } \\
\text { System } \\
\text { Name }\end{array}$ & $\begin{array}{c}\text { Explanation of Name } \\
\text { and Treatment } \\
\text { Procedure }\end{array}$ & System Metals & $\begin{array}{l}\text { Typical Dec } \\
\text { Agents } \\
\text { and Conc. }\end{array}$ & $\frac{\text { Ataminati }}{{ }^{\circ} \mathrm{C}}$ & $\begin{array}{c}\text { n Param } \\
\text { Time } \\
\text { h }\end{array}$ & Df & $\begin{array}{c}\text { Waste } \\
\text { Processing }\end{array}$ & Prior Use ${ }^{b}$ & Remarks & $\begin{array}{l}\text { Sec. V } \\
\text { Ref. }\end{array}$ \\
\hline $\begin{array}{l}\text { Sulfuric } \\
\text { acid }\end{array}$ & One-step process. & $\begin{array}{l}\text { Stainless steel- } \\
\text { highly } \\
\text { corrosive } \\
\text { Carbon steel- } \\
\text { highly } \\
\text { corrosive }\end{array}$ & $100 \mathrm{~g} / \mathrm{L} \mathrm{H}_{2} \mathrm{SO}_{4}$ & 70 & 1 & 2 & $\begin{array}{l}\text { Neutralization, } \\
\text { filtration, } \\
\text { evaporation. }\end{array}$ & $\begin{array}{l}\text { Decontami- } \\
\text { nated carbon } \\
\text { steel reactor } \\
\text { systems. }\end{array}$ & $\begin{array}{l}\text { Highly corrosive. } \\
\text { Limited use on local } \\
\text { contamination. }\end{array}$ & A.1.c \\
\hline $\begin{array}{l}\text { Phos- } \\
\text { phoric } \\
\text { acid }\end{array}$ & One-step process. & $\begin{array}{l}\text { Stainless steel } \\
\text { Carbon steel }\end{array}$ & $100 \mathrm{~g} / \mathrm{L} \mathrm{H}_{3} \mathrm{PO}_{4}$ & 85 & $0.3-4$ & $10-20$ & $\begin{array}{l}\text { Neutralization, } \\
\text { filtration, } \\
\text { evaporation. }\end{array}$ & $\begin{array}{l}\text { Decontami- } \\
\text { nation of } \\
\text { Hanford } \\
\text { N-Reactor. } \\
\text { Carbon steel } \\
\text { and brass } \\
\text { piping of } \\
\text { BONUS } \\
\text { reactor. }\end{array}$ & $\begin{array}{l}\text { Rapid decontamina- } \\
\text { tion of carbon steel } \\
\text { and copper alloys. If } \\
\text { contact over } 20 \text { min, } \\
\text { redeposition occurs. } \\
\text { Relatively expensive. }\end{array}$ & A.1.d \\
\hline $\begin{array}{l}\text { Sulfamic } \\
\text { acid }\end{array}$ & One-step process. & $\begin{array}{l}\text { Carbon steel } \\
\text { Copper }\end{array}$ & $\begin{array}{l}90 \mathrm{~g} / \mathrm{L} \text { sulfamic } \\
\text { acid }\end{array}$ & 50 & $1-4$ & 3 & $\begin{array}{l}\text { Neutralization, } \\
\text { filtration, } \\
\text { evaporation. }\end{array}$ & $\begin{array}{l}\text { Decontami- } \\
\text { nated carbon } \\
\text { steel compo- } \\
\text { nents of } \\
\text { PWRs. }\end{array}$ & $\begin{array}{l}\text { Not as active as } \\
\text { phosphoric acid but } \\
\text { no redeposition. } \\
\text { Not a suitable one- } \\
\text { step for stainless } \\
\text { steel. }\end{array}$ & A.1.e \\
\hline $\begin{array}{l}\text { Nitric and } \\
\text { hydro- } \\
\text { fluoric } \\
\text { acids }\end{array}$ & $\begin{array}{l}\mathrm{HNO}_{3}-\mathrm{HF} \\
\text { One-step process. }\end{array}$ & Stainless steel & $\begin{array}{l}3.5 \mathrm{M} \mathrm{HNO}_{3} \\
0.04 \mathrm{M} \mathrm{HF} \\
3 \% \mathrm{HF} \\
20 \% \mathrm{HNO}_{3}\end{array}$ & $60-85$ & $0.5-1.5$ & 1000 & $\begin{array}{l}\text { Two-step } \\
\text { precipitation } \\
\text { process. }\end{array}$ & $\begin{array}{l}\text { Savannah } \\
\text { River Site } \\
\text { waste glass } \\
\text { canisters. } \\
\text { Laboratory } \\
\text { testing at } \\
\text { ICPP. }\end{array}$ & Very effective. & A.1.f \\
\hline $\begin{array}{l}\text { Nitric and } \\
\text { sulfuric } \\
\text { acids }\end{array}$ & $\begin{array}{l}\mathrm{HNO}_{3}-\mathrm{H}_{2} \mathrm{SO}_{4} \\
\text { One-step process. }\end{array}$ & Stainless steel & $20 \% \mathrm{HNO}_{3}$ & 100 & & & & $\begin{array}{l}\text { PRTR to } \\
\text { remove the } \\
\text { rupture of a } \\
\text { MgO-PuO }{ }_{2} \text { fuel } \\
\text { element. }\end{array}$ & $\begin{array}{l}\text { Can be used for } \\
\text { removing ceramic } \\
\text { plutonium fuel } \\
\text { element rupture debris } \\
\text { from reactor system. }\end{array}$ & A.1.g \\
\hline
\end{tabular}


Table 1. (contd)

\begin{tabular}{|c|c|c|c|c|c|c|c|c|c|c|}
\hline $\begin{array}{l}\text { Process or } \\
\text { System } \\
\text { Name }\end{array}$ & $\begin{array}{c}\text { Explanation of Name } \\
\text { and Treatment } \\
\text { Procedure }\end{array}$ & $\begin{array}{l}\text { Metallic } \\
\text { Materials }\end{array}$ & $\begin{array}{l}\text { Typical Dec } \\
\text { Agents } \\
\text { and Conc. }\end{array}$ & $\begin{array}{l}\text { Temp., } \\
{ }^{\circ} \mathrm{C}\end{array}$ & $\frac{\text { In Param }}{\text { Time, }}$ & $\mathrm{Df}^{\mathrm{a}}$ & $\begin{array}{c}\text { Waste } \\
\text { Processing }\end{array}$ & Prior Use $\mathrm{e}^{\mathrm{b}}$ & Remarks & $\begin{array}{l}\text { Sec. V } \\
\text { Ref. }\end{array}$ \\
\hline $\begin{array}{l}\text { Fluoro- } \\
\text { boric } \\
\text { acid }\end{array}$ & $\begin{array}{l}\mathrm{HBF}_{4} \\
\text { DECOHA process for } \\
\text { recycling and } \\
\text { regenerating } \mathrm{HBF}_{4} \text {. }\end{array}$ & $\begin{array}{l}\text { Stainless steel } \\
\text { Carbon steel } \\
\text { Nickel alloys }\end{array}$ & $1 \underline{\mathrm{M}} \mathrm{HBF}_{4}(5 \%)$ & 30.98 & & $50-100$ & $\begin{array}{l}\text { DECOHA } \\
\text { process, or } \\
\text { neutralization, } \\
\text { precipitation, } \\
\text { ion exchange. }\end{array}$ & $\begin{array}{l}\text { Laboratory } \\
\text { testing of } \\
\text { ICPP, } \\
\text { Alaron } \\
\text { Corporation, } \\
\text { ORNL K-25. }\end{array}$ & Very effective. & A.1.i \\
\hline Oxalic acid & Generally one step. & Stainless steel & $\begin{array}{l}100 \mathrm{~g} / \mathrm{L} \text { oxalic } \\
\text { acid }\end{array}$ & 85 & $1-4$ & $3-20$ & & $\begin{array}{l}\text { Decontamina- } \\
\text { tion of heat } \\
\text { exchanger at } \\
\text { Savannah } \\
\text { River Plant. } \\
\text { Decon- } \\
\text { tamination of } \\
\text { Hanford PRTR. }\end{array}$ & $\begin{array}{l}\text { Removes rust. } \\
\text { Reacts with steel to } \\
\text { form highly insoluble } \\
\text { ferrous oxalate } \\
\text { precipitate. }\end{array}$ & A. $1 . \mathrm{j}$ \\
\hline Citric acid & $\begin{array}{l}\text { Generally combined } \\
\text { with oxalic acid. }\end{array}$ & Stainless steel & & & & & & & & A.1.k \\
\hline $\begin{array}{l}\text { Nitric and } \\
\text { hydro- } \\
\text { chloric } \\
\text { acids }\end{array}$ & $\mathrm{HNO}_{3}+\mathrm{HCl}$ & $\begin{array}{l}\text { Stainless steel } \\
\text { Carbon steel }\end{array}$ & $\begin{array}{l}4.7 \mathrm{~g} / \mathrm{L} \mathrm{HNO}_{3} \\
13 \mathrm{~g} / \mathrm{L} \mathrm{HCl}\end{array}$ & & $4-8$ & & & $\begin{array}{l}\text { Testing at } \\
\text { Kernkraftwerk } \\
\text { Lingen GmbH. }\end{array}$ & & A.1.h \\
\hline $\begin{array}{l}\mathrm{Ce}(\mathrm{IV}) \\
\text { process I }\end{array}$ & $\mathrm{Ce}(\mathrm{IV}) / \mathrm{HNO}_{3}$ & Stainless steel & $\begin{array}{l}0.5-1 \underline{\mathrm{M}} \mathrm{HNO}_{3} \\
1.4-2.7 \text { moles } \\
\mathrm{Ce} / \mathrm{m}^{2}\end{array}$ & 65 & 6 & $\begin{array}{l}1000- \\
2000 \\
\text { for } \\
{ }^{137} \mathrm{Cs}\end{array}$ & $\begin{array}{l}\text { Ion exchange } \\
\text { with some } \\
\text { oxidative } \\
\text { degradation of } \\
\text { the resin, } \\
\text { evaporation. }\end{array}$ & $\begin{array}{l}\text { Lab tests at } \\
\text { PNL. }\end{array}$ & $\begin{array}{l}\text { Good dissolution } \\
\text { reagent for plutonium } \\
\text { oxide. } \\
\text { Not a high-salt } \\
\text { system, potentially } \\
\text { less waste to be } \\
\text { expected. }\end{array}$ & A.3.a \\
\hline
\end{tabular}


Table 1. (contd)

\begin{tabular}{|c|c|c|c|c|c|c|c|c|c|c|}
\hline $\begin{array}{l}\text { Process or } \\
\text { System } \\
\text { Name }\end{array}$ & $\begin{array}{c}\text { Explanation of Name } \\
\text { and Treatment } \\
\text { Procedure }\end{array}$ & $\begin{array}{c}\text { Metallic } \\
\text { Materials }\end{array}$ & $\begin{array}{l}\text { Typical D } \\
\text { Agents } \\
\text { and Conc. }\end{array}$ & $\begin{array}{l}\text { Temp., } \\
{ }^{\circ} \mathrm{C}\end{array}$ & $\frac{\underset{h}{\text { Time }}}{h}$ & Df & $\begin{array}{c}\text { Waste } \\
\text { Processing }\end{array}$ & Prior Use $^{b}$ & Remarks & $\begin{array}{c}\text { Sec. V } \\
\text { Ref. }\end{array}$ \\
\hline $\begin{array}{l}\mathrm{Ce}(\mathrm{IV}) \\
\text { process II }\end{array}$ & $\mathrm{Ce}(\mathrm{IV}) / \mathrm{H}_{2} \mathrm{SO}_{4}$ & Stainless steel & & & & & & & Japanese patents. & A.3.a \\
\hline $\begin{array}{l}\mathrm{Ce}(\mathrm{IV}) \\
\text { process III }\end{array}$ & $\mathrm{Ce}(\mathrm{IV})-\mathrm{F} / \mathrm{HNO}_{3}$ & Stainless steel & $\begin{array}{l}8 \underline{\mathrm{M}} \mathrm{HNO}_{3} \\
0.05 \mathrm{M} \mathrm{Ce}(\mathrm{IV}) \\
0.1 \underline{\mathrm{M}} \mathrm{KF}\end{array}$ & & & & & & & A.3.b \\
\hline $\begin{array}{l}\mathrm{Ag}(\mathrm{II}) \\
\text { process }\end{array}$ & $\mathrm{Ag}_{2} \mathrm{~S}_{2} \mathrm{O}_{8} / \mathrm{HNO}_{3}$ & Stainless steel & $\begin{array}{l}3 \underline{\mathrm{M}} \mathrm{HNO}_{3} \\
0.5 \underline{\mathrm{M} \mathrm{K}} \mathrm{S}_{2} \mathrm{O}_{8} \\
0.2 \mathrm{M} \mathrm{AgNO}_{3}\end{array}$ & 65 & 6 & & $\begin{array}{l}\text { Use ascorbic } \\
\text { acid to recover } \\
\text { silver; hydra- } \\
\text { zine, etc.; to } \\
\text { suppress } \\
\text { nitrate. }\end{array}$ & $\begin{array}{l}\text { Lab tests at } \\
\text { PNL. }\end{array}$ & & A.3.c \\
\hline
\end{tabular}

aDecontamination factors (DFs) reported in this column are typical of system.

${ }^{b}$ Example of prior use of this system. Other examples may be included in text.

cPressurized water reactor (PWR).

dEthylenediaminetetraacetic acid (EDTA).

ePlutonium Recycle Test Reactor (PRTR).

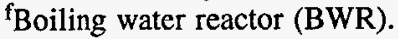

gCanadian Deuterium Uranium Pressurized Heavy Water (CANDU PHW) reactor.

hAtomic Energy of Canada Limited (AECL).

iBrookhaven National Laboratory (BNL).

jOak Ridge National Laboratory (ORNL).

kIdaho Chemical Processing Plant (ICPP).

'Pacific Northwest Laboratory (PNL) 
On the basis of the results of the literature survey, six decontamination agents/processes were selected for further evaluation in the laboratory:

- Fluoroboric acid

- $\quad$ Nitric plus hydrofluoric acid

- $\quad$ Alkaline-persulfate/Citrox

- $\quad \operatorname{Ag}(\mathrm{II})$-persulfate-nitric acid

- Oxalic acid-hydrogen peroxide-hydrofluoric acid

- $\quad$ Electropolishing using a nitric acid electrolyte

All six show promise for use in the in situ decontamination of decommissioned facilities, and all have been demonstrated in either laboratory or actual full-scale processes.

\section{SELECTION CRITERIA}

The selection of appropriate in situ decontamination technology for cleaning the interiors of process piping and equipment in the decommissioning of DOE nuclear facilities is the goal of this project. However, it is not appropriate in this survey to give a thorough comparison of all the processes competing in the decontamination field today; thus, we will highlight a few key criteria that can be used to select certain technologies and processes for further evaluation.

The selection of a decontamination process depends primarily on the nature of the contaminated layers. Important features of contaminated layers that determine resistance to chemical decontaminants are chemical composition, structure, morphology, and adherence to the base metal. The more accurately the constituents of contamination layers are known, the easier it becomes to choose an efficient method to remove the surface oxides. Although a considerable amount of pertinent data is available on types and location of radioisotopes within the oxide film in water-cooled reactors, little or nothing is known for other types of facilities, and there has been no detailed characterization of their contamination layers. Generally speaking, scale and contamination layers that remain in fuel reprocessing (and related) facilities are very different from those in nuclear power reactors. The generation of scale in fuel reprocessing facilities results from various chemical processes and process conditions, but actinide and fission products, including $\mathrm{Pu}, \mathrm{Am}, \mathrm{Cu}, \mathrm{Cs}$, $\mathrm{Ce}, \mathrm{Ru}$, and $\mathrm{Sr}$, appear to be major radioactive components of the oxide layer. The selected decontamination method must be able to remove such contaminated layers from the metal surface. In addition, the internal layer may differ in density and mechanical properties from the external layer; thus, the decontamination technologies should be those that are suitable to the internal layer.

The types of surface and materials of construction should be considered prior to selecting decontamination methods. Most piping and tanks used in the nuclear industries are constructed of type 304L or 347 stainless steel [CONNER-1995A, 1995B]. However, more exotic materials, e.g., Hastelloy or titanium, are sometimes used. The effectiveness of decontamination methods for stainless steel systems is one of the criteria for our evaluation. 
The requirement for in situ decontamination of equipment interiors is important in the choice of the decontamination technique; thus, the available in situ techniques and equipment were given priority in our survey.

The achievement of high DFs is obviously a criterion for decontamination. Many processes described in the literature are likely to give adequate DFs, although some solvents have greater ability for coping with the more intractable oxides. The DF can be dramatically changed by the type and strength of the solvent apj)lied. However, the DF is not the only significant measure of decontamination effectiveness. Other important factors are secondary waste generation and the potential for recontamination. Secondary wastes include spent decontaminant solutions as well as the contaminants and substrate materials that were removed. In some decontamination processes, where the main priority is to achieve: high DFs without regard to the production of secondary wastes, more waste disposal problems are created than are solved. Because of the increasing costs of disposal, emphasis is currently on minimization of decontamination waste.

Since radioactivity cannot be eliminated by physical or chemical processes, the only disposal option is to concentrate the radionuclides and convert them to an appropriate waste form. Several methods are currently used, which include blending ion-exchange resins into the waste tanks, and direct solidificatior. of the waste. Some novel radwaste handling methods are also being developed. In all cases, the waste generated during the decontamination must be compatible with available radwaste disposal facilities, which may limit some processes. If a process requires new disposal facilities, the economic aspects also need to be evaluated.

Finally, there is the issue of recontamination, which occurs when a freshly decontaminated surface, with its corrosion film removed, is contaminated by the cleaning solution. Thus, an important measurement of decontamination effectiveness is whether the decontamination process is able to retard and prevent reccntamination.

In conclusion, in selecting decontamination processes we choose practical and proven decontamination methods that can be used for in situ decontamination of equipment interiors, to achieve our goal of the maximum decontamination with minimal secondary waste generation. 


\section{CONSTITUENTS OF CONTAMINATED LAYERS}

As stated previously (Section III), knowledge of the constituents of contamination layers is important in selecting the most effective decontamination method; thus, information on contamination is briefly reviewed.

Radioactive contamination varies in its form and composition, depending on the nuclear facilities involved. These can be divided into two main groups. The first group includes the commercial power reactors, with their coolant systems and associated loops, piping systems, steam generators, etc. The second group includes other radioactive systems and components, such as the facilities used for fuel handling, dissolution, processing, and waste handling. These facilities can be further divided into aqueous and pyrochemical systems. Although a considerable amount of pertinent data is available on water-cooled reactors, there is little information on other facilities.

\section{A. Contamination of Reactor Coolant Systems and Components}

In primary reactor systems, radioactive contamination on the internal surfaces is caused by the deposition from the reactor coolant of neutron-activated particles, dissolved elements, and fission products and transuranics. Generally, the presence of fission products such as ${ }^{90} \mathrm{Sr}$ and ${ }^{137} \mathrm{Cs}$, together with $\mathrm{Pu}, \mathrm{Am}$, and $\mathrm{Cm}$, in the coolant results from fuel cladding failure. These deposits become part of the oxide layer that forms on the inside of the piping. This layer has a complex structure that depends on a variety of parameters, such as coolant chemistry, temperature of formation, system materials, and operating time. Over long periods of time, the radionuclides in the layer can diffuse into the base metal or penetrate along grain boundaries. In water-cooled reactors, two types of oxide form on the internal surfaces of reactor piping: (1) an adherent inner layer formed by in situ corrosion of the base metal and (2) a relatively loose outer layer formed by deposition or precipitation of crud from the coolant. The composition and form of these layers vary with the type of reactor. The principal radionuclides that originate from neutron activation and that must be considered during decommissioning are ${ }^{54} \mathrm{Mn}\left(\mathrm{t}_{1 / 2}=312 \mathrm{~d}\right),{ }^{55} \mathrm{Fe}\left(\mathrm{t}_{1 / 2}=2.68 \mathrm{yr}\right)$, ${ }^{60} \mathrm{Co}\left(\mathrm{t}_{1 / 2}=5.27 \mathrm{yr}\right),{ }^{63} \mathrm{Ni}\left(\mathrm{t}_{1 / 2}=100 \mathrm{yr}\right)$, and ${ }^{59} \mathrm{Ni}\left(\mathrm{t}_{1 / 2}=7.6 \times 10^{4} \mathrm{yr}\right) .{ }^{2}$ Normally, the end of plant operation and the beginning of decommissioning are separated by several months or years; therefore, short-lived nuclides need not be considered [KOCH]. To achieve good decontamination, the composition of the oxide layers must be known in order to select the appropriate decontamination process.

The composition of surfaces in the primary systems of PWRs differs from that in BWRs. The stainless steel used in the reactor coolant piping of PWRs becomes coated by an inner layer of magnetite under the elevated temperature and the reducing conditions of the coolant during operation. Another constituent of the adherent inner layer is $\mathrm{Cr}$ (III), which forms compounds such as iron chromate ( $\mathrm{FeO} \cdot \mathrm{Cr}_{2} \mathrm{O}_{3}$ - a very insoluble oxide), nickel ferrite $\left(\mathrm{NiO} \cdot \mathrm{Fe}_{2} \mathrm{O}_{3}\right.$ ), and cobalt ferrite $\left(\mathrm{CoO} \cdot \mathrm{Fe}_{2} \mathrm{O}_{3}\right)$. The inner layer has a relatively high level of activity compared with the outer layer and is very hard to remove. The loose outer layer, which is formed by the deposition of crud from the circulating water, tends to be iron- and nickel-rich, whereas the inner layer tends to be iron- and chromium-rich.

${ }^{2}$ The symbol $t_{1 / 2}=$ half-life. 
In BWRs, where the v/ater chemistry is typically oxidizing, the most stable chromium ion is $\mathrm{Cr}$ (VI), which stays in solution and is removed by the primary-circuit ion-exchange columns. As a result, the oxide layers usually contain less than $5 \mathrm{wt} \%$ chromium, which, in contrast to the oxide layers that form in PWRs, is soluble. The inner layer generally consists of magnetite and hematite plus some nickel ferrite, and the outer layer is usually hematite. However, as the film grows, the supply of oxygen to the inne: layer is reduced, and over the years, the layer converts to various forms of magnetite.

The differences in constitution of the oxide layers between PWRs and BWRs requires the use of different decontamination procedures. The insoluble trivalent chromium of the oxide layer in PWRs has to be oxidized to the hexavalent state before the layer becomes amenable to dissolution, whereas BWR oxide films are directly soluble in an appropriate acid.

In general, contaminaion tends to accumulate in horizontal pipe runs, dead legs, elbows, valves, pumps, heat exchangers, and in any area where flow velocity is reduced or where eddies develop.

\section{B. Contamination of Nuclear Fuel Cycle Facilities and Related Systems}

Scale and contamination layers that remain in fuel reprocessing (and related) facilities are very different than those in commercial nuclear power reactors. Power reactors typically involve water systems at high tempercitures and pressures, whereas generation of scale in fuel reprocessing facilities results from various processing chemicals and conditions. For instance, the acid in nitrate solutions used in the dissolution and separation steps in fuel reprocessing tends to inhibit the formation of an internal oxide layer; deposition of radionuclides is thus limited. However, acid etching may cause erosion at the grain boundaries of metal. The deep location of this contamination prevents decontamination solutions from being effective in its removal. This type of mechanism can be very localized, such as around welds, but the low $\mathrm{pH}$ of the acidic solutions may contribute to diffusion of the contaminants into surface oxides of the metal. Corrosion test data from Idaho Chemical Processing Plant (ICPP) vessels and piping confirm the contribution of acid etching to difficult decontamination [D]EMMER-1994B]. Another source of contamination is the use of tributylphosphate in PUREX-type systems, which leads to the generation of dibutyl phosphate and other radiolytic and acidic degradation products. These organics and their metal salts can form heavy, pasty deposits in pipes and tanks, which are often very difficult to remove [IAEA-1988].

In other types of nuilear facilities, such as hot cells and mixed-oxide fuel-fabrication plants, high levels of contamination may exist in process vessels, cells, etc., as a result of normal operations. In $\mathrm{UO}_{2}$ fuel fabrication plants, low levels of activity are caused by the processing of $\mathrm{UO}_{2}$. Where fuels are processed as dry powders, material will settle by gravity onto horizontal surfaces and may accumulate in nooks and crannies that are not accessible to routine cleaning operations.

In ventilation systems the surface contamination is usually loose, although adherence can be increased by oily films that are often found on the inside of ducts, particularly downstream of fans. Since the exhaust systems operate at negative pressures, they tend to draw in dust and 
aerosols that may contain activity. Deposition tends to be heavier in sections of the ducting where the direction or velocity of the fluid changes or at the edges of joints and flanges.

Solutions that dry on a surface account for a great deal of contamination. This type of contamination depends on the solution used in the piping. Solutions that dry on the top inner wall of pipes are the most difficult to remove. Quite often, flushing reaches only the bottom and sides of the pipe; however, the highly radioactive solids remaining on the top may be removed easily if the pipe is accessible [DEMMER-1994A]. 


\section{EXISTING DECONTAMINATION PROCESSES}

\section{A. Aqueous Systems}

Cleaning with aqueous chemical reagents is probably the system most universally used for the decontamination of the metal surfaces of piping, components, and equipment in nuclear facilities. The solutions contact the contaminated items and dissolve either the contamination film covering the base metal or thi base metal itself. Dissolution of the films alone is intended to be nondestructive to the base metal and is generally used if the facility is to be operated again. Dissolution of the base metal is only considered for decommissioning purposes, where the equipment will not be reused.

The advantages of aqueous solutions for chemical decontamination are that they can be used for inaccessible surfaces; they can decontaminate process equipment and piping in place, which requires fewer work hours; and they can also be used remotely. Aqueous chemical decontamination produces few airbcrne hazards; uses chemical agents that are readily available; produces wastes that can be handled rernotely; and, generally, allows the recycling of the wash liquors after further processing. The disadvantages of aqueous chemical decontamination are that it is not usually effective on porous surfaces; it can produce large volumes of waste (although volume may be reduced by a radioactive waste treatment system); it may generate mixed wastes; and it can result in corrosion and safety problems when misapplied. Aqueous chemical decontamination requires different reagents for different surfaces, and drainage control. For large jobs, chemical storage and collecting equipment may have to be constructed, and sometimes criticality concerns may be raised.

Aqueous chemical decontamination may use either dilute or concentrated reagents. A distinction is made between concentration (or "soft") processes (with a reagent concentration of about $1 \%$ ) and concentrated (or "hard") processes (with a reagent concentration greater than $1 \%$ ). In general, the methods that ıse concentrated solutions achieve higher DFs than the dilute techniques. However, the highly concentrated solutions are usually more corrosive to the materials of construction, and removal of their residues may be difficult. More importantly, waste treatment of spent reagents can present some difficulties because of the quantity of chemicals involved. Dilute solutions are easier to prepare and are less corrosive to base material but generally result in lower DFs. These reagents are usec. in either single- or multiple-stage processes, and sometimes procedures are repeated to achieve higher DFs. Ion exchangers are often used for in situ regeneration and/or for removal of spent reagents and radioactive contaminants.

Information on typical processes is listed below, as well as some promising laboratory progress that may lead to future decontamination systems.

\section{1. $\quad$ Acid Systems}

The use of acids as decontamination agents is not new. Nitric and tartaric acids were early favorites [PERRI(jO-1979]. Today, acid solutions are widely used in numerous chemical decontamination processe: 
Mineral acids $\left(\mathrm{HCl}, \mathrm{HNO}_{3}, \mathrm{H}_{3} \mathrm{PO}_{4}\right.$, and $\left.\mathrm{H}_{2} \mathrm{SO}_{4}\right)$ are effective scale solvents. These acids can be used by themselves as dilute solutions, in mixtures with acid salts and other compounds, and in combination with each other. Their main purpose is to attack and dissolve metal oxide films, lower the $\mathrm{pH}$ of solutions to increase metal-ion solubility, or provide hydrogen ions for ion-exchange with metal ions on metal/metal-oxide surfaces. They can be used on almost all metal surfaces except active metals such as zinc. Mineral acids work rapidly and very effectively for some purposes.

Aggressive acids such as $\mathrm{HF}$ and $\mathrm{HBF}_{4}$ can provide more effective decontamination; however, they can also damage the base metal. Furthermore, excessive corrosion will deplete the reagent (complex the fluoride) and thus create additional liquid waste. In most cases, a small amount of these acids is added to other acids to accelerate dissolution of oxide layers.

These acids are extensively used as surface etchants, to reduce the wall thicknesses of tubes. Etchants for stainless steels are based on nitric and hydrochloric acids. For example, a $50 \% \mathrm{HCl}-13 \% \mathrm{HNO}_{3}$ was suitable for etching most stainless steels [BOLER]. Phosphoric and hydrofluoric acids are also used in small quantities in some formulations. The chemical milling of high-tensile steels is generally carried out by nitric and sulfuric acids [HARRIS-1976]. A mixture of nitric, sulfuric, and phosphoric acids was used to chemically mill $18 \%$ nickel maraging steels [ANON], while nitric and sulfuric acid mixtures were suggested as milling agents for $1 \% \mathrm{Cr}-\mathrm{Mo}$ steels [LANGSTON].

The advantages of using the strong acids as decontaminants are that they are relatively cheap, quick, and effective. The disadvantages are that they present safety and handling problems, may require neutralization before waste treatment, and are incompatible with many materials. Explosive or poisonous gases can be produced in reactions with some compounds.

Weaker, complexing acids are often used in combination with other chemicals to remove iron oxide deposits from steel surfaces. These weak acids include formic, acetic, citric, oxalic, and sulfamic acids. The Citrox, CAN-DECON and CAN-DEREM processes use citric and oxalic acids in low concentration for decontamination of nuclear plant cooling systems (see Sections V.2 and V.5). Ammonium citrate and oxalate are also available commercially for decontamination.

Weak acids are generally used on metal surfaces and act by dissolving the metal oxide film and complexing (or solubilizing) the metal ion. This complexing (or chelating) property gives weak acids a great advantage over the strong, mineral acids. They are also less corrosive and toxic and have fewer material compatibility problems. Sulfamic acid has the added advantage of being a solid that can be shipped and stored as a dry powder and mixed on site. Weak acids contain no chloride or fluoride and, thus, can be used on stainless and high-alloy steels. Oxalic and citric acids are commonly used to clean stainless steel. The complexing acids are used extensively on all metal surfaces where reuse or nondestructive cleaning is the objective. They may be used with or without inhibitors, depending on the acid and the conditions; oxalic, citric, and sulfamic acids, being the strongest, are often used in combination with inhibitors. The complexing acids may be mixed together to get the full range of chelating abilities, or they may be matched to the specific 
surface and contaminant; mixtures of oxalic and citric acids are the most widely used. Oxidizing agents are often used with the acids to condition the metal so that it may be solubilized.

Some disadvantages of weak acids are that they are more expensive than some of the strong acids; they react more slowly than stronger acids; although they are less corrosive than strong acids, they still requile some material compatibility and personnel safety considerations; they can break down at high temperatures; and they require neutralization before being treated in a radioactive waste system.

\section{a. Hydrochloric Acid}

Hydrochloric acid is the most popular of all acid etchants and widely used in the chemical milling industry. Hydrochloric acid is used for cleaning piping and boilers in Germany [HEITMANN]. Chemizal cleaning of the primary coolant loop using hydrochloric acid is accomplished by utilizing temperatures greater than $100^{\circ} \mathrm{C}$ and $\mathrm{pH}$ values as low as 4.0 . Before the addition of hydrochloric acid to the system, hydrazine is added to the acid solution to reduce the corrosion rate and to prevent the reduction of ferric oxide to magnetite.

Hydrochloric acid was also the first chemical cleaning agent used for utility boilers. In the United States, hydrochloric acid was applied in decontamination of the BONUS reactor $\mathrm{Cr} / \mathrm{Mo}$-steel main stzam system and the stainless steel primary purification system [PRWRA]. Initial laboratory testing was carried out at $70^{\circ} \mathrm{C}$ by using $10 \mathrm{vol} \% \mathrm{HCl}$ to clean stainless steel piping that was contaminated with the activation products ${ }^{60} \mathrm{Co},{ }^{58} \mathrm{Co}$, and ${ }^{65} \mathrm{Zn}$ and small quantities of fission products: such as ${ }^{137} \mathrm{Cs}$. The tests showed that a DF of 10 could be achieved. Actual system decontamination at BONUS was performed later by filling the system with $100 \mathrm{~g} / \mathrm{L}$ of $\mathrm{HCl}$ at $70^{\circ} \mathrm{C}$ for $2 \mathrm{~h}$. As in the laboratory tests, the maximum DF was about 10 for stainless steel and $\mathrm{Cr} / \mathrm{Mo}$ systems. The decontamination waste was neutralized by addition of sodium hydroxide and sodium citrate and then filtered and evaporated.

Hydrochloric acid is a very aggressive leachant that is usually used in onestep processes. It is probably the most popular chemical cleaning solution for large equipment systems because (1) it is cheap; (2) it can be inhibited to a reasonably satisfactory degree; (3) it reacts with corrosion products; and (4) it does not form insoluble salts in process equipment [LOUCKS]. However, the chloride ions are strongly corrosive to stainless steels, which is the most important reason that $\mathrm{h} y$ drochloric acid is not considered for the nuclear industry [AYRES1970B]. This aggressive decontaminant can be used in stainless steel systems (pipes and tanks) only if they are to be discarded after decontamination. However, inhibited hydrochloric acid can be used on carbon steel systems.

\section{b. $\quad$ Nitric Acid}

Nitric acid is often specified for use in systems made of austenitic stainless steel or aluminum because these metals tend to be passivated by strong oxidizing agents and, therefore, do not corrode rapidly when exposed to inhibited nitric acid. The concentrated acid is occasionally used for removing certain organic deposits. A typical process uses $10 \mathrm{vol} \% \mathrm{HNO}_{3}$ at $75^{\circ} \mathrm{C}$. 
Nitric acid has been used to dissolve $\mathrm{U}$ and $\mathrm{Pu}$ and their oxides in stainless steel and Inconel systems. For instance, in cleaning the Eurochemic reprocessing plant shutdown, nitric acid was used in a two-phase approach [DETILLEUX, BROOTHAERTS-1979A, -1979B]. The purpose of this cleaning was to dissolve plutonium dioxide, fission products, sludge deposits, and residual contamination from piping and components. In the first phase, the plant equipment was rinsed with typical PUREX-type solutions, while allowing collection and detection of fissile material. Nitric acid proved to be the most efficient rinsing agent, and the contact times of the rinse solutions in the various equipment varied from 5 to $15 \mathrm{~h}$. The nitric acid was recycled by using the high-level waste evaporator and the acid recovery system. The second phase of the decontamination was carried out to further reduce the radiation levels within the plant. For this phase, a solution of $0.1 \underline{\mathrm{M} \mathrm{KMnO}} \mathrm{KM}_{4}$ and $8 \mathrm{MHNO}_{3}$, with an 8-d contact time, proved to be the most efficient decontamination agent, for both plutonium and fission products. A small volume of oxalic acid was added to the $\mathrm{KMnO}_{4} / \mathrm{HNO}_{3}$ solution to destroy the permanganate heel that remained in the equipment after removal of the bulk volume. The same $\mathrm{KMnO}_{4} / \mathrm{HNO}_{3}$ solution was recommended [GORODINSKY] for the decontamination of stainless steel equipment in a reprocessing plant. Nitric acid was used in Italy to decontaminate an evaporator and storage tanks [FARINELLI].

Nitric acid was used in two processes to decontaminate the cell of an acid recovery evaporator at the Tokai Reprocessing Facility in Japan. First, a general treatment by $\mathrm{HNO}_{3}$ was followed by a sodium hydroxide rinse. To decontaminate equipment bottoms, a threestage process was used (i.e., AP-nitric acid-EDTA) [HAYASHI]. The THOREX pilot plant was decontaminated by alternating between with (1) $20 \%$ sodium hydroxide containing $2 \%$ sodium tartrate and (2) $20 \%$ nitric acid [McCORKLE]. Hanford KE-Reactor recirculating loops were successfully decontaminated with AP that was followed by nitric acid and water rinses [WEED1963]. Testing at Hanford Atomic Products Operation (HAPO) confirmed that nitric acid will remove uranium, uranium oxide, and some associated fission products and may be able to remove a portion of the crud films and associated radionuclides [AYRES-1962].

Although nitric acid is effectively used for dissolving uranium and its oxides in stainless steel and Inconel systems, it cannot be used on carbon steel because of the high corrosion rate. Nitric acid is a strong oxidizing agent; therefore, users need to know its compatibility with various materials.

\section{c. Sulfuric Acid}

Sulfuric acid is also used for removing iron oxide deposits and cleaning steel systems. Its primary applications are for stainless steel and carbon steel. However, sulfuric acid is highly corrosive to carbon and stainless steels, and inhibitors must be used with it. Treatment conditions are typically at temperatures from 47 to $70^{\circ} \mathrm{C}$ for 30 to $60 \mathrm{~min}$.

Sulfuric acid (35\%), inhibited with phenyltheourea, decontaminated and defilmed carbon steel at room temperature in about $6 \mathrm{~h}$ with low corrosion rates. Inhibited sodium bisulfate was also used to decontaminate carbon steel reactor compounds [AYRES-1970A]. An advantage of using sulfuric acid is that it does not cause stress cracking of stainless steel. The disadvantages of sulfuric acid treatments include the precipitation of $\mathrm{Ca}, \mathrm{Ba}$, and $\mathrm{Sr}$ sulfates that 
may block narrow passages. However, this is not usually a problem. Dilute, inhibited sulfuric acid is used at nuclear installation; for removing localized contamination known to be free of calcium compounds. However, it has not been used extensively as a decontamination solvent because the DFs are relatively low [LOUC:KS]. A treatment with $100 \mathrm{~g} / \mathrm{L}$ of $\mathrm{H}_{2} \mathrm{SO}_{4}$ at $70^{\circ} \mathrm{C}$ for $1 \mathrm{~h}$ achieved a DF of only 2 [NEA].

Waste processing procedures after sulfuric acid treatment are typically neutralization, filtration, and evaporation.

\section{d. $\quad$ Phosphoric Acid}

Phosphoric acid, particularly in dilute (8 to 10\%), inhibited solutions, is very effective for decontaminating mild steel. Such solutions proved to be good metal cleaners, rapidly defilming and decontaminating carbon steel piping. At a temperature of 60 to $70^{\circ} \mathrm{C}$, inhibited phosphoric acid removed all visible film and 95 to $99 \%$ of the contamination in contact times of 10 to $20 \mathrm{~min}$ [WEED-197C].

Phosphoric acid was chosen as an oxide remover for decontamination testing at HAPO [AYRES-1960, 1962; DEMMTTT]. The primary objective of this program was to develop satisfactory procedures for decontaminating reactor recirculating-coolant systems that were contaminated by uranium oxides, fission products, and activated corrosion products. In preliminary laboratory investigations, treatment with phosphoric acid solution in a one-step procedure proved to be effective for decontaminating carbon steel surfaces (DF $\geq 10$ ) that had been exposed to high-temperature water systems but only moderately effective for stainless steel surfaces. However, if preceded by an AP or peroxide-bicarbonate step, the phosphoric acid was more effective (DF $=10$ to 20 for $\mathrm{AP} / \mathrm{H}_{3} \mathrm{PO}_{4}$ ) for both carbon and stainless steel. Other mixtures containing phosphoric acid were also tested in this program. For example, an inhibited phosphoric acid decontaminant process was effective in removing contaminants from ruptured fuel elements.

UNC Nuclear Industries used phosphoric acid to decontaminate carbon steel coolant piping in the N-Reactior [KRATZER]. The decontamination was performed by placing the reactor in the once-through backup cooling mode using demineralized water and injecting inhibited concentrated phosphoric acid into the coolant stream. The dilute spent acid was routed from the reactor to a waste storage tank from which it was subsequently shipped for evaporation and storage. The $8 \%$ phosphoric acil applied to the carbon steel piping at $85^{\circ} \mathrm{C}$ for about 20 min was effective in removing activated corrosion products from the carbon steel and in removing nonadherent deposits from the: Zircaloy-2 fuel surfaces. During the 1979 decontamination, $62 \mathrm{~m}^{3}$ of concentrated phosphoric arid applied to the reactor coolant system removed about $476 \mathrm{Ci}$ of activated corrosion products. This process generated $1700 \mathrm{~m}^{3}$ of waste solution. Corrosion of the carbon and low-alloy steels irı contact with the solution ranged from 0.8 to $1.6 \mu \mathrm{m}$.

Phosphoric acid (15 vol\%) was also used for the decontamination of the BONUS reactor carbon steel and brass piping and reactor components in preparation for entombment [DOE]. The selection was based on a test program similar to that described earlier for hydrochloric acid. As in the laboratory tests, DFs of between 5 and 37 were generally achieved in the 
actual decontamination flushes. The carbon steel condensate system was then passivated using ammonium hydroxide followed by a rust-inhibiting rinse of TURCO-4517 solution.

Phosphoric acid is relatively expensive but may be used in certain situations where using hydrochloric acid is undesirable. At elevated solution temperatures $\left(80^{\circ} \mathrm{C}\right)$, contact time is important for carbon steel and copper-based alloys. If the contact time is longer than $20 \mathrm{~min}$, redeposition will occur, which may reduce DFs.

\section{e. $\quad$ Sulfamic Acid}

Sulfamic acid with an inhibitor is considered to be an effective decontaminant for carbon steel and aluminum. It is not as active as phosphoric acid, but it is only mildly corrosive to carbon steel and does not cause reprecipitation.

Typically, 9\% sulfamic acid and water is applied to carbon steel and aluminum at temperatures of 45 to $80^{\circ} \mathrm{C}$. Because it is a less reactive reagent, longer contact times ( 1 to $4 \mathrm{~h}$ ) may be necessary than with other reagents, and multiple contacts may be required. Sulfamic acid has not been used extensively in decontaminating reactor carbon steel systems but is acknowledged to be effective. An inhibited $8 \%$ sulfamic acid solution at $85^{\circ} \mathrm{C}$ decontaminated carbon steel components of PWRs or BWRs in $2 \mathrm{~h}$ [AYRES]. Monel and nickel that had been exposed to water at a maximum temperature of $300^{\circ} \mathrm{C}$ were cleaned by immersion in boiling $25 \%$ sulfamic acid for $1 \mathrm{~h}$ [MCGREW]. However, sulfamic acid cleaner is not a suitable single-step decontaminant for stainless steel [WEED-1962A]. Waste processing procedures for sulfamic acid cleaning are neutralization, filtration, and evaporation.

\section{f. $\quad$ Nitric Acid plus Hydrofluoric Acid}

More aggressive acids such as HF are very effective decontaminants. Hydrofluoric acid, however, can damage the base metal. Small amounts may be added to nitric acid to accelerate the dissolution of oxide layers. The effectiveness of the $\mathrm{HNO}_{3}-\mathrm{HF}$ mixture is primarily due to the corrosion (removal) of the stainless steel surface [JOHNSTON]; however, excessive corrosion will deplete the reagent (complex the fluoride) and, thus, create additional liquid waste.

A solution of $3.5 \underline{\mathrm{M}} \mathrm{HNO}_{3}-0.04 \underline{\mathrm{M}} \mathrm{HF}$ was used as a cleaning/etching solution on stainless steel [RANKIN-1992]. In another application, Maffei immersed contaminated type 406 and 430 stainless steel in $20 \% \mathrm{HNO}_{3}-2 \% \mathrm{HF}$ solutions at $54^{\circ} \mathrm{C}$ until the scale that had formed on the steel was loosened or dissolved [MAFFEI].

The Thermal and Nuclear Research Center of Italia Electricity studied the use of aggressive chemicals (e.g., $\mathrm{HNO}_{3}$ and $\mathrm{HF}$ ) for stainless steel decontamination [BREGANI1987, 1990]. The decontamination processes were tested on small pipes and complex components (valves) removed from the primary system of the Garigliano BWR. Many solutions were tested, including various combinations of hydrochloric, hydrofluoric, and nitric acid, both in flow conditions and in chemical baths. The $\mathrm{HNO}_{3} / \mathrm{HF}$ solution was the most effective at removing contamination. Generally, the decontamination processes could remove more than $95 \%$ of the 
radioactivity, but some residual radioactivity remained inside the valves, probably in the dead areas, such as crevices, welds, bends, and gaskets. Additional static tests with various concentrations of $\mathrm{HF}$ and $\mathrm{HNO}_{3}$ showed that the weight loss and, thus, the corrosion rates on the nonoxidized surfaces reached a maximum when $3 \% \mathrm{HF}$ was used with 5-10\% $\mathrm{HNO}_{3}$. The highest $\mathrm{DF}$ on oxidized contaminated surfaces was achieved by using $1.5-3 \% \mathrm{HF}-5 \% \mathrm{HNO}_{3}$.

Spent radioactive waste solutions from surface decontamination can be treated by means of neutralization with $\mathrm{NaOH}$ and/or $\mathrm{CaO}$. Precipitation is improved by adding chitosan to the waste solution. Nitric acid can be recycled via a high-level waste evaporation/acid recovery system or destroyed either chemically or by heating.

An $\mathrm{HNO}_{3}-\mathrm{HF}\left(3 \% \mathrm{HF}-20 \% \mathrm{HNO}_{3}\right.$ ) reagent was considered to be the most efficient reagent for the decontamination of stainless steel equipment contaminated by actinides and fission products in the THOREX and PUREX pilot plants at Oak Ridge National Laboratory (ORNL) [SADOWSKI]. The process conditions used at ORNL were 60 to $85^{\circ} \mathrm{C}$ for 0.5 to $1.5 \mathrm{~h}$. An $\mathrm{HNO}_{3}-\mathrm{HF}$ solution, alternated with an alkaline complexing solution, was recommended for decontamination of stainless steel because it was efficient, only mildly corrosive to the equipment, stable to heating and aging, and inexpensive. Further, mixing the two decontamination solutions caused neutralization and, the efore, allowed convenient waste disposal.

An $\mathrm{HrNO}_{3}-\mathrm{HF}$ treatment with rinsing was used in decontamination of Savannah River Plant waste glass canisters [RANKIN-1982]. The technique involved using $\mathrm{HNO}_{3}-\mathrm{HF}$ mixtures followed by oxalic acid. In the first etch step, the surfaces of the canisters were treated with $3.9 \underline{\mathrm{M}} \mathrm{HNO}_{3}-0.4 \underline{\mathrm{M}} \mathrm{HF}$ at room temperature for $1 \mathrm{~h}$ followed by a water rinse. A second cleaning step used boiling oxalic acid $(100 \mathrm{~g} / \mathrm{L})$ for $1 \mathrm{~h}$. A second water rinse was then completed. Both the $\mathrm{HNO}_{3}-\mathrm{FF}$ and the $\mathrm{H}_{2} \mathrm{C}_{2} \mathrm{O}_{4}$ steps were repeated a second time. This technique successfully removed oxide film contaminated with plutonium from type 304L stainless steel.

In Swe:den, the decontamination of PWR and BWR stainless steel coolant systems achieved DFs $>1000$ by using a solution of $0.1-0.3 \% \mathrm{HF}$ and $1 \% \mathrm{HNO}_{3}$ at temperatures from 50 to $80^{\circ} \mathrm{C}$ and contact times from 1 to $3 \mathrm{~h}$. About 1.3 to $5 \mu \mathrm{m}$ of surface was milled by this reagent. The secondary wastes from this single-step technique were successfully processed by using a two-step precipitation process [NEA].

The ICPP Decontamination Development Group evaluated various methods of decontamination [DEMME:R-1994B]. A solution of 3.55 $\underline{\mathrm{M}} \mathrm{HNO}_{3}-0.04 \underline{\mathrm{M}} \mathrm{HF}$ was found to be the most effective chemical in the test matrix. Using simulated contaminant (SIMCON) coupons, cesium DFs of 6 and zirconiun DFs of 14 were reported. These DFs are better than those for the baseline commercial solvent, TURCO 4502 ( 5.5 for cesium; 0 for zirconium), and waste volumes were significantly lower. Also, laboratory tests indicated that $0.04 \mathrm{M} \mathrm{HF}$ has a corrosion rate of $0.002 \mathrm{~mm} / \mathrm{yr}(0.08 \mathrm{mil} / \mathrm{yr})$, fcr less than TURCO 4502, which can have corrosion rates as high as $2.54 \mathrm{~mm} / \mathrm{yr}$ (100 mil/yr). (Seə Section V.A.5 for more information on TURCO products.)

Because hydrofluoric acid is corrosive, it can cause problems when used remotely; corrosion from the vapors can occur throughout the entire cell block. Process vessels and exhaust ducts may need to be fabricated from more expensive, corrosion-resistant materials. Also, 
disposal of hydrofluoric acid-containing waste is difficult; complexing agents such as aluminum or zirconium are required. Calcium can also be used to precipitate $\mathrm{CaF}_{2}$ from solution. Other problems include controlling the contact time, which is difficult with large, remote systems, and the neutron dose from the $(\alpha, \mathrm{n})$ reaction with fluorine, which can lead to elevated radiation fields.

\section{g. Nitric plus Sulfuric Acids}

The corrosion resistance of stainless steel in a mixture of nitric and sulfuric acids has been the subject of a number of papers [LITVINOVA, KRYSTOW, McKINNELL, CHARLES]. It is well known that austenitic stainless steels corrode rapidly in dilute sulfuric acid, whereas exposure to nitric acid causes almost negligible corrosion. Therefore, a mixture of both acids may have a use in chemical decontamination of stainless steel systems.

One application of $\mathrm{HNO}_{3}-\mathrm{H}_{2} \mathrm{SO}_{4}$ mixtures was in the Plutonium Recycle Test Reactor (PRTR) at Hanford [VIEBROCK]. Residuals from the rupture of a $\mathrm{MgO}-\mathrm{PuO}_{2}$ fuel element in the PRTR were not removed effectively by regular decontamination methods such as the APACE process [PERRIGO-1967]. In a series of corrosion tests on type 304L stainless steel, various mixtures of $\mathrm{HNO}_{3}-\mathrm{H}_{2} \mathrm{SO}_{4}$ were evaluated by Perrigo. The corrosion rate at temperatures up to $100^{\circ} \mathrm{C}$ varied from 0.18 to $37 \mathrm{~mm} / \mathrm{yr}(6.9$ to $1453 \mathrm{mil} / \mathrm{yr})$ when exposed for $100 \mathrm{~h}$. The corrosion rate increased with $\mathrm{HNO}_{3}$ concentration, reaching a maximum at $20 \mathrm{wt} \% \mathrm{HNO}_{3}$. At higher $\mathrm{HNO}_{3}$ concentrations, the corrosion rate decreased until a minimum was reached at $90 \mathrm{wt} \% \mathrm{HNO}_{3}$. A further increase in $\mathrm{HNO}_{3}$ concentration rapidly increased the corrosion rate again.

\section{h. Nitric Acid plus Hydrochloric Acid}

A series of tests was carried out by Kernkraftwerk Lingen GmbH to develop vigorous decontamination techniques [PASCALI]. Preliminary tests on inactive samples with strong inorganic acids showed that a marked surface removal of the austenitic metal plates occurred in only two acid mixtures $\left(\mathrm{HCl}-\mathrm{HNO}_{3}\right.$ and $\mathrm{HCl}$ with $\mathrm{H}_{2} \mathrm{O}_{2}$ added $\left.{ }^{3}\right)$. A "nitrochloric" acid mixture $\left(4.7 \mathrm{~g} / \mathrm{L} \mathrm{HNO}_{3}+13 \mathrm{~g} / \mathrm{L} \mathrm{HCl}\right.$ ) was chosen for further studies. In spite of the low acid concentration, treatment for 4 to $8 \mathrm{~h}$ was sufficient to remove 10 to $30 \mu \mathrm{m}$ of material. The expected volume of waste generated by this process is shown by the following example. For a $2000-\mathrm{m}^{2}$ surface area in which $30 \mu \mathrm{m}$ of material is to be removed, cleaning the primary water area would generate about 13 tons of solid materials and $1600 \mathrm{~m}^{3}$ of waste water; decontamination of the steam and condensate area would generate another 5.5 tons of solid material and $700 \mathrm{~m}^{3}$ of waste water. It is important to note that the secondary wastes generated appear to be large, and their treatment needs further investigation.

\section{i. Fluoroboric Acid}

Fluoroboric acid is used for decontamination by dipping, recycling systems, or spraying. The technology was designed to remove oxide and contamination layers in a

\footnotetext{
${ }^{3}$ The tests with the mixture $10 \% \mathrm{HCl}-1 \% \mathrm{H}_{2} \mathrm{O}_{2}$ were not continued because of the quick decay of the $\mathrm{H}_{2} \mathrm{O}_{2}$ and the very strong tendency for local attack. Some perforation depths of up to $150 \mu \mathrm{m}$ resulted after a pickling duration of $30 \mathrm{~min}$.
} 
controllable, uniform, and efficient manner [HANULIK]. Rollor reported that thin layers of contaminated metal can be removed from the surface of a contaminated object by using fluoroboric acid [ROLLOR-1992]. Consizquently, the level of damage to an object and the corresponding amount of waste produced can be minimized by controlling the process to remove only the thickness of metal required fo: a specific decontamination.

Fluoroboric acid was examined as a possible nonsodium chemical decontamination reagent at the ICIP [DEMMER-1994B]. Coupon tests showed $1 \underline{\mathrm{M}} \mathrm{HBF}_{4}$ to be an excellent decontamination reagent with high DFs: 13 for Cs and 37 for $\mathrm{Zr}$.

A commercial vendor, Alaron Corporation (Rockville, MD), patented a fluoroboric acid process for the decontamination of radioactively contaminated metals from commercial reactors to achieve frez-release activity levels [ROLLOR-1995]. Decontamination factors of 50 to 100 were achieved by using this process [ROLLOR-1992].

In general, fluoroboric acid reacts with a metal to produce the corresponding metal-fluoroborate and hydrogen gas. The acid reacts similarly with metal oxides, generating water rather than hydrogen gas as a reaction end product. The effectiveness of these reactions depends in large part upon the respective solubilities of the various metals in this acid; they are high for iron and other components of stainless steel $\left(\geq 200 \mathrm{~g} / \mathrm{L}\right.$ in $\left.50 \% \mathrm{HBF}_{4}\right)$. During dissolution, the solution $\mathrm{pH}$ is maintained above 4 to 5 as a result of the formation of the salt of the acid rather than the free acid.

One disadvantage of using fluoroboric acid is the relatively large volume of secondary waste that is generated by the addition of aluminum nitrate to complex the fluoride ions. To decrease this waste volume, a process called DECOHA was developed by Recytes ${ }^{4}$ in Switzerland [ROLLOR-1992]. The DECOHA process includes a metal dissolution step followed by electrochemical recovery of disso.ved metals and subsequent reformation of the fluoroboric acid.

The DIECOHA process is generally applied at temperatures between $30^{\circ} \mathrm{C}$ and $98^{\circ} \mathrm{C}$. Some metals, such as carbon steel, Zircaloy, and aluminum, may be treated at room temperature; however, stainless steels and nickel alloys require higher temperatures for realistic application times. The speed of the DECOHA process follows a typical temperature dependency. For every $10^{\circ} \mathrm{C}$ increase in temperature, the reaction requires half as much time for completion. Typical removal rates range from 3 to $4 \mu \mathrm{m} / \mathrm{h}$ at $80^{\circ} \mathrm{C}$, for nickel alloys in $50 \% \mathrm{HBF}_{4}$, to 20 to $25 \mu \mathrm{m} / \mathrm{h}$ at $21^{\circ} \mathrm{C}$, for aluminum in $5 \% \mathrm{HBF}_{4}$.

The flc oroboric acid technology generates metal-containing waste as a result of surface removal. Waste generation is about $1 \mathrm{~g} / \mathrm{m}^{2}$ per micrometer depth of bare metal removal. The acid can be electrolyticaly regenerated and recycled, and the radioactive waste can be plated out at the cathode and solidified in cement. The final quantity of cement-solidified waste is 20 to $50 \mathrm{~g} / \mathrm{m}^{2}$ of decontaminated mital. Other waste treatment options are neutralization and precipitation with solidification in cement: $\left(200\right.$ to $500 \mathrm{~g} / \mathrm{m}^{2}$ ), or treatment by ion exchange followed by

\footnotetext{
${ }^{4}$ Recytes SA, Geneva, Switzerland, purchased Alaron Corporation (Rockville, MD) during the last quarter of 1991 so as to transfer the DECOHA technology into Western markets.
} 
solidification of the resin in cement $\left(400\right.$ to $\left.700 \mathrm{~g} / \mathrm{m}^{2}\right)$. The optimum material for solidification of this waste needs to be determined [BEAUJEAN].

\section{j. $\quad$ Oxalic Acid}

Oxalic acid is effective in removing rust from iron. It is an excellent complexant for niobium and fission products [MANION]. Oxalic acid has been of some use in a single-step process for stainless steel decontamination; however, it will react with stainless steel to form a highly insoluble ferrous oxalate precipitate.

Oxalic acid was used at the Savannah River Plant to clean stainless steel heat exchangers. The process consisted of filling the system with water, adding a corrosion inhibitor ( $2.6 \mathrm{~g} / \mathrm{L}$ ferric sulfate), steam heating to $70^{\circ} \mathrm{C}$, adding oxalic acid to $2 \mathrm{wt} \%$, and recirculating the mixture. The system was drained, rinsed with water, and neutralized with $50 \% \mathrm{KOH}$, and then drained and rinsed again with water. Decontamination factors of 3 to 20 were achieved. At $90^{\circ} \mathrm{C}$, oxalic acid reacted with the stainless steel to form a highly insoluble, tenacious ferrous oxalate film. Subsequent treatment with sulfuric and nitric acid was necessary to remove this precipitate [CARLSON].

The PRTR at Hanford was decontaminated twice during the 1960s. The first decontamination (1962) required a number of chemical reagents to remove both the fuel debris and the activated corrosion products [AYRES-1962]. Oxalic acid was employed for removal of the latter, but extended exposure of the reactor coolant system to the acid caused a ferrous oxalate precipitate to collect on the piping, which led to low DFs. To alleviate this precipitation problem, ammonium citrate and EDTA were used in place of oxalic acid, which resulted in DFs of 1.8 to 56.5 .

In early screening tests at the General Electric Vallecitos Nuclear Center, $0.01 \mathrm{M}$ oxalic acid, nitrilotriacetic acid, and EDTA dissolved $80 \%$ of the ${ }^{60} \mathrm{Co}$ on BWR out-of-core surfaces in less than $72 \mathrm{~h}$ [ANSTINE].

A solution of nitric acid ( $3.5 \underline{\mathrm{M}})$ and oxalic acid $(0.5 \underline{\mathrm{M}})$ was developed as a decontaminant by Westinghouse Idaho Nuclear Company (WINCO) [DEMMER-1994B], in both plant and in SIMCON coupon tests. Decontamination factors for $\mathrm{Cs}$ and $\mathrm{Zr}$ were 4.5 and 1.3, respectively. The mixture appears to have a general reductive property, along with a strong acidic dissolution and complexation capability.

A dilute solution of oxalic acid $(0.02 \underline{\mathrm{M}})$ and hydrogen peroxide $(0.05 \underline{\mathrm{M}})$ was suggested for removing film and scale from carbon steel at room temperature. Although this solution purportedly removes some films and rust from carbon steel, it did not remove the films formed on carbon steel in the WHC N-Reactor. At higher temperatures and/or higher concentrations, mixtures of oxalic acid and peroxide are very effective decontaminants, but they are also exceedingly corrosive [AYRES-1970A]. 
Oxalic acid is used in a second step after AP preconditioning (see following sections); but because precipitates are formed, the technique is not of interest to us. Problems may also occur during evaporation, when oxalic acid can cause the formation of solid crystals.

k. $\quad$ Citric $A$ cid

Organi: acids have replaced mineral acids to a great extent in the chemical cleaning industry [BELL-1964A, 1964B]. Citric acid is one of the most effective of the organic acids.

A mixture of citric $(0.2 \underline{\mathrm{M}})$ and oxalic $(0.3 \mathrm{M})$ acids plus a corrosion inhibitor was very effective at decontaminating stainless steel when used after AP in a two-step process. Alkaline permanganate was circulated at $105^{\circ} \mathrm{C}$ for $2 \mathrm{~h}$; the system was then rinsed with water until the $\mathrm{MnO}_{4}^{-}$was completely reinoved and the $\mathrm{pH}$ was $>10$; the dilute $(10 \%)$ mixture was circulated for $2 \mathrm{~h}$ at room temperature, and finally, the system was rinsed until the conductivity of the rinse water was $<50 \mathrm{MS}$. Citrate icins were added to complex the iron and inhibit the formation of any precipitate. The dilute mixture neutralizes traces of residual sodium hydroxide (from the AP) and dissolves any residual $\mathrm{MnO}_{2}$ (by reduction to $\mathrm{Mn}^{2+}$ ). The process was not very effective unless preceded by the AP flush [AI'RES-1970B].

An organic acid treatment was demonstrated at Capenhurst Gaseous Diffusion Plant [ORNL]. This treatment used citric and sulfuric acids in sequence for removal of $U$ and Tc, respectively, from metal surfaces. Secondary wastes from this process are (1) citric acid containing metal ions, especially $\mathrm{U}$, and (2) sulfuric acid containing metal ions, especially $\mathrm{Tc}$ and $\mathrm{Ni}$. Citric acid is relatively benign to the environment, biodegradable, and treatable by ion exchange for removal of radionuclide and other metal ions. Remaining effluents may be treatable at a sewage treatment plant. Sulfuric acid is also treatable by ion exchange (IX) with possible recycling of clean acid. Tertiary wastes are spent ion-exchange resins.

\section{1. $\quad$ Mixed Organic Acids}

Citric acid was recommended for decontamination of grout-processing equipment, including mixers, pumps, and piping [CLEMMER]. In laboratory coupon tests at $60^{\circ} \mathrm{C}$, a $6 \mathrm{~N}$ citric acid solution achieved $>95 \%$ removal of grout within $3 \mathrm{~h}$. Pilot-scale decontamination tests showed that a $6 \underline{\mathrm{N}}$ citric acid solution at $60^{\circ} \mathrm{C}$ was effective in removing thick deposits of grout from many components, and residual deposits were $<0.015 \mathrm{~mm}$ ( $1 \mathrm{mil}$ ). Vigorous agitation was important to achieving good decontamination.

An experimental study tested the decontamination effectiveness of mixtures of citric acid, oxalic acid, and EDTA with actual BWR and PWR samples [SPERANZINI-1990B]. Under certain conditions, oxalic acid was the most effective reagent for dissolution of oxides, but the conditions for most effertive dissolution in solutions of oxalic acid and/or citric acid were difficult to define and control. Citric acid is not a very effective solvent for metal oxides, and its function in decontamination solutions is to provide buffering and increased $\mathrm{Fe}^{3+}$ solubility and to reduce the quantity of ferrous oxalate precipitates that form on surfaces. EDTA solutions at $117^{\circ} \mathrm{C}$ dissolved oxides at rates comparable to those for oxalic acid-containing solutions. Since oxalic acid 
is likely to cause intergranular attack in sensitized type 304 stainless steel, experiments were carried out to assess whether its removal from solvents would affect decontamination effectiveness. It was concluded that effective decontamination of BWR and PWR systems could be achieved with mixtures of citric acid and EDTA only.

\section{Alkaline Permanganate Systems}

Alkaline permanganate is an oxidizing agent that is used to condition films on stainless steel, Inconel, and Incoloy [AYRES-1979]. Alkaline permanganate does not dissolve the oxide film itself, but transforms it into a state that is dissolved more easily [AYRES-1979, WATKINS]; it is normally used as the pretreatment agent in a multistep process. A variety of other reagents, such as ammonium citrate, EDTA, oxalic acid, and sulfamic acid, have also been successfully used in various applications to remove oxide coatings on stainless steel, carbon steel, and Inconel. These are typically two-stage processes; the first (alkaline) stage is intended to oxidize the chromium oxide layers to yield soluble chromate ions and the second (acid-complexing) stage is primarily a dissolution reaction. Most of these processes were developed for application to both BWRs and PWRs. The various AP systems will be introduced in the following sections. The $\mathrm{AP} / \mathrm{HNO}_{3}$ and $\mathrm{AP} / \mathrm{H}_{3} \mathrm{PO}_{4}$ processes were described previously in Sections V.1.b and V.1.d.

\section{a. $\quad$ Alkaline Permanganate (AP)}

Typical AP solutions contain 3 to $20 \% \mathrm{NaOH}$ and 1 to $5 \% \mathrm{KMnO}_{4}$. The AP solution usually includes an inhibitor to reduce general corrosion rates and a wetting agent to reduce surface tension. Usual treatment conditions are 90 to $110^{\circ} \mathrm{C}$ for 1 to $10 \mathrm{~h}$. An AP solution consisting of $10 \mathrm{wt} \% \mathrm{NaOH}$ and $5 \mathrm{wt} \% \mathrm{KMnO}_{4}$, applied at $107^{\circ} \mathrm{C}$ for $30 \mathrm{~min}$, gave satisfactory results in decontamination of the Army Package Power Reactor (APPR-1), a PWR [ZEGGER1959A,-1959B, PANCER].

An AP solution was used to decontaminate primary piping systems in the Shippingport PWR and was very effective in treating the radioactive corrosion film [ABRAMS]. The AP solution leached chromium from corrosion product deposits so that most of the ${ }^{51} \mathrm{Cr}$ activity was removed; some of the ${ }^{54} \mathrm{Mn},{ }^{60} \mathrm{Co},{ }^{58} \mathrm{Co}$, and ${ }^{58} \mathrm{Fe}$ were also removed by the AP treatment.

An important feature of these systems is that the dilute AP conditions the films for removal, especially, the films on stainless steel. It also conditions films on Inconel and Incoloy, presumably by the same mechanism, although no information is available about the structure or composition of the films on these alloys after treatment with AP. The AP has no apparent effect on films that form on carbon steel after exposure to high-temperature water, which is logical since these films do not contain chromium atoms.

\section{b. Alkaline Permanganate-Ammonium Citrate (APAC)}

In APAC systems, an AP solution is followed by an ammonium citrate (AC) solution. The corrosion film is pretreated with $13 \mathrm{~g} / \mathrm{L} \mathrm{KMnO}_{4}$ and $100 \mathrm{~g} / \mathrm{L} \mathrm{NaOH}$, fol-

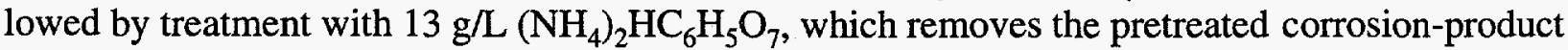
film. Dilute $\mathrm{AC}$ removes residual $\mathrm{MnO}_{2}$ from the AP solution and neutralizes the $\mathrm{OH}^{-}$. However, 
dilute reagents usually require higher temperatures and longer contact times to enhance effectiveness. When used in concent ated form, APAC attacks the remaining corrosion film; however, redeposition has been a significant problem with this process.

Approximately 10 chemical agents were evaluated in laboratory bench-type experiments as part of the decontamination program of the APPR-1 [ZEGGER-1960, PANCER]. Small pieces of contaminated type 304 stainless steel piping were treated with AP, followed by a rinse solution of oxalic acid, citric acid, or AC. All the treatments were effective in removing the activated corrosion product (siale), but AP treatment at about $100^{\circ} \mathrm{C}$, followed by a rinse with $5 \%$ citric acid-1/2\% Versene, or $5 \% \mathrm{AC}$, at 75 to $95^{\circ} \mathrm{C}$ gave the most promising results. The average gamma DF was 50. The total jenetration per decontamination treatment $(2.5$ to $3.0 \mathrm{~h})$ varied from 0.05 to $0.15 \mu \mathrm{m}(0.002$ to $0.006 \mathrm{mil})$ for stainless steel (annealed) and was $0.15 \mu \mathrm{m}(0.006 \mathrm{mil})$ for sensitized material.

The A?AC multistep process was used for plant decontamination at the Shippingport PWR to remove activated corrosion and wear products that had deposited in the primary piping system [ABRAMS]. The AP treatment consisted of injecting AP into the reactor coolant until the $\mathrm{KMnO}_{4}$ concentration reached $13 \mathrm{~g} / \mathrm{L}$. The coolant containing the AP was then recirculated for $24 \mathrm{~h}$ at $120^{\circ} \mathrm{C}$. The AP was removed from the coolant by demineralizers. After passing through the demineraizers, the coolant was used to flush the system, including any dead legs, to remove any residual AP solution. Demineralization of the AP solution required $24 \mathrm{~m}^{3}$ $\left(850 \mathrm{ft}^{3}\right)$ of resin. This treatment removed significant gross radioactivity.

Once the system was completely flushed, $\mathrm{AC}$ was added to the recirculating reactor coolant and maintaine 1 at 12 to $13 \mathrm{~g} / \mathrm{L}$ for $28 \mathrm{~h}$ at $120^{\circ} \mathrm{C}$. The $\mathrm{AC}$ removed 90 to $99 \%$ of the deposited corrosion product activity from smooth surfaces, but it was not effective for the removal of activity from crevices or from low-flow or crud trap areas. However, the average radiation levels in the steam generator and pipe walls were reduced by a factor of $\sim 50$. The dominant activities in the waste $\mathrm{Al}^{\mathrm{C}}$ solution were ${ }^{60} \mathrm{Co},{ }^{58} \mathrm{Co},{ }^{54} \mathrm{Mn}$, and ${ }^{59} \mathrm{Fe}$, which were removed with demineralizers. Demineralization of the AC solution required $28 \mathrm{~m}^{3}\left(990 \mathrm{ft}^{3}\right)$ of resin.

In general, the $\mathrm{AC}$ solution is not effective in removing contamination from dead-leg areas and crevices or in removing aged films from some stainless steel surfaces. The dilute (1.5\%) AP and AC solutions used in the Shippingport PWR removed the film from the metal surfaces but did not dissolve ii; the film and radionuclides were merely transported to another part of the reactor. Acids or other more efficient complexing reagents, other than ammonium citrate, might dissolve this precipitate [AYRES]. Improvements in the system to put more crud in solution at a faster rate will help prevent the buildup of radiation levels in crud traps. Another disadvantage of the APAC procedure is the generation of a large quantity of liquid waste due to the extensive rinses between treatment stages. Moreover, the concentration of AP and AC made ion-exchange treatment of the waste soluticns impractical, especially in the case of the strongly oxidizing AP solutions. Consequently, the waste processing is inconvenient and expensive [PICK]. Tests on various resins and AP concen rations at Brookhaven National Laboratory (BNL) showed that if the solutions were cooled from the normal operating temperature $\left(>80^{\circ} \mathrm{C}\right)$ to room temperature and the concentration of AP were reduced sufficiently, the solution could be demineralized by using ion- 
exchange resins. However, at these low concentrations, the reagent was less effective in removing chromium from PWR oxides [PICK].

\section{c. Alkaline Permanganate-Ammonium Citrate-EDTA (APACE)}

A modification of the APAC process, in which EDTA $(\sim 0.1 \%)$ was added to the ammonium citrate to keep the iron oxides in solution, was developed as APACE. The use of EDTA inhibits the redeposition of the contamination on pipe walls, while permitting the oxides to be removed in the waste processing step by ion exchange. This markedly improves DFs. However, no agreement has been reached as to the value of the EDTA addition; consequently, both APAC and APACE are used [WEED-1962A].

The APACE process was originally developed at Westinghouse for decontamination of stainless steel in PWRs. Either APAC or APACE was considered the most satisfactory at Hanford in 1962. Testing showed that the APACE process is preferable for decontamination of a stainless steel reactor with no carbon steel in the primary system.

However, APACE was ineffective in decontaminating portions of the Hanford PRTR, which had been in service for about 3 yr [AYRES]. The same effect was seen during the decontamination of the M3G7 Loop in 1963; DFs ranged from 1.2 to 3.0, with most areas having DFs $<2$. Thus, APACE was ineffective on films that had been aged in hightemperature water. But at high temperatures and with longer contact times, APACE was effective in removing films from the Shippingport PWR, and the process may have limited value as a decontaminant for some reactor components [AYRES-1970B].

If debris and fission products are present, e.g., after fuel element failure, the APACE procedure should be preceded by recirculation of $10 \mathrm{vol} \%$ nitric acid; this process is referred to as the APACE- $\mathrm{HNO}_{3}$ process [AYRES].

Waste procedures for APACE are the same as those for APAC.

\section{d. Alkaline Permanganate-Oxalic Acid (APOX)}

The APOX process is based on the application of inhibited oxalic acid after the AP stage. This process was very effective at removing the adherent film on stainless steel. The oxalic acid stage was typically run at $85^{\circ} \mathrm{C}$ for $2 \mathrm{~h}$ [AEA].

The two-step APOX process effectively removed aged films on hightemperature stainless steel water piping in the PRTR, whereas four similar processes (APACE, APBis, ${ }^{5} \mathrm{AP} / \mathrm{HNO}_{3},{ }^{6}$ and $\mathrm{APPhos}$ ) had little effect [AYRES-1970B]. Decontamination factors were greater than 150 using APOX, but less than 2.5 for the other four processes.

\footnotetext{
${ }^{5} \mathrm{APBis}$ is AP followed by sodium bisulfate.

${ }^{6} \mathrm{AP} / \mathrm{HNO}_{3}$ is $\mathrm{AP}$ followed by $\mathrm{HNO}_{3}$.

${ }^{7} \mathrm{APPhos}$ is AP followed by $\mathrm{H}_{3} \mathrm{PO}_{4}$.
} 
A simi.ar APOX system (AP treatment followed by a solution containing oxalic acid buffered with diammonium-hydrogencitrate, adjusted with ammonium hydroxide to a $\mathrm{pH}$ of 3.5) was used in preparation for a steam generator repair program at the Gundremmingen Nuclear Power Plant in Gesmany. Decontamination factors ranged from 5 to 12 [EICKEL$\mathrm{PASCH}]$.

When the first oxalic acid formulations were used, a fine grayish-white film formed and deposited on the steel surfaces, carrying with it some of the activity. This precipitate was probably ferrous oxalate. While the amount of precipitate formed in a stainless steel system was not great if contact times were $<4 \mathrm{~h}$, longer contact times or the presence of carbon steel resulted in large amounts of p.ecipitate and low DFs. Because of the formation of ferrous oxalate, an APACE process was needed to remove the oxalate.

Improved oxalic acid solutions were developed (Citrox) that are essentially as effective as the inhibited oxalic acid solutions but form insoluble oxalates only after much longer contact times [AYRES-1962]. Citrox is described in the next section.

The licjuid waste can be deionized in mixed-bed demineralizers, and the resins are disposed of as solic. waste.

\section{e. Alkaline Permanganate-Oxalic Acid-Citric Acid (AP-Citrox)}

Citrox is a mixture of oxalic acid, citric acid, and an inhibitor. In the APCitrox process, Citrox is used in the second stage after the AP treatment. This is an effective decontamination method for stainless steel. The major process disadvantage identified for oxalatebased solvents was precipitation of ferrous oxalate, and several approaches to eliminate, minimize, or control the precipitation were evaluated. These approaches included the addition of corrosion inhibitors to reduce the rate of ferrous generation, oxygenation of the solvent to oxidize the ferrous to ferric, rapid regeneration to maintain the ferrous concentration below the solubility limit, and addition of complexing agents to increase the solubility of ferrous. The AP-Citrox process is highly corrosive to carbon steel and 400 series stainless steels; therefore, its use is confined to 300 series stainless steels and. Inconel [PEACH].

The Citrox mixture will neutralize traces of the alkaline solution, dissolve any $\mathrm{MnO}_{2}$, and complex the iron, thereby keeping it in solution and retarding redeposition. Citrox was evaluated at the General Electric Vallecitos Nuclear Center as a dilute decontamination agent for the BWR primary system [ANSTINE]. In the tests, a dilute form of Citrox $(0.01 \mathrm{M}$ oxalic acid-0.005 $\mathrm{M}$ citric acid, $\mathrm{pH} 3.0$ ) at $90^{\circ} \mathrm{C}$ combined with 0.5 to $1.0 \mathrm{ppm}$ dissolved oxygen was effective in dissolving $80 \%$ of the ${ }^{60} \mathrm{Co}$ in a BWR out-of-core contamination film on representative primary system piping.

In 1984, Pacific Nuclear successfully decontaminated the reactor water cleanup system at Carolina Power \& Light's Brunswick \#2 BWR by using a three-step, dilute Citrox process [NEI]. The three steps were a Citrox step, a dilute AP step, and a second Citrox step. Very favorable decontemination results (DFs ranging from about 40 to 200) were also obtained in the SENA steam generators by using the two-step AP-Citrox process [COUEZ]. The 
decontamination of the East German KKW nuclear system utilized a related dilute AP-Citrox process, in which dilute Citrox was used first, followed by dilute AP, then by nitric-oxalic acid, and finally dilute Citrox [CHOPPIN].

When decontamination from fuel rupture debris is undertaken, an additional step beyond the AP and Citrox steps is needed. In one such process, known as OPG-AP-Citrox [PERRIGO-1979], the first step was fuel debris dissolution by a $\sim 6 \%$ oxalic-peroxide-gluconic (OPG) solution. The solution consisted of $0.2 \%$ oxalic acid, $3.2 \% \quad \mathrm{Na}_{2} \mathrm{C}_{2} \mathrm{O}_{4}, 1.5 \% \mathrm{H}_{2} \mathrm{O}_{2}$, $0.1 \%$ oxine, $0.3 \%$ gluconic acid, and $1 \%$ sodium gluconate.

The liquid waste from the process can be deionized by using mixed-bed demineralizers, and the resins are disposed of as solid waste. The resin volume is of the same order of magnitude as the system volume to be decontaminated.

\section{f. Alkaline-Persulfate/Citrox}

The alkaline-persulfate/Citrox method is similar to the AP-Citrox process but uses a concentrated alkaline solution of potassium persulfate rather than $\mathrm{KMnO}_{4}$ to pretreat the chromium-rich surface oxide and render it soluble in a citrate-oxalate solution. This process was developed for the chemical decontamination of the internal surfaces of the CANDU PHW (CANadian Deuterium Uranium Pressurized Heavy Water) reactor fueling machines [SPEKKENS].

Fueling machines have a complex internal geometry and consist mostly of stainless steel. The major isotopes of the surface oxides were the fission products ${ }^{106} \mathrm{Ru},{ }^{144} \mathrm{Ce}$, and ${ }^{137} \mathrm{Cs}$. The activation products ${ }^{60} \mathrm{Co}$ and ${ }^{65} \mathrm{Zn}$ also made significant contributions to the surface contamination. The AP system could not be used in fueling machines because it would severely attack the chromium-plated surface. However, the alkaline-persulfate/Citrox process was successfully used to decontaminate this system and produced DFs comparable to the AP-based process (DF $>10)$, with no obvious corrosive effects on any of the system materials tested.

The persulfate ion $\left(\mathrm{S}_{2} \mathrm{O}_{8}{ }^{2-}\right)$ is an extremely powerful oxidizing agent, even stronger than permanganate, particularly in alkaline solution. Persulfate oxidation reactions often proceed slowly but are catalyzed by dissolved metals such as $\mathrm{Ag}^{+}$or $\mathrm{Cu}^{2+}$. The optimum conditions were determined to be $0.2 \underline{\mathrm{M}} \mathrm{K}_{2} \mathrm{~S}_{2} \mathrm{O}_{8}$ in $1 \underline{\mathrm{M} \mathrm{NaOH}}$ applied at $85^{\circ} \mathrm{C}$ for approximately $4 \mathrm{~h}$ [SPEKKENS]. In situations where the base metal must be protected, alkaline conditions must be used since acidic persulfate solutions can be highly corrosive. Acidic persulfate was used in conjunction with $\mathrm{Ag}(\mathrm{II})$ to dissolve $\mathrm{PuO}_{2}$. This work is discussed in Section V.A.3.c.

\section{g. $\quad \underline{\text { APSul }}$}

The APSul reagent consists of AP followed by sulfamic acid $\left(\mathrm{NH}_{2} \mathrm{SO}_{3} \mathrm{H}\right)$. The two-step process is similar to the AP-Citrox technique and is effective in removing the contamination film from stainless steel piping without forming a precipitate or causing redeposition. 
When $9 \%$ sulfamic acid was applied at 70 to $80^{\circ} \mathrm{C}$ for 2 to $6 \mathrm{~h}$, DFs of about 20 were obtained by using the APSul process [PERRIGO-1979].

The liquid waste can be deionized by using mixed-bed demineralizers, and the resins are disposed of as solid waste. The resin volume is the same order of magnitude as the system volume to be decontarninated.

\section{h. $\underline{\text { MOPAC }}$}

The MOPAC process is a modified APAC/APOX process, which has been applied for in situ decontamination at the Gundremmingen BWR [EICKELPASCH].

The MOPAC process, as developed by Kraftwerk Union AG, Germany, was used for decontamination of the main coolant pump and the recuperative heat exchanger in the Biblis Power Station [JUNG]. The process, which is similar to the APAC process, was executed in two steps: in the first step, the oxide layer of the material was brought into contact with AP solution to oxidize the trivaler.t chromium oxides to the more soluble hexavalent state. The crystal structures of $\mathrm{Fe}, \mathrm{Co}$, and $\mathrm{Ni}$ are partially destroyed by oxidation of the chromium. Therefore, the second step was to dissolve the activity-containing layer by using an acidic solution. A demineralized-water rinse was performed between the two steps. The average DF was between 10 and 200 .

The volume of liquid waste for each oxidation and decontamination bath was approximately $1.7 \mathrm{~m}^{3}$ for the decontamination of reusable components-the primary loop. The oxidizing solutions, which have low activity, are normally evaporated and combined with boric acid concentrates. Nuclides are precipitated from solutions with high levels of activity. The decontamination solutions, which are acidic and highly radioactive and contain complexing agents, are not evaporated, but are either mixed with the evaporator concentrate for activity adjustment or used for $\mathrm{pH}$ control.

Another MOPAC process, called MOPAC88, is based on the use of lowconcentration citric acid, oxa ic acid, and EDTA; this process has also been successfully tested [KOCH].

\section{i. $\quad$ Nitric Acid-Potassium Permanganate (NP)}

With traditional AP decontamination solutions, the corrosion rates for the base metal are fairly low becc.use of the basic nature of the solution, and they are controlled even when AP solutions are used at high concentrations. However, strongly alkaline solutions are inherently high in sodium an 1 potassium, which leads to high waste volumes. For this reason, adapting the oxidizing chemistry of the AP reagents to a nitric acid system offers large benefits. Permanganate in an acid form has similar applications as AP.

Nitric acid-potassium permanganate (NP) decontamination solutions have been tested in the nuclear industry with some success. Decontamination factors after NP treatment at the Ringhals 2 (Sweden) nuclear reactor system were 6.4 to 7.3 , whereas DFs were 1.9 to 2.3 for AP in similar systems. IJsing NP instead of AP reduces waste volume significantly. The 
potassium/sodium content of NP is $99.44 \%$ lower than that of AP. Dissolution rates of chromium out of the oxide were greater in NP solution than in AP solution [OH].

The nitric acid and permanganate concentrations in NP were optimized [DEMMER-1994B]. Because of its ready acceptability in process waste streams, this solution is of particular interest to process support personnel; however, it is harsh and corrosive. At the original concentrations $\left(0.5 \mathrm{M} \mathrm{HNO}_{3}-0.05 \mathrm{M} \mathrm{KMnO}_{4}\right)$ the instantaneous corrosion measurement was about $500 \mathrm{mil} / \mathrm{yr}(12.7 \mathrm{~mm} / \mathrm{yr})$. Subsequent tests showed that a potassium permanganate concentration of $0.005 \mathrm{M}$ should be sufficient for the oxidative decontamination step. At that concentration, the corrosion measurement for NP was only about $100 \mathrm{mil} / \mathrm{yr}(2.54 \mathrm{~mm} / \mathrm{yr})$, which is close to that for the AP system.

Decontamination solutions of AP and NP are often used with reductive solutions such as those containing a low-oxidation-state metal ion (LOMI). [The LOMI process will be discussed in Section V.5.a.(5).] A preoxidizing AP or NP step is required to oxidize and remove films present on PWR components. Decontamination with LOMI is similar to wellmanaged NP and AP decontaminations.

\section{Highly Oxidizing Systems}

Catalyzed electrolytic plutonium oxide dissolution (CEPOD) was first used at Pacific Northwest Laboratory (PNL) in 1974 for dissolution of the plutonium-containing residues that remained after the dissolution of mixed-oxide reactor fuels. In the CEPOD process, $\mathrm{PuO}_{2}$ is dissolved as $\mathrm{PuO}_{2}^{2+}$ in an anolyte (nitric acid) that contains small catalytic amounts of elements that form kinetically fast, strongly oxidizing ions, such as $\mathrm{Ce}(\mathrm{IV}), \mathrm{Co}$ (III), or $\mathrm{Ag}$ (II). These ions are continuously regenerated at the anode; they act in a catalytic manner, carrying electrons from the solid $\mathrm{PuO}_{2}$ surface to the anode of the electrochemical cell [RYAN, WHEELWRIGHT].

The CEPOD cell (dissolver) consists of two compartments, separated by a porous membrane, with an electrode in each compartment. Dissolution of high-fired $\mathrm{PuO}_{2}$ was demonstrated in both laboratory- and pilot-scale dissolvers [WHEELWRIGHT]. Although the process was developed for the dissolution of $\mathrm{PuO}_{2}$ in a special electrolytic cell, the strongly oxidizing ions may be used in the decontamination of stainless steels (chemical milling). This use is described in more detail below.

\section{a. $\quad$ Cerium(IV) Process}

The beneficial effect of $\mathrm{Ce}(\mathrm{IV})$ on the dissolution rate of $\mathrm{PuO}_{2}$ powders in nitric acid (without an applied electrical current) has been studied since 1942 [CALIFORNIA, WILSON, URIARTE, UNGER-1973A, -1973B, -1973C, -1974]. Solutions of Ce(IV) or Ag(II) are also known to attack the surface of stainless steel without the need for an applied electrical current. Therefore, these reagents could be used to decontaminate stainless steel without having to build a special dissolver. The solutions resulting from the decontamination process could be regenerated by electrolytic means or, if the volumes are fairly small, disposed of directly to an on-site treatment facility. 
Consiclerable development work was performed by PNL for West Valley Nuclear Services on the use of Ce(IV) in nitric acid to remove surface contamination from stainless steel glass waste canisters [BRAY-1988A, -1988B, -1992]. Bray found that Ce(IV) was effective in chemically milling stainless steel and that three moles of $\mathrm{Ce}(\mathrm{IV})$ were required to dissolve one mole of iron (Eq. 1):

$$
3 \mathrm{Ce}^{4+}+\mathrm{Fe}^{0}---->3 \mathrm{Ce}^{3+}+\mathrm{Fe}^{3+}
$$

A large amount of tetravalent cerium was consumed for complete decontamination; approximately $11.4 \mathrm{~L}$ of $0.005 \underline{\mathrm{M}} \mathrm{Ce}(\mathrm{IV})-0.5 \underline{\mathrm{M}} \mathrm{HNO}_{3}$ solution removed a $1-\mu \mathrm{m}$ layer of stainless steel from $930 \mathrm{cnl}^{2}\left(1 \mathrm{ft}^{2}\right)$ of surface. To overcome this problem, a method involving electrochemical regeneration of $\mathrm{Ce}(\mathrm{IV})$ from $\mathrm{Ce}(\mathrm{III})$ was proposed.

In these studies, Bray tested (1) nonradioactive coupons to determine corrosion rates and (2) radioactively contaminated coupons to determine DFs. Both nonoxidized and fully oxidized stainless steel (type 304L) coupons were prepared. The fully oxidized samples were prepared by soaking each coupon in a cesium chloride solution for $24 \mathrm{~h}$ and air drying them [BRAY-1992]. The coupons 'were then heat treated in a furnace for $16 \mathrm{~h}$ at $600^{\circ} \mathrm{C}$ in an air atmosphere to simulate canister filling. Coupons were exposed to various concentrations of $\mathrm{HNO}_{3}$ and $\mathrm{Ce}(\mathrm{IV})$. The $\mathrm{Ce}(\mathrm{IV})$ was prejared in an electrochemical cell to ensure that all of the cerium was present in the tetravalent stati. However, a white precipitate that was thought to be an insoluble cerium salt formed in a solution of $0.5 \underline{\mathrm{M}} \mathrm{HNO}_{3}-0.02 \underline{\mathrm{M}} \mathrm{Ce}(\mathrm{IV})$ at $90^{\circ} \mathrm{C}$. A solubility problem may exist under these conditions.

For contaminated but unoxidized coupons [BRAY-1988B], it was necessary to remove only 2 to $3 \mu \mathrm{m}$ of the metal surface to provide adequate decontamination. For oxidized coupons, however, lemoval of 2.5 to $5 \mu \mathrm{m}$ was needed [BRAY-1992]. Treatment with a solution of 0.5 to $1.0 \mathrm{M} \mathrm{HINO}$ containing 1.4 to 2.7 moles $\mathrm{Ce}(\mathrm{IV}) / \mathrm{m}^{2}$ of surface area (about $0.01 \underline{\mathrm{M}})$ for $6 \mathrm{~h}$ at $65^{\circ} \mathrm{C}$ deconaminated the surface adequately. Nitric acid $(0.5 \underline{\mathrm{M}})$ alone was ineffective. Decontamination factors of 1000 to 2000 were observed for ${ }^{137} \mathrm{Cs}$. It was also observed that chemical milling was inversely proportional to temperature and that surface dissolution was essentially uniform with min.mal intergranular attack. Full-scale tests are needed to confirm the coupon data and to determirie whether a layer of loosely held oxide that remained on coupon surfaces can be removed by high-pressure water jets. Precipitation of $\mathrm{CeO}_{2}$ at low nitric acid concentrations is another potenticl problem [BRAY-1992, HARMON].

The use of Ce(IV) was also demonstrated on actual contaminated steels. At PNL, high DFs were achieve 1 when this process was applied to transuranic- and fission productcontaminated stainless steel equipment (ion-exchange column end fittings on $\mathrm{Pu}$ and Am purification equipment) [RYAN]. In a second demonstration, five tanks that had continued concentrated plutonium solutions were decontaminated to $<100 \mathrm{nCi} / \mathrm{g}$ of metal without dismantling of the system. One tank, $30.5 \mathrm{~cm}$ (12 in.) in diameter, contained $159 \mathrm{~kg}$ of stainless steel Raschig rings. The tank was rinsed with $10 \underline{\mathrm{M}} \mathrm{HNO}_{3}$, treated with $\mathrm{Ce}(\mathrm{IV})$ in $4 \underline{\mathrm{M}} \mathrm{HNO}_{3}$, then rinsed with dilute $\mathrm{HNO}_{3}$. A total of $176 \mathrm{~g}$ of plitonium was recovered from these solutions by using ion exchange. 
An estimated $0.44 \mathrm{~g}$ of plutonium remained in the tank (about $15 \mathrm{nCi} / \mathrm{g}$ metal) after treatment, i.e., the $\mathrm{DF}$ was about 400 .

The Ce(IV) process was also tested in 1993 with SIMCON 1 and SIMCON 2 coupons at Idaho National Engineering Laboratory. These coupons were developed to allow comparison of cleaning techniques for various decontamination methods. The SIMCON 1 coupons were prepared by pipeting $0.1 \mathrm{~mL}$ of a surrogate solution containing 1-mg quantities of $\mathrm{Cs}$ and $\mathrm{Zr}$ onto each surface and then allowing the coupons to air dry. The SIMCON 2 coupons were heat treated at $700^{\circ} \mathrm{C}$ for $24 \mathrm{~h}$ [DEMMER-1994A]. Contamination is typically more difficult to remove from SIMCON 2 coupons. The SIMCON 1 samples were cleaned with $0.5 \underline{\mathrm{M}}$ cerric nitrate- $2 \mathrm{M} \mathrm{HNO}_{3}$ at $70^{\circ} \mathrm{C}$ for about $1 \mathrm{~min}$ and then rinsed with water. This test produced a clean, shiny surface with no detectable contamination. For the SIMCON 2 test, the same solution was used for $13 \mathrm{~min}$ at $80^{\circ} \mathrm{C}$. After treatment, the coupon did not have a bright surface, and more brushing and rinsing were required to clean it. The treatment reduced the $\mathrm{Zr}$ contamination by $77 \%$ and the Cs contamination by $61 \%$ (DFs $<2$ ).

A potentially effective electrolyte was patented in Japan [ONUMA-1990A, $-1990 \mathrm{~B}$, ENDA]. Based upon the information reported, the method appears to be the same as the CEPOD system described earlier. In these patents, an aqueous solution of nitric or sulfuric acid and an oxidizing metal salt containing Ce(IV) are used for chemical decontamination. The solution is effective for stainless steel contaminated with radioactive materials that are generated in nuclear power stations and nuclear fuel reprocessing plants. This electrolyte solution appears to be especially suitable for metal surfaces that contain radioactively contaminated pits. In these cases, simple chemical dissolution of the solid deposits is not sufficient to comply with current decontamination guidelines.

Spent $\mathrm{Ce}(\mathrm{IV})-\mathrm{HNO}_{3}$ decontamination solutions typically contain low concentrations of salts and dissolved metals. Some of the contamination may be present as filterable solids. Dissolved metals may be removed by ion exchange, and the nitric acid may be recovered by evaporation and reused [MUNSON]. The Ce(IV) can be regenerated from $\mathrm{Ce}$ (III) by electrolytic means. Additional development work on the waste treatment for this system is required. cussed in Section V.C.

Foams and gels containing Ce(IV) have also been developed. These are dis-

\section{b. $\quad$ Ce(IV) with Fluoride Promoters}

In studies on the dissolution of refractory $\mathrm{PuO}_{2}$, Harmon found that mixing $\mathrm{KF}$ and $\mathrm{Ce}(\mathrm{IV})$ in certain mole ratios with $8 \mathrm{M} \mathrm{HNO}_{3}$ led to more rapid dissolution than solutions of $\mathrm{Ce}(\mathrm{IV})$ or $\mathrm{KF}$ alone [HARMON]. A solution of $8 \underline{\mathrm{M}} \mathrm{HNO}_{3}-0.05 \underline{\mathrm{M}} \mathrm{Ce}(\mathrm{IV})-0.1 \underline{\mathrm{M}} \mathrm{KF}$ was effective. At nitric acid concentrations lower than $6 \underline{\mathrm{M}}$, the solution was less effective than $\mathrm{HNO}_{3}-\mathrm{Ce}$ (IV) or $\mathrm{HNO}_{3}-\mathrm{KF}$. It was also found that ruthenium catalytically reduces $\mathrm{Ce}$ (IV) in nitric acid. 


\section{c. $\quad \underline{\operatorname{Ag}(\mathrm{II})} \underline{\text { Process }}$}

Divalent silver $[\mathrm{Ag}(\mathrm{II})]$ is more effective at charge transfer than $\mathrm{Ce}(\mathrm{IV})$ or $\mathrm{Co}$ (III) and has been used in laboratory $\mathrm{PuO}_{2}$ dissolutions. Since silver is a Resource Conservation and Recovery Act (RCRA) land ban material, a method was needed to remove and recover silver from anolyte solutions. Such a process was developed at PNL: ascorbic acid is used to reduce and precipitate silver from solution [BLANCHARD]. Hydrazine and hydroxylamine adequately suppress nitrite, which would otherwise deplete the reducing agent, ascorbic acid. This process has been successfully demonstrated at both bench and process scale.

The use of the peroxydisulfate ion to promote $\mathrm{PuO}_{2}$ dissolution in $4 \underline{\mathrm{M}} \mathrm{HNO}_{3}-0.01 \underline{\mathrm{M}} \mathrm{Ag}$ (II) was studied [HORNER]. Addition of $0.03 \mathrm{M} \mathrm{S} \mathrm{O}_{8}^{2-}$ did not improve the dissolution rate, a result which Horner attributed to the apparent instability of $\mathrm{S}_{2} \mathrm{O}_{8}^{2-}$ in hot acidic solutions. The use of the peroxydisulfate ion as a means to oxidize $\operatorname{Ag}(\mathrm{I})$ to $\operatorname{Ag}(\mathrm{II})$ was also studied [FISHER]. In this study, the addition of $\left(\mathrm{S}_{2} \mathrm{O}_{8}^{2-}\right)$ increased the dissolution rate of $\mathrm{PuO}_{2}$. Optimum conditions were $0.5 \underline{\mathrm{M} \mathrm{K}} \mathrm{S}_{2} \mathrm{O}_{8}-0.2 \underline{\mathrm{M}} \mathrm{Ag}-3 \underline{\mathrm{M}} \mathrm{HNO}_{3}$ at $40^{\circ} \mathrm{C}$. The ratio $\mathrm{K}_{2} \mathrm{~S}_{2} \mathrm{O}_{4} / \mathrm{PuO}_{2}$ must be greater than or equal to 1.33. In a comparison of $\mathrm{PuO}_{2}$ dissolution rates between a chemically catalyzed silver solution (persulfate addition), CEPOD, and the traditional $12 \underline{\mathrm{M}} \mathrm{HNO}_{3}-$ $0.18 \underline{\mathrm{M}} \mathrm{HF}$ acid mixture, the catalyzed solution dissolved $\mathrm{PuO}_{2}$ more rapidly than did CEPOD. However, the time needed to reach $100 \%$ dissolution (about $20 \mathrm{~min}$ ) was approximately the same (within 2 to $3 \mathrm{~min}$ ). Dissolution in the $\mathrm{HNO}_{3}-\mathrm{HF}$ mixture was much slower; only $90 \%$ of the $\mathrm{PuO}_{2}$ had dissolved in 40 mir.

\section{Peroxide Systems}

Hydrogen peroxide, mixed with acids such as sulfuric and oxalic acids, can be used to clean systems that are contaminated by fuel debris and fission products [MUNSON]. The process involves oxidation of the fuel components by the peroxide followed by dissolution of the fuel by the acid. Mixtures of $\mathrm{H}_{2} \mathrm{C}_{2}$ with carbonates or oxalates were recognized as good oxidants for uranium oxides and were later applied to remove uranium and uranium-oxide fuel element residues [AYRES-1967]. Solutions containing hydrogen peroxide, oxalic acid, and hydrofluoric acid decontaminate stainless steel $\in$ :ffectively.

Hydrogen peroxide acts as a corrosion promoter at lower concentrations and as an inhibitor at higher concentrations. When $\mathrm{H}_{2} \mathrm{O}_{2}$ is added to $0.3 \mathrm{M}$ oxalic acid at room temperature, filming and corrosive attack of mild steel begins at $0.05 \mathrm{M} \mathrm{H}_{2} \mathrm{O}_{2}$; at $0.2 \mathrm{M} \mathrm{H}_{2} \mathrm{O}_{2}$, the metal becomes clean and attack is rapid; between $0.3 \mathrm{M}$ and $1.0 \mathrm{M} \mathrm{H}_{2} \mathrm{O}_{2}$, chemical polishing occurs; and above $1.0 \mathrm{M} \mathrm{H}_{2} \mathrm{O}_{2}$, the metal is passivated. There are many advantages to using peroxide. Peroxide solutions are stable at room temperature; the only peroxide reaction is that of oxidizing iron. Peroxide reagents are very easy to prepare; the reactions can be controlled easily and accurately by proper formulation or by variations in temperature; the reagents are relatively inexpensive; and the excess reagent can be decomfosed easily so that the amount of solid waste is kept to a minimum. 


\section{a. $\quad$ Hydrogen Peroxide-Oxalic Acid-Hydrothermic Acid (OPP)}

Oxalate peroxide (OPP) is a mixture of $\mathrm{M}_{2} \mathrm{C}_{2} \mathrm{O}_{4}$ and $\mathrm{H}_{2} \mathrm{C}_{2} \mathrm{O}_{4}$. It is used for the simultaneous dissolution of $\mathrm{UO}_{2}$ and decontamination of metals. The oxalic acid decontaminates the surface, and the hydrogen peroxide enhances this action and passivates the steel. The peroxide destroys the oxalic acid, preventing reuse of the solvent, but the decontamination is fast enough to be effective before the oxalic acid is consumed. The use of OPP has been associated more with cleanup of uranium and uranium oxides after a fuel failure than with general decontamination, although it has been demonstrated to be an effective decontamination method for carbon steel.

Hydrogen peroxide acts as a carbon steel cleaner at concentrations up to $0.2 \mathrm{M}$ and as a passivator at concentrations higher than 1.0 $\mathrm{M}$ [MESERVEY-1970]. In tests at ORNL, carbon and stainless steels that were heated to about $200^{\circ} \mathrm{C}$ and treated with OPP $(\mathrm{pH} 4)$ exhibited DFs of 100 to 1,000 or higher.

A solution of $0.25 \underline{\mathrm{M}} \mathrm{H}_{2} \mathrm{C}_{2} \mathrm{O}_{4}-0.3 \mathrm{M} \mathrm{H}_{2} \mathrm{O}_{2}$ polished mild steel in $15 \mathrm{~min}$ at $35^{\circ} \mathrm{C}$. All of the film and some of the metal were removed to give a very smooth surface with a bright finish. The cleaning action and the corrosivity can be controlled by adjusting the concentrations of the components (especially the peroxide) and the temperature. At high temperatures, peroxide is rapidly destroyed by reaction with oxalic acid [AYRES-1971].

\section{b. Hydrogen Peroxide-Oxalic Acid-Hydrofluoric Acid}

Fluoride may also be added to the OPP reagent to decontaminate stainless steel. One solution recommended is $0.4 \underline{\mathrm{M} \mathrm{H}} \mathrm{H}_{2} \mathrm{C}_{2} \mathrm{O}_{4}-0.1 \underline{\mathrm{M}} \mathrm{HF}-0-1.0 \underline{\mathrm{M}} \mathrm{H}_{2} \mathrm{O}_{2}$. This system decontaminated stainless steel in 2 to $4 \mathrm{~h}$ at 90 to $95^{\circ} \mathrm{C}$. The efficiency (and corrosivity) can be increased by reducing the peroxide concentration to $0.01 \underline{\mathrm{M}}$. Similar solutions are recommended for decontaminating Zircaloy because the contamination and black oxide are removed completely with no pitting of the Zircaloy. The corrosivity can be controlled by varying the concentrations of the peroxide and the fluoride. Corrosion rates were very low when $\mathrm{Al}^{3+}$ was added to repress ionization of the fluoride [MESERVEY-1963].

\section{c. Hydrogen Peroxide-Oxalic Acid-Citric Acid}

Reagents containing oxalic acid, citrate, and peroxide can be used for decontaminating mild steel at room temperature if the peroxide concentration is lower than $0.08 \underline{\mathrm{M}}$ [AYRES-1971]. Other variations of peroxide-acid mixtures include $0.34 \underline{\mathrm{M}}$ peroxide, $0.16 \underline{\mathrm{M}}$ citric acid, and $0.4 \underline{\mathrm{M}}$ ammonium oxalate applied at $90^{\circ}$ to $95^{\circ} \mathrm{C}$.

A mixture of $0.4 \underline{\mathrm{M}}$ ammonium oxalate, $0.16 \underline{\mathrm{M}}$ citric acid, and $0.34 \underline{\mathrm{M}}$ hydrogen peroxide adjusted to $\mathrm{pH} 4$ effectively decontaminated carbon steel and stainless steel systems that had not been heated to more than $200^{\circ} \mathrm{C}$. The resulting DFs ranged from $10^{2}$ to $10^{3}$ for the carbon steel and stainless steel [AYRES-1970B]. 


\section{d. $\quad$ Hydrogen Peroxide-Oxalic Acid-Gluconic Acid (OPG)}

Oxalic-peroxide-gluconic decontamination solution is composed of oxalic acid, sodium oxalate, hydrogen peroxide, gluconic acid, and sodium gluconate. It was used successfully for decontaminatior of carbon steel, type 300 series stainless steels, Inconel, Zircaloy-2, and aluminum that were contaminated with fission products and fuel debris [AYRES-1970B].

Sugge:sted optimum concentrations for OPG solutions are $2.3 \mathrm{~g} / \mathrm{L}$ oxalic acid, $32 \mathrm{~g} / \mathrm{L}$ sodium oxalate, $15 \mathrm{~g} / \mathrm{L}$ hydrogen peroxide, $10 \mathrm{~g} / \mathrm{L}$ sodium gluconate, and $5 \mathrm{~g} / \mathrm{L}$ gluconic acid (50\% solution). Also, $1 \mathrm{~g} / \mathrm{L}$ 8-hydroxyquinoline is added to stabilize the peroxide. The effectiveness of the OPG solution depends largely on the concentration of hydrogen peroxide in the solution. The OPG patent specifies that, at temperatures from 25 to $80^{\circ} \mathrm{C}$, the $\mathrm{pH}$ should range from 4.4 to 4.6 at the initiation of application and from 4.8 to 4.9 at the end of the application [WEED-1968]. Tae buffer system maintains the $\mathrm{pH}$ at about 4.5 during most of the application time to increase the stability of the peroxide.

An OPG solution has been used to dissolve fuel debris in both a multistep and a single-step decontamination procedure. In the 1962 decontamination of the PRTR, OPG was used in the second step of a nine-step decontamination procedure. The OPG solution was recirculated for $1 \mathrm{~h}$ at $90^{\circ} \mathrm{C}$ [AYRES-1970B]. Its application was preceded by an application of the related fuel-debris dissolution solution, OPP, and followed by applications of APOX and APACE.

In the .966 decontamination of the Fuel Element Rupture Test Facility loop of the PRTR, OPG was applied to dissolve $\mathrm{UO}_{2}$ and $\mathrm{PuO}_{2}$ in a single-step process. The solution was circulated sequentially through each of eight heat exchangers at a rate of $10 \mathrm{gal} / \mathrm{min}$ and temperature of $40^{\circ} \mathrm{C}$ and throug, h the rest of the test loop, excluding the actual test section, at $70 \mathrm{gal} / \mathrm{min}$ [MUNSON]. The application time for each heat exchange unit was planned to be $75 \mathrm{~min}$, but actual times varied. In this decontamination, OPG was used for dissolution of fuel debris and was so effective at removing loop activity that the AP-Citrox procedure that had been planned to follow the OPG step was never used. Radiation exposure rates at the heat exchangers were reduced, in the best case, by a factor of 8000 .

The principal problem associated with the application of OPG appears to be in maintaining the peroxide concentration at an effective level. Hydrogen peroxide decomposition occurs because of (1) catalytiz decomposition by iron and related oxides and (2) oxidation of the organic chemicals. Both processes become more rapid with increasing temperature. Frequent replenishment of the solution is required to maintain the peroxide concentration; therefore, it is expected that waste solution volumes will be high.

One pcssible way to reduce the waste volume would be to use a more dilute solution of OPG. This optior. needs further study because lower concentrations will shorten the effective solution lifetime, with possible adverse effects such as redeposition. Corrosion rates might also increase.

One method for handling this waste is evaporation, which poses no particular difficulties. If any hydrogen peroxide remains in solution when it reaches the evaporator, it 
will either be converted to oxygen and water or it will oxidize some of the organic compounds, converting them to carbon dioxide and water. Evaporation of the large volume of dilute rinse water will be straightforward and will add little to the waste volume. Precipitation can be accomplished by the addition of calcium oxide or calcium hydroxide (lime or slaked lime). The calcium oxalate will precipitate, incorporating most of the radionuclides that were held in solution by the oxalate anion. A second method for handling this waste is to use ion exchange for the entire cleanup.

\section{e. Hydrogen Peroxide-Sulfuric Acid}

Mixtures of $1.0 \underline{\mathrm{M}} \mathrm{H}_{2} \mathrm{O}_{2}-1.0 \underline{\mathrm{M}} \mathrm{H}_{2} \mathrm{SO}_{4}$ and $0.075 \underline{\mathrm{M} \mathrm{H}} \mathrm{H}_{2} \mathrm{O}_{2}-0.015 \underline{\mathrm{M}}-\mathrm{H}_{2} \mathrm{SO}_{4}$ were applied to reactor systems that were contaminated after fuel element ruptures [GRIGGS, SCHENKER]. Following a fuel failure in 1958, the Hanford $\mathrm{H}$ loop was decontaminated by recirculating a $0.075 \mathrm{M} \mathrm{H}_{2} \mathrm{O}_{2}-0.015 \mathrm{M} \mathrm{H}_{2} \mathrm{SO}_{4}$ solution through the loop circuit [SKARPELOS]. The solution was in contact with the stainless steel loop for $90 \mathrm{~min}$ and was applied to the system twice, followed by a high-velocity water flush, which resulted in decontamination (and dose reduction) factors of 4 to 10 for moderately contaminated equipment.

\section{f. Hydrogen Peroxide-Carbonate}

The combination of peroxide and carbonate was used to dissolve uranium compounds in the mining industry (oxidation of uranium to the hexavalent state by peroxide, followed by complexation with carbonate) [CLEGG] and to dissolve copper compounds in the chemical cleaning industry.

A peroxide-carbonate mixture is especially useful for decontaminating nuclear reactors when fission products and $\mathrm{UO}_{2}$ particles are present, as might be the case after a fuel element rupture. Because tests have shown that most AP systems are not effective in this situation, it is desirable to remove the fission products and $\mathrm{UO}_{2}$ before using the other solutions. A peroxide-carbonate solution at $60^{\circ} \mathrm{C}$ is an effective way of accomplishing this removal [WEED$1962 \mathrm{~A}]$.

\section{g. Hydrogen Peroxide-Carbonate-EDTA}

Recently, Babcock \& Wilcox, under contract to DOE, initiated research and development for the application of chelant-based solvents to the removal of uranium compounds from contaminated process equipment [PALMER]. Chelant screening tests have been completed; a solvent composed of EDTA, ammonium carbonate, and hydrogen peroxide at $\mathrm{pH} 9.0$ (adjusted with $\mathrm{NH}_{4} \mathrm{OH}$ ) dissolved more than $95 \%$ of the uranium dioxide (at a solvent loading of $4 \mathrm{~g} / \mathrm{L} \mathrm{UO}_{2}$ ), in approximately $2 \mathrm{~h}$ at room temperature.

This type of solvent appeared to be promising for several reasons:

- Since uranium dioxide was dissolved effectively at room temperature, the solvent could be utilized in surface decontaminations without interference from chelation of iron, which does not occur readily at low temperatures. 
- Sirce EDTA is known to be corrosive to metals at higher temperatures, the solvent could be applied at higher temperatures to remove base metal, thereby releasing contamination trapped within the grain boundaries.

- The addition of carbonate and hydrogen peroxide will not complicate the secondary waste stream, since they are not hazardous materials.

The addition of chelant would be required for cleaning surfaces contaminated with heavier deposits, to stabilize the uranium ions in solution and prevent precipitation from occurring during the cleaning process. Chelant would also be required to effect base metal corrosion for release of bulk contamination.

Potential scenarios include the following:

- Application of chelate-carbonate-peroxide solvent at room temperature (to chelate surface uranium contamination), followed by heating to $93^{\circ} \mathrm{C}$ (to remove several mil of base metal), then cooling to room temperature with a peroxide spike (to chelate contamination released during base metal removal).

- Application of chelate-carbonate-peroxide solvent at $93^{\circ} \mathrm{C}$ (to remove base metal) followed by cooling to room temperature with a peroxide spike (to chelate uranium).

A similar solution, peroxide-bicarbonate-carbonate (PBC), is composed of $0.5 \mathrm{M}$ hydrogen peroxide, $0.25 \mathrm{M}$ sodium carbonate, $0.25 \mathrm{M}$ sodium bicarbonate, $1.0 \mathrm{~g} / \mathrm{L}$ of 8-hydroxyquinoline, and $0.012 \mathrm{M}$ EDTA. This mixture is usually applied at 60 to $80^{\circ} \mathrm{C}$ and recirculated for $1 \mathrm{~h}$ and was effective at dissolving uranium and $\mathrm{UO}_{2}$. It also attacked high-fired $\mathrm{PuO}_{2}$, but at a very low rate [AYRES-1970B]. It is relatively ineffective at removing corrosion or fission products absorbed onto metal surfaces.

Peroxide-bicarbonate-carbonate solutions are used for fuel-debris dissolution prior to the application of a two-step film removal procedure such as APACE, APOX, or APBisulf. Because PBC is reportedly ineffective at removing corrosion products and absorbed fission products, use of one of the AP solutions is essential for effective system decontamination [WEED-1962B].

A PBC solution was used for the decontamination of the Irradiation Rupture Prototype (IRP), a test loop composed entirely of stainless steel, which was designed for testing decontamination solutions and fuel element rupture characteristics. The PBC was applied prior to APACE [AYRES-1970B]. During the application of PBC-APACE to the IRP, which was contaminated by uranium oxide and fission products, the PBC step reduced exposure rates in the loop from $1400 \mathrm{mR} / \mathrm{h}$ to $200 \mathrm{mR} / \mathrm{h}(\mathrm{DF}=7)$. The APACE step then reduced exposure rates to $10 \mathrm{mR} / \mathrm{h}$ $(\mathrm{DF}=20)$ [AYRES-1970B]. 
A similar procedure was used to decontaminate the General Electric Hanford $3 \times 3$ loop at the Engineering Test Reactor. Two half-hour applications of PBC replaced the standard 1-h application. Other aspects of the decontamination were the same as in the standard procedure [WEED-1962B]. On the $3 \times 3$ loop, the two applications of PBC prior to the APACE step removed $85 \%$ of the $\mathrm{UO}_{2}$ present in the loop [WEED-1962B].

A combination of PBC and APOX was also used to decontaminate the IRP. The procedure followed was similar to that used to apply the PBC-APAC. There was a tenfold reduction of loop activity during the $\mathrm{PBC}$ step. Additional activity was then removed by the APOX steps that followed [AYRES-1970B].

In a PBC-AP-Bisulf procedure that was used to decontaminate the IRP, the PBC was recirculated at $60^{\circ} \mathrm{C}$, the $\mathrm{AP}$ at $100^{\circ} \mathrm{C}$, and the Bisulf (a proprietary bisulfate solution) at 60 to $90^{\circ} \mathrm{C}$ [WEED-1962B]. The $\mathrm{PBC}$-AP-Bisulf procedure removed $\mathrm{UO}_{2}$ and fission products from the loop of the IRP.

The PBC solution has intrinsic limitations that will probably preclude its application as a solo decontamination agent and restrict its role even as a co-decontaminant. These limitations are as follows: (1) the solution is unstable and becomes ineffective after about $1 \mathrm{~h}$ [AYRES-1960]; (2) the PBC mixture is relatively ineffective for removal of corrosion products or fission products absorbed on metal surfaces (which necessitates use of an additional procedure after PBC to remove the absorbed activity [WEED-1962B]; and (3) when used in conjunction with APOX on carbon steel, PBC is not as effective because of redeposition [AYRES-1970B].

The method of choice for disposal of waste after PBC decontamination is evaporation. Any peroxide will either be converted to oxygen and water or oxidize some of the organic compounds (EDTA and 8-hydroxyquinoline), converting them to carbon dioxide and water when the solution reaches the evaporator. Evaporation of a large volume of deionized rinse water would add little to the waste volume but would complicate waste storage and possible disposal of purified liquids. Ion exchange should be used to purify the rinses.

\section{h. Alkaline Tartrate Peroxide (ATP)}

The formulation for the alkaline tartrate peroxide (ATP) reagent is $10 \% \mathrm{NaOH}, 1.5 \%$ sodium tartrate, and $1.5 \% \mathrm{H}_{2} \mathrm{O}_{2}$ [WEED-1962B]. This solution is usually applied after pretreatment with 5 to $35 \% \mathrm{HNO}_{3}$. Water rinses are used between the two steps. The temperature at which ATP is applied ranges from 80 to $90^{\circ} \mathrm{C}$ [WATSON]. A process using ATP appears to be effective only in the removal of fission products; it is unlikely to be able to remove corrosion layers.

The ATP reagent was used for decontamination in conjunction with $\mathrm{HNO}_{3}$ in the Homogeneous Reactor Experiment [GRIGGS]. First $\mathrm{HNO}_{3}$ and then ATP were applied to the circulation system to remove fission product activity without removing the oxide film covering the system. Niobium, zirconium, ruthenium, and iodine activity were removed by the ATP, and cerium, lanthanum, barium, and zirconium by the $\mathrm{HNO}_{3}$. The extensive water rinsing between chemical applications removed strontium and iodine [GRIGGS, CAMPBELL]. An overall DF of 
15 was reported by Griggs, and a reduction in exposure rate from $1000 \mathrm{R} / \mathrm{h}$ to $5-100 \mathrm{R} / \mathrm{h}$ was reported by Campbell. The Campbell figures, however, included a 6-week decay time. Three applications of the $\mathrm{HNO}_{3}$-ATP procedure, including extensive rinsing, resulted in the removal of more than $200 \mathrm{Ci}$ each of $\mathrm{Zr}$ and $\mathrm{Ce}$, and more than $1000 \mathrm{Ci}$ each of $\mathrm{Ba}, \mathrm{Sr}$, and La. Large amounts of $\mathrm{Nb}, \mathrm{Ru}$, and I were also removed [CAMPBELL].

Use of ATP will result in about twice as much waste as is usually produced by a single-step process beciuuse of the high concentration of chemicals. Decomposition of the tartrate by peroxide is expected, even though it will be complexed with metals from the fuel debris. Large quantities of $\mathrm{NaOH}$ will remain with fuel and fission products.

Either evaporation or ion exchange are viable concentration steps. If direct solidification of the unconcentrated decontamination solution is employed, some neutralization may be required, depending on the solidification process.

\section{Miscellaneous $\underline{\text { Systems }}$}

There are many commercial processes in the decontamination field. The reagents are usually combinations of various chelators, oxidizing agents, reductants, inhibitors, and surfactants. This section discusses various proprietary decontamination systems and describes some of the more common reagents.

\section{a. Proprictary Systems}

Many proprietary decontamination systems have been developed in the United States and abroad. Typical "high-concentration" processes are NS-1 and TURCO; some "low-concentration" processes are CAN-DECON, CAN-DEREM, POD, CORD, OZOX-A and LOMI. Both alkaline and acid pretreatment steps are employed in these processes.

\section{(1) $\underline{\mathrm{NS}-1}$}

The NS-1 process was developed by Dow Chemical Company and uses proprietary chemicals at: high concentrations [HARMER-1979, -1986; DNS-D1-034]. The NS-1 solvents, which contain about $7.5 \%$ solids composed of organic and inorganic materials, were designed primarily to dissolve highly radioactive deposits of nickel ferrite without any undue corrosion that might compronise the future utility and safety of the reactor systems being decontaminated.

The NS-1 process was used on the Commonwealth Edison Dresden-1 reactor, a dual-cycle BWR, in 1984. An extensive test program was started in 1973 to prepare for this operation. In the chemical cleaning operations, the Dresden-1 system was filled with the reagent mixture at 118 to $129^{\circ} \mathrm{C}$ for $100 \mathrm{~h}$. The primary system decontamination used $312,000 \mathrm{~L}$ of full-strength NS-1. In the Unloading System (Reactor Water Heat Removal) at Dresden-1, where the piping and equipment was made of carbon steel and copper-nickel alloy rather than stainless steel, a spiecially formulated NS-2 solvent was employed. 
The full-scale chemical decontamination of Dresden-1 was effective. A total of $755 \mathrm{Ci}$ of ${ }^{60} \mathrm{Co}$ was removed from the primary system. During the decontamination operation, $90 \%$ of the ${ }^{60} \mathrm{Co}$ was in solution by the end of the 34 th hour of the $100-\mathrm{h}$ run, and $95 \%$ was in solution at the end of the 46th hour. Cobalt- 60 was the dominant species in the decontamination waste. Approximately $292 \mathrm{~kg}(650 \mathrm{lb})$ of iron and $35 \mathrm{~kg}$ (300 lb) of nickel were removed from the primary system. The most accurate measurements gave DFs well above 100 , which indicated significant removal of the radioactive deposits. Chemical cleaning of the heat exchanger system resulted in the removal of nearly $1.6 \mathrm{Ci}$ of ${ }^{60} \mathrm{Co}$.

Nearly 2,600,000 $\mathrm{L}$ of waste was generated during the chemical cleaning. Treatment of these radioactive liquid wastes required volume reduction and water purification. A waste treatment facility was built at Dresden-1 for these purposes. The primary method of processing the spent cleaning solvent and rinse water was evaporation. The resulting liquid concentrate was stored and awaits solidification and final burial at a designated site (as of 1986). Water that was recovered during evaporation, as well as the dilute rinses, was processed by various chemical means, re-evaporated, treated with activated carbon, and/or demineralized before its radionuclide and chemical content was low enough to allow it to be returned to Dresden Station for treatment or disposal. The final waste volumes totaled $41,600 \mathrm{~L}$ of concentrated NS-1, $9 \mathrm{~m}^{3}$ of resin, and $3000 \mathrm{~kg}$ of carbon. About 2,550,000 L of processed water was returned to the Dresden plant. During the course of decontamination, the demineralizer and evaporator functioned as designed. One problem was that an unanticipated and atypical organic compound (acetone), which contaminated the overheads from evaporation, could not be removed using predesigned process equipment or chemical treatments.

\section{(2) TURCO 4502 and 4521}

In 1988, the Savannah River Laboratory evaluated various commercially available decontamination chemicals [SHURTE]. In this evaluation, type 304 stainless steel and Inconel 625 coupons were used to compare these commercial solutions with a $10 \%$ oxalic acid solution. On the basis of these tests, Inconel is more difficult to decontaminate than stainless steel. Of the 17 chemicals evaluated, five decontaminated the stainless steel coupons to below background levels. For the Inconel, only two removed the contamination to below background levels. The two best decontamination solutions were oxalic acid and TURCO product 4521. TURCO 4521 is a proprietary agent composed of oxalic and citric acids plus ammonium oxalate. It is marketed by the TURCO Company, Cincinnati, $\mathrm{OH}$.

Another commercially available decontamination chemical marketed by the TURCO Company, TURCO 4502 , is a proprietary solution containing AP. It is one of a suite of chemicals marketed under the TURCO DECONTAMINATION umbrella. These products were specifically tailored to the cleaning and decontamination needs of the nuclear industry. The company has since dropped the TURCO DECONTAMINATION line, but specially mixed chemicals (such as TURCO 4502) are still available upon request.

The ICPP laboratories tested the effectiveness of TURCO 4502 at cleaning SIMCON 2 test coupons [DEMMER-1994B]. The TURCO Company recommends using TURCO 4502 at a concentration of $0.24 \mathrm{~kg} / \mathrm{L}$ ( $2 \mathrm{lb} / \mathrm{gal})$. Previous ICPP usage indicated satisfac- 
tory performance at a quarter of this concentration. The solutions were, therefore, mixed to a concentration of $60 \mathrm{~g} / \mathrm{L}(0.5 \mathrm{lb} / \mathrm{gal})$ for bench-top testing. The TURCO 4502 was moderately successful at removing cesiurn from the SIMCON 2 coupon, but it was unsuccessful at removing zirconium. This is probably because of TURCO's oxidizing nature; reducing chemistries and complexing chemicals (fluoride, $\mathrm{ZrF}_{3}$ ) were typically much better at removing zirconium. In fact, TURCO 4502 had the lowest DF for zirconium of any decontaminant tested. Other disadvantages of TURCO 4502 were its high corrosion rates and waste generation problems. The short-term corrosion rate of $90 \mathrm{mil} / \mathrm{yr}(2.3 \mathrm{~mm} / \mathrm{yr})$ is the second highest of the chemicals tested at the ICPP. The long-term corrosion rate: for this solution is much lower as the metal is passivated during external contact. Thus, use cf TURCO 4502 could cause corrosion problems downstream of the intended vessel.

The waste generation problems of TURCO 4502 are similar to those of AP; i.e., they stem from use of concentrated sodium and potassium compounds. At the ICPP, the AP waste was calcined by using the fluidized-bed calciner. Nonradioactive additives (predominantly aluminum nit:ate) had to be added to prevent sodium and potassium agglomeration in the calciner, at a volume ratio of approximately four volumes of aluminum nitrate to one volume of AP. The addition resulted in high waste volumes for this procedure.

\section{CAN-DECON}

The CAN-DECON process was developed for CANDU-type reactors. The rights for the use of this system were licensed to W. P. London and Associates Limited, Niagara Falls, Ontario, Canadla for marketing through a subsidiary, London Nuclear Decontamination Limited. An important objective of this system was to minimize the exchange of hydrogen for deuterium in the heavy water of a reactor [LACY, STEWART, SMEE, TOROK].

The process is based on the direct addition of chemicals to the coolant after shutdown. The chericals, which are applied in dilute form, are those reagents normally used in high-concentration processes; for example, citric acid, oxalic acid, and EDTA. The operation usually runs for 24 to $43 \mathrm{~h}$ at 85 to $125^{\circ} \mathrm{C}$. A high coolant flow is maintained through the primary system coolant purification system, where particulates are filtered and cationic contamination is removed by resins. Thus, the solution can be regenerated and recycled to the primary coolant system for further use. The obvious advantage of this process is a minimum generation of liquid wastes since reagents can also be removed by mixed-bed resins.

The CAN-DECON process has been used in a number of BWRs for decontamination of the complete reactor system (including fuel), and when combined with an AP or NP step, it becomes a very effective method for decontaminating PWRs also. This system was also used in the Pickering Nullear Generating Station Unit 1 heat transport system [KRASZNAI].

There are several advantages to using the CAN-DECON process in a decommissioning campaign. First, the reagent is added as a concentrated slurry to the water already in the system, so the system does not need to be drained or flushed and large storage tanks are not needed. Second, the process generates little or no liquid wastes. All deposits are removed in the process, and the dissolved radioactive contaminants are concentrated on ion-exchange resins 
and filters. The reagent itself is removed using a mixed-bed ion-exchange resin. The only liquid wastes would be those resulting from resin stirring operations and from draining and venting of deadlegs. This represents a few thousand liters at most. Third, the process allows the use of existing radioactive waste systems. Fourth, costs are low. The overall simplicity of CAN-DECON, the use of existing systems, and the absence of large quantities of radioactive liquid waste makes the process less costly to apply than decontaminations that use strong acids.

One of the disadvantages is the low DFs, in the range of 5 to 15 . For decommissioning, DFs in the range of 50 to 100 , or even higher, are desirable. However, because there will be only limited corrosion constraints associated with decommissioning, the CAN-DECON process can be modified to obtain DFs in this higher range without sacrificing the advantages previously discussed. These modifications include use of more concentrated reagents and higher operating temperatures. The normal reagent concentration is $0.1 \mathrm{wt} \%$, but there is no technical reason why this cannot be increased to $0.5 \mathrm{wt} \%$ (but above this concentration, solubility may become a problem depending upon the temperature) [NEA]. One consequence of the higher reagent concentration will be the need to use five times as much mixed-bed resin to remove it. This may exceed the capacity of the existing radioactive waste system and will undoubtedly increase the cost.

Another method to remove the reagent is to thermally degrade it. At the temperatures of 200 to $250^{\circ} \mathrm{C}$, the reagent will decompose. The final decomposition products are $\mathrm{H}_{2}, \mathrm{~N}_{2}, \mathrm{CO}_{2}$, and $\mathrm{H}_{2} \mathrm{O}$. These gases would be removed by the off-gas system. Any residual intermediate decomposition products could be removed by a small amount of mixed-bed resin. The contaminants would have to be removed prior to decomposition, or the thermal treatment performed external to the cleaned system, to prevent redeposition. Normal process temperatures are in the range of 85 to $125^{\circ} \mathrm{C}$. Raising the temperature to approximately $150^{\circ} \mathrm{C}$ will increase the base metal corrosion rate, but it is generally recognized that to achieve very high DFs, removal of the outer layer of base metal may be necessary. Normally during the CAN-DECON process, corrosion is avoided in order to leave a passive surface; however, as already stated, for decommissioning purposes, this may no longer be a significant consideration.

\section{CAN-DEREM}

Several years of laboratory study at Atomic Energy of Canada Limited (AECL) has resulted in the evolution of the CAN-DECON process into the CAN-DEREM process [SPERANZINI-1990A].

One problem identified in the CAN-DECON process was the possibility of intergranular attack (IGA) in sensitized type 304 stainless steel and the related potential for increased susceptibility of the metal to stress corrosion cracking. Further studies showed that effective decontamination of BWR and PWR systems could be achieved with mixtures of citric acid and EDTA (the formulation used in the CAN-DEREM process) with minimal risk of causing IGA or other localized attack in sensitized type 304 stainless steel. The possibility of intergranular attack was considered to be particularly significant at temperatures above $100^{\circ} \mathrm{C}$, where the possibility of localized attack is highest. However, at temperatures below $100^{\circ} \mathrm{C}$, use of mixtures 
of citric acid, oxalic acid, and EDTA (the formulation used in the CAN-DECON process) could be considered, since the risk of localized attack is minimal.

The new process was applied at the Beaver Valley Power Station in 1989 with good results and negligible corrosion rates. Two applications of the AP/CAN-DEREM process $\left(0.1 \mathrm{wt} \% \mathrm{AP}\right.$ at $95^{\circ} \mathrm{C}$ for $12 \mathrm{~h} ; 0.1 \mathrm{wt} \%$ CAN-DEREM at $120^{\circ} \mathrm{C}$ for 6 to $\left.24 \mathrm{~h}\right)$ were carried out for decontamination of the Beaver Valley channel heads.

The Beaver Valley steam generator B was decontaminated by using a four-step decontamination process consisting of alternating applications of an oxidizing AP solution circulated through the steam generator at $95^{\circ} \mathrm{C}$ for $12 \mathrm{~h}$ and a reducing CAN-DEREM solution circulated at $120^{\circ} \mathrm{C}$. for $8 \mathrm{~h}$. In total, the decontamination sequence consisted of AP/CAN-DEREM/AP/CAN-J)EREM steps applied using a decontamination circuit consisting of pumps, heaters, and ion-exchange columns.

Overall, DFs ranging from 6.2 to 6.5 were achieved. About $96 \%$ of the activity removed was due to ${ }^{58} \mathrm{Co}$ and ${ }^{60} \mathrm{Co}$. Corrosion rates for all materials were low, close to detection limits in most cases, and comparable to laboratory results. There was no localized attack and little, if any, evidence of seneral corrosion. As a result, the CAN-DEREM process is currently being qualified for use in PWR full heat transport systems in a major program being carried out by Westinghouse in the United Sitates. Westinghouse and PNC Services of Richmond, WA, are two companies licensed to apply the CAN-DEREM and CAN-DECON processes in the United States.

\section{(5) $\quad \underline{\text { LOMI }}$}

A novel series of decontaminants known as low-oxidation-state metal ion (LOMI) reagents, cleveloped in the United Kingdom, contain two basic components: a metal ion in a low oxidation state and a chelating agent [DIERCKS].

The best developed LOMI reagent is vanadous picolinate, which, at concentrations of 0.01 to $0 . \mathrm{C} 01 \mathrm{M}$, is effective in removing oxides low in chromium in a singlestage application. The first formulation of the LOMI reagent contained 0.002 to $0.004 \underline{\mathrm{M} \mathrm{V}}{ }^{2+}$, 0.001 to $0.002 \mathrm{M}$ picolinic arid, and 0.001 to $0.002 \mathrm{M}$ formate ions in thoroughly deoxygenated water with sufficient sodium yydroxide to adjust the $\mathrm{pH}$. Use of this first formulation generated a relatively large amount of raclioactive ion-exchange waste. Therefore, a second-generation LOMI reagent, containing less formate and sodium hydroxide, was introduced, which resulted in a $50 \%$ reduction in the amount of ion-exchange resin required for waste cleanup.

The LOMI process utilizes $\mathrm{V}^{2+}$ ions in the form of vanadium picolinate to reduce $\mathrm{Fe}^{3+}$ ions in the; corrosion-product scale to the more soluble $\mathrm{Fe}^{2+}$ state. The $\mathrm{V}^{2+}$ ions are oxidized to $\mathrm{V}^{3+}$. Oxidized $\mathrm{V}^{3+}$ ions are also formed by the reaction of $\mathrm{V}^{2+}$ with oxidizing species formed from the radiolysis of water. Therefore, formic acid is added to the reagent to scavenge these oxidizing radicals. The presence of formate also regenerates $\mathrm{V}^{2+}$ ions.

The LOMI decontamination process is similar to the CAN-DECON process. The reactor coolant is first adjusted to neutral $\mathrm{pH}$ and a low dissolved-oxygen level and is 
then brought to a temperature of 80 to $90^{\circ} \mathrm{C}$. The chemical decontamination solution is injected, and a side stream of circulation coolant is passed through filter and cation exchange resin columns to regenerate the solution on line. Decontamination times are very short-typically about 1 to $3 \mathrm{~h}$. As described in Section V.2, combining LOMI with AP or NP increases decontamination efficiencies.

The LOMI process was tested at Pacific Northwest Laboratory on the steam generator of the Surry-1 reactor. The process was successful in reducing the radiation; dose rates in the chemical head area were reduced by factors of 7 to 10 [IAEA-1985].

The LOMI process is the established decontamination process for the Winfrith Steam Generating Heavy Water Reactor (SGHWR) in the United Kingdom [COMLEY]. In 1984, it was also used to decontaminate heat exchangers and recirculation pipework in the Monticello BWR in the United States. Experience to date indicates that this process is an effective method for BWR piping and fuel [IAEA-1985]. It can also be used to decontaminate structural materials including carbon steel; types 304, 316, 321, and 410 stainless steel; Inconel 600; Inconel 800; and Zircaloy-2.

The advantages of the LOMI reagent are that it has low corrosion rates without the use of an inhibitor and that it reacts rapidly [BRADBURY]. Its disadvantages are that it is fairly expensive and the process creates a relatively large volume of waste.

The volume of radioactive demineralization resin generated during LOMI decontamination is somewhat larger than that for the similar Citrox or CAN-DECON processes, because the active ingredients of LOMI are more concentrated and contain added cations. An electrochemical treatment, ELOMIX (electrochemical LOMI ion exchange) has been developed for the LOMI process [WOOD]. This treatment reduces the radwaste by using an electrochemical cell to continuously remove the radioactive elements from solution. Ion exchange resins are used as an intermediate, rather than a final, waste form and are continuously regenerated by the passage of electric current. The radioactivity is deposited as metal particles that can be hydraulically transported to a vessel for encapsulation.

(6) $\quad$ CORD

The low-concentration Chemical Oxidizing Reduction Decontamination (CORD) process is an example of a modern decontamination procedure that can be applied in decommissioning [WILLIE, BERTHOLDT]. The process is a modification of the OZOX process (Section V.a.8). Developed by Kraftwerk Union AG, Germany, the process consists of the following steps: (1) oxidation by an acidic permanganate, (2) reduction by an organic acid, (3) decontamination by a dicarboxylic acid, and (4) discharge or purification via ion exchange. It may be applied to both BWR and PWR oxide films. Operating temperatures are around $95^{\circ} \mathrm{C}$, and the concentrations of chemicals are less than $3 \mathrm{~g} / \mathrm{L}$.

In the first step of the process, acidic permanganate is added to the system for oxidation of the chromium to the hexavalent state. Dicarboxylic acid is then added directly, without the fluid contents of the system having to be replaced. The permanganate is reduced to the manganous form by the decontamination solvent. Dissolved metals are removed by 
ion exchange as part of the process or by subsequent evaporation of the solution. This procedure is referred to as one cycle and can be applied several times.

The CORD process was employed for decontamination of the primary coolant system of the BR 3 reactor, Mol, Belgium. The BR 3 reactor is a PWR with 10.5-MW electric power output. The inner surface area of the whole primary loop is about $1000 \mathrm{~m}^{2}$, and the volume is $15 \mathrm{~m}^{3}$. The existing plant systems were used for preparing, heating, and circulating the solutions, assisted by an automated mobile decontamination appliance. The resulting DF was 43 , and waste conditioning for the loop piping was performed with the BR 3 plant ion-exchange purifica ion system.

\section{(7) $\quad \underline{\text { POD }}$}

The PWR oxidative decontamination (POD) process uses a combination of NP, nitric and oxalic acids, and Citrox. The NP/POD procedure was developed in the United Kingdom and tested at BNL in the Central Electricity Generating Board development program [PICK]. To prevent degradation of the ion-exchange resins by AP, a nitric acid/permanganate solution $(0.1 \%$ permanganate, $\mathrm{pH} 2.5)$ was used in the first stage. Process temperatures were 85 to $95^{\circ} \mathrm{C}$ for contact times of 5 to $24 \mathrm{~h}$. In the second stage, oxalic $(1.4 \mathrm{~g} / \mathrm{L})$ and nitric $(1.5 \mathrm{~g} / \mathrm{h})$ acids were applied for approximately $1 \mathrm{~h}$ to destroy excess permanganate and reduce the manganese dioxide to manganous. In the third stage, oxalic $(0.45 \mathrm{~g} / \mathrm{L})$ and citric $(0.96 \mathrm{~g} / \mathrm{L})$ acids with $\mathrm{KOH}(0.42 \mathrm{~g} / \mathrm{L})$ were applied for 5 to $7 \mathrm{~h}$ to dissolve the layer of chromium-depleted oxides. Finally, the solution was processed in an ion-exchange system.

Reported DFs with PWR specimens ranged from 4 to 25 , with typical values of 5 to 10 . A second application of the process more than doubled the DF, which reached more than 100 in the best case.

\section{OZOX-A}

The OZOX-A process, whose prime reagent is oxalic acid, is a proprietary development of Kraftwerk Union AG and was used to decontaminate the steam generator channel head at the Millstone-2 reactor in the United States [NEI]. A multiple-step application of chemicals was followed by high-pressure $(700 \mathrm{MPa})$ water lancing of the cold-leg channel head. The overall DF was about 7. The DF achieved in the hot-leg channel head area was about 2. Application of the OZOX-A trealment to the FR-2 Research Reactor in Germany was also successful. Chemicals were applied at temperatures of 75 to $95^{\circ} \mathrm{C}$ for several hours, and DFs ranged from 2 to 35.

\section{ESI Solutions}

Two commercial decontamination products are available from Environmental Scientific, Inc. (IESI, Research Triangle Park, NC) called SmearAway and ESI-318ND. These products are reporterl to produce similar results to the Ce(IV) gel without the high acidity $\left(10 \mathrm{M} \mathrm{HNO}_{3}\right)$ of the gel. They are advertised as being useful for removing contamination fixed by oil, grease, dirt, soil, and grime. These low-foam decontaminating agents are neutral (ESI-318ND 
is slightly alkaline) nonhazardous cleaning agents. No DF information was reported in the company's literature.

\section{b. $\quad$ Alkaline Reagents}

The primary alkaline salts discussed are potassium hydroxide, sodium hydroxide, sodium carbonate, trisodium phosphate, and ammonium carbonate. Alkaline salts (i.e., bases) are used to (1) remove grease and oil films, (2) neutralize acids, (3) act as surface passivators, (4) remove paint and other coatings, (5) remove rust from mild steel, (6) solubilize species that are soluble at high $\mathrm{pH}$, and (7) provide the right chemical environment for other agents. As degreasers, they are normally mixed with detergents; most commercial detergents contain mild caustic compounds. Some important species such as iodine, are more soluble in alkaline solutions and can be effectively washed from the surface.

Bases are principally used for removing grease, oil, mild scale, and organic deposits. They also remove loosely adsorbed materials and smearable activity, although DFs are usually low. Alkaline reagents are often used alternately with strong acids to clean materials, especially stainless steel. An acid recovery evaporator cell in Japan was decontaminated by $\mathrm{HNO}_{3}$ treatment followed by an $\mathrm{NaOH}$ rinse [HAYASHI].

Alkaline solutions act aggressively on paints, coatings, and films. The treatment softens the paint so that it can be removed by mechanical means. This process is often preferable to dissolving the paint completely because that may contaminate the surface underlying it. Alkaline solutions may be used on all nonporous surfaces, except aluminum and magnesium, which react with strong bases. The strong bases $(\mathrm{KOH}, \mathrm{NaOH})$ are used for harsh attack, and weak bases $\left(\mathrm{NH}_{3}, \mathrm{H}_{2} \mathrm{NNH}_{2}, \mathrm{NH}_{2} \mathrm{OH}\right)$ are used when milder conditions are required.

Dilute alkaline complexing solutions were used in the second step of a decontamination process for stainless steels at Pacific Northwest Laboratory [AYRES]. In one experiment, a sample of stainless steel, conditioned in AP, was treated with a $3 \%$ solution of triethylenetetraminehexaacetic acid (TTHA), citric acid, $\mathrm{N}_{2} \mathrm{H}_{4}$, and $\mathrm{NH}_{2} \mathrm{OH}$. At $98^{\circ} \mathrm{C}, 94 \%$ of the activity was removed in $30 \mathrm{~s}$. After $5 \mathrm{~min}$, the DF was 250 . With additional exposure $(1 \mathrm{~h})$, the DF reached 4000 . Reagents of this type are attractive as reactor decontaminants since $\mathrm{N}_{2} \mathrm{H}_{4}$, $\mathrm{NH}_{2} \mathrm{OH}$, EDTA, and some organic acids decompose in heat and radiation fields to form harmless substances such as $\mathrm{NH}_{3}$ and $\mathrm{CO}_{2}$. Any residual decontaminant inadvertently left in the system will be rapidly decomposed when the reactor is brought back into operation.

Other advantages of alkaline solutions are that they are inexpensive and easy to store, have fewer material compatibility problems than acids, and can be applied in the form of gels to ceilings and walls. Many new complexing agents have proved valuable in dissolving compounds of $\mathrm{Fe}, \mathrm{Ni}$, and $\mathrm{Cr}$ in alkaline solutions $(\mathrm{pH}>10)$. The disadvantages of alkaline solutions include their slow reaction times and their destructive effect on aluminum. In addition, bases can be safety hazards because they can cause burns if workers come into contact with them. 


\section{c. $\quad \underline{\text { Acid Salts }}$}

The salts of various weak and strong acids can be used alone or in combination with various acids to decontaminate metal surfaces. The most commonly used salts are sodium bisulfate, sodium sılfate, ferric sulfate, ammonium oxalate, ammonium citrate, and sodium fluoride.

These acid salts function similarly to the acids themselves, by dissolving or complexing the metal oxide surface, but they also provide sodium and/or ammonium ions to replace contaminants at ion-exchange sites. A salt is frequently used in combination with its corresponding acid and gives better DFs than the acid alone. The salts are less corrosive than their corresponding acids and have fewer material compatibility problems, but they are generally corrosive enough to require inhibitors. Their application as single agents is limited, with the exception of $\mathrm{NaHSO}_{4}$, which is often used alone for mild decontamination of carbon steel and aluminum.

Acid salts increase the versatility of acid decontamination, produce less corrosive solutions, and are safe: for personnel than the acids. The disadvantages of acid salts are that they present some corrosion considerations for both equipment and personnel; they have limited application without addition of an acid to lower the solution $\mathrm{pH}$, and they are slower acting than the acids. The use of salts also increases waste volumes.

\section{d. Compexing Agents}

A complexing agent is a chemical species that forms a stable complex with a metal ion. There are two classes of complexants: those that preferentially form complexes with certain ions and those that birld the metal at two or more locations, which are known as chelating agents. The most common complexing agents used in decontamination are EDTA and its homologues, organic acids, and sorlium or ammonium salts of the organic acids.

The use of chelating agents for the chemical cleaning and decontamination of nuclear steam generating equipment is well known. Current, state-of-the-art technology for the dissolution of magnetite, copper, and other metals and metal oxides from the secondary side of nuclear steam generators uses EDTA-based solvents. Technologies developed for the decontamination of commercial nuclear power reactors (e.g., LOMI and CAN-DEREM) also utilize chelating agents.

The formation of stable complexes with metal ions prevents redeposition from the solution and aids in scale removal. This is important, since metal ions have a strong affinity for bare metal surfaces. Complexing agents are used with solutions of detergents, acids, and/or oxidizing agents to dramatically increase DFs. The ability of the agent to complex metal ions depends on the specific ion, its oxidation state, and the solution $\mathrm{pH}$.

The chelator EDTA forms stable complexes with iron, nickel, cobalt, chromium, and other di- and trivalent ions. Mixtures of citric acid and EDTA, at a neutral $\mathrm{pH}$, readily remove high-temperature film and scale from mild steel and conditioned high-temperature films from stainless steels. Solutions of EDTA, citric acid, or hydrazine, at a pH between 6 and 8 , 
should be compatible with decontamination equipment. The reagents are relatively noncorrosive and nontoxic. Hydrazine is preferred because it (1) provides a reducing atmosphere, (2) can be decomposed by heat, and (3) will not form a residue in crevices. EDTA can be recovered by reducing the $\mathrm{pH}$, which forces its precipitation as the free acid.

A very effective decontaminating agent for metal surfaces is a mixture of oxalic and citric acids. The metal ion preferences of the two acids complement each other, and they also dissolve oxide films. Oxalic-citric acid mixtures are also used with EDTA. When using the organic acids as complexing agents, the precautions described for organic and weak acids should be considered.

The advantages of using complexing agents are that they can increase the DF of most decontaminating agents by providing greater solubilities of metallic ions, and they are relatively safe and nontoxic. The disadvantages of chelating agents are their expense and the difficulty in treating their solutions by ion exchange [JOHNSON]. Wastes containing complexing agents may also present a disposal problem.

\section{e. REDOX Agents}

An oxidizing agent increases the oxidation state of another chemical species, and a reducing agent lowers its oxidation state. A change in oxidation state may be beneficial for decontamination because some elements are more soluble in some oxidation states than in others. Frequently, these two classes of chemicals are used together to maintain a specified redox potential of a decontamination solution.

Most of these agents have been discussed in previous sections; thus, they are only briefly summarized here. The oxidizing agents most commonly used in decontamination are potassium permanganate, potassium dichromate, and hydrogen peroxide. Oxidizing agents are used extensively in decontamination to condition metal oxide films, dissolve fission product debris, dissolve various chemical species, and oxidize metal surfaces either for protection or corrosion. Many metallic and other compounds either break down or are more soluble when in higher oxidation states, and base metals must be oxidized if they are to be dissolved. Most metal surfaces can be treated with oxidizing agents, but conditions must be adjusted to avoid excessive corrosion.

Solutions of AP are used extensively to condition metal oxide films, especially on stainless steel. Because the strong oxy-acids $\left(\mathrm{HNO}_{3}, \mathrm{H}_{2} \mathrm{SO}_{4}, \mathrm{H}_{3} \mathrm{PO}_{4}\right)$ may also act as oxidizing agents, these are usually used alone, but hydrogen peroxide finds application in solutions with the other nonoxidizing acids and salts. Solutions of organic acids and peroxide frequently achieve DFs superior to those of a strong oxidizing acid, but without some of the corrosion and safety problems.

The advantages of using oxidizing agents are that they complement various acid decontamination solutions, allow less corrosive acids or salts to be used, and perform a unique function in the dissolution of many compounds. The disadvantages include some metal corrosive action, violent reactions with some compounds, loss of activity during storage, and the need to be neutralized before waste treatment. 
Reduc.ng agents alone have limited application in decontamination because metals will plate out when reduced, and this is usually undesirable. Under specific conditions, reducing agents could be usecl to protect a metal surface or reduce higher oxidation states for complexing agents. Possible reducing agents are sodium hypophosphite and hydrazine. Hydrogen peroxide may also be used as a reducing reagent.

\section{B. Electrochemical Processes}

The electrochemical decontamination process is used to remove contamination that is on or in metal surfaces by the controlled removal of a thin layer of the surface metal, including corrosion films that would otherwise be difficult to remove. The process can be used to remove a variety of radionuclides, including $\mathrm{Pu}, \mathrm{U}, \mathrm{Ra}, \mathrm{Co}, \mathrm{Sr}, \mathrm{Cs}$, and $\mathrm{Am}$. Electrochemical processes can be used to remove corrosion films that have been baked on or ground into the metal surface. The technique can be applied by immersing the components in a bath or used in situ for the inside of tanks, pumps, and large pipes and the outside of large components. Electrochemical decontamination is applicable to components wit. relatively complex shapes.

Higher DFs can be achieved by the removal of a few tens of micrometers of material. Decontamination to background level is feasible if sufficient material is removed. Volumes of secondary waste solutions are low, but the waste may require chemical treatment before disposal.

The principal disadvantage of electrochemical decontamination is the expense resulting from relatively high installation costs. The process is labor intensive; exposure to $\beta / \gamma$ radiation can be a problem with highly active material unless the equipment is adapted for remote operation; and nonconducting surface layersi must be removed before the process can be applied. The technique may also be unsuitable for component parts that have close tolerances. Another disadvantage associated with electropolishing tr:chniques is that nonconductive components cannot be cleaned; thus, coatings (e.g., paint, epoxy) rnust be removed from conducting components before cleaning can be performed. Exposure levels could be excessive when cleaning highly contaminated parts unless remote techniques are employed. Components may need to be cleaned repeatedly if excessive amounts of contamination are: allowed to build up in the electrolyte.

Electropolishing, as clistinguished from electroetching, is a special case of electrochemical decontamination. The electropolishing technique has been widely used in the metal finishing industry. It was not until the 1970 s, however, that the nuclear industry recognized its potential for cleaning radiologically contaminated equipment. Currently, the technology is gaining popularity in the nuclear industry for surfare pretreatment as well as for decontamination operations.

In electropolishing, the metal object to be decontaminated serves as an anode in an electrolytic cell, and the condition: are such that high potential areas (projections) are preferentially dissolved to yield a level surface. The ions resulting from the electrochemical dissolution accumulate in the immediate vicinity of the anode and then diffuse into the bulk of the solution. Radioactive contamination is removed as the metal is released into solution. The amount of metal requiring removal is a function of surface topography and depth of contamination, but it generally ranges from 5 to $50 \mu \mathrm{m}$ for surfaces that are not heavily corroded or pitted. This corresponds to an 
electropolishing time of 3 to $30 \mathrm{~min}$ for a typical current density of $16 \mathrm{~mA} / \mathrm{cm}^{2}$. After electropolishing, the part is removed from the electrolyte and rinsed in hot water.

Traditionally, the technique uses phosphoric acid as an electrolyte and a high current density to produce a smooth surface, which is desirable if the item decontaminated is to be reused. If the item is not to be reused, electrolytes such as nitric acid can be used at lower current densities; this will result in a rougher finish. Other potential electrolytes are sulfuric or oxalic acids. Several alkaline electrolytes have also been studied.

Electropolishing with sulfuric acid electrolytes was found to be the most thorough method to remove radionuclides and other foreign material that may be deposited on or in the outer surface of glass canisters during any of the high-level waste processes [NESBITT]. Both of the electrolytes $\left(55 \% \mathrm{H}_{3} \mathrm{PO}_{4}\right.$ or $\left.55 \% \mathrm{H}_{3} \mathrm{PO}_{4}+10 \% \mathrm{H}_{2} \mathrm{SO}_{4}\right)$ were effective in removing all of the exposed oxide. Treatment at $160 \mathrm{~mA} / \mathrm{cm}^{2}$ current density and $80^{\circ} \mathrm{C}$ for $1 \mathrm{~h}$ removed approximately $200 \mu \mathrm{m}$ of base metal, or a thickness corresponding to that of the oxide layer.

In situ electropolishing techniques are under development for use in decontaminating large tanks, the interior of long pipes, pool walls, and other contaminated surfaces that cannot be either transported to or immersed in a conventional electropolishing cell [ALLEN-1978, TURNER, RANKIN-1990]. Electrochemical decontamination using a movable cathode does not require large volumes of electrolyte, so it does not produce correspondingly large quantities of liquid waste. It is based on the principle of an insulated unit that holds the cathode at a fixed distance from the surface [PAVLIK]. This technique has been used in Hungary, and DFs of 20 to 500 were achieved. An in situ technique for pipe interiors was also demonstrated at the Hanford N-Reactor [ALLEN1984]. The inside of the pipe was electropolished $2 \mathrm{ft}(0.61 \mathrm{~m})$ at a time by using a movable cathode. The electrolyte was pumped through the cathode into the pipe, which was isolated from the primary coolant system by valves, and returned to the external electrolyte reservoir through a drain line at each end of the loop. Each $2-\mathrm{ft}(0.61-\mathrm{m})$ section of pipe was electropolished for $20 \mathrm{~min}$ at a current of approximately $110 \mathrm{~mA} / \mathrm{cm}^{2}$. The hydrogen generated by the electropolishing process was flushed out of the pipe by the circulating electrolyte at $15 \mathrm{~L} / \mathrm{min}$ and was vented from the external electrolyte reservoir.

A contaminated electrolyte solution is a product of the electropolishing process. Development of primary and secondary waste treatment processes and solution recycle systems is required.

\section{Phosphoric Acid Electrolytes}

Typical conditions for using a phosphoric acid electrolyte are as follows: 40 to 80 vol\% $\mathrm{H}_{3} \mathrm{PO}_{4}$, operating temperatures of 40 to $80^{\circ} \mathrm{C}$, electrode potential of 8 to $12 \mathrm{~V} \mathrm{dc}$, and current densities of 60 to $270 \mathrm{~mA} / \mathrm{cm}^{2}$. The time required to achieve a smooth surface is typically 5 to $30 \mathrm{~min}$.

Studies at PNL demonstrated that phosphoric-acid-based systems are effective on steel, stainless steel, and a number of other alloy systems [ALLEN-1985]. The electrolyte's hygroscopic nature helps to minimize airborne contamination. Phosphoric acid's good complexing 
characteristics may be a significant factor in minimizing recontamination from the buildup of activity in the electrolyte.

Studies performed at PNL in cooperation with Rockwell Hanford Operations and United Nuclear Industries showed that components heavily contaminated with plutonium oxide were decontaminated from $1,000,000 \mathrm{dpm} / 100 \mathrm{~cm}^{2}$ to background levels in less than $10 \mathrm{~min}$ [ALLEN-1985].

Phosphoric-acid-based electrolytes are not effective in decontaminating welds. It is believed that metallurgical changes caused by welding make welded areas less soluble than the base materials. It has also been observed that low current densities produce nonuniform metal removal and that high current densities; produce excessive oxygen evolution [DOE].

\section{Nitric Acid Electrolytes}

Two sets of orrerating conditions are used in nitric-acid-based systems: high current densities and low current densities. Representative operating parameters for high-density, nitricacid-based electropolishing de:contamination are as follows: nitric acid concentrations of 6 to $12 \underline{\mathrm{M}}$, operating temperature of 10 to $35^{\circ} \mathrm{C}$, electrode potential of 5 to $8 \mathrm{~V} \mathrm{dc}$, and current densities of 400 to $2000 \mathrm{~mA} / \mathrm{cm}^{2}$. At $400 \mathrm{~mA} / \mathrm{cm}^{2}$, decontamination times range from 1 to $2 \mathrm{~h}$, which corresponds to the removal of 0.3 mil of surface material. Because of the low current density, a basketstyle anode can be used, thus eliminating the need to move the anode contacts during the decontamination cycle [DOE].

Studies performed at Harwell Laboratory, Oxfordshire, United Kingdom, showed that treatment with nitric acid electrolytes at low current density achieved DFs greater than $10^{4}$ for components contaminated with colloidal plutonium and $\mathrm{PuO}_{2}$ in about 2.2 and $1.7 \mathrm{~h}$, respectively. Harwell Laboratory also demonstrated that nitric-acid-based systems are effective on steel, stainless steel, and a number of alloy systems. Dissolved substrate in the electrolyte at levels up to $20 \mathrm{~g} / \mathrm{L}$ had only a minor effect on recontamination of the object being cleaned [DOE].

Nitric-acid-based electrolytes were recommended for the decontamination of plutonium-contaminated stainless steel pipes [AEA]. Nitric acid has many advantages over other electrolytes, especially the ease $0 .:$ subsequent processing by standard waste-handling techniques. The throwing power of nitric acid is significantly better than that of phosphoric acid, for example, and the viscosity is lower. This means that special counterelectrodes are not required and that rinsing with water is straightforward

The laboratory test by AEA indicated that DFs exceeding $10^{4}$ were achieved for stainless steel samples contaminated with "colloidal" Pu(IV) nitrate and "particulate" Pu(IV) oxide. The DFs were 35,000 for colloidal plutonium when nitric acid was used at a low concentration for $2.8 \mathrm{~h}$, and 52,000 when medium acid concentration was used for $0.5 \mathrm{~h}$. Decontamination factors of 16,000 were achieved for prarticulate plutonium when a medium acid concentration was used for $0.5 \mathrm{~h}$. The oxide required more concentrated nitric acid for effective decontamination because of its low solubility in the dilute acid. Similar results were achieved on surfaces contaminated with 
enriched $\mathrm{UO}_{2}$. The AEA staff also successfully decontaminated the inside of tubes contaminated with ${ }^{60} \mathrm{Co}$ and plutonium using a nitric acid electrolyte [AEA].

Nitric-acid-based electrolytes operated at low current density provide good results on welded surfaces. The systems may generate hydrogen and nitrogen oxide gases, but these gases can be controlled or eliminated by using the proper electrode materials and electrolyte additives.

Harwell Laboratory investigated the relationship between cathode materials and chemical additives and their effect on hydrogen and nitrogen oxide production in nitric-acid-based electrolyte systems [DOE].

\section{Sulfuric Acid Electrolytes}

In experimental studies conducted at ORNL [BENNETT], DFs of 1000 to 3000 were obtained by electrostripping deposited radioactivity from stainless steel surfaces that were used as the anode in $2 \%$ sulfuric acid at current densities as low as $1.6 \mathrm{~mA} / \mathrm{cm}^{2}$. Stainless steel cathodes were used. The method was successfully applied to contaminated equipment.

The Unit Committee on High Purity and Power Plant Water (T-7D) of the National Association of Corrosion Engineers undertook a survey of descaling procedures [NACE]. They summarized various sulfuric-acid-electrolyte applications for iron- and nickel-based alloys exposed to high-temperature water. $\mathrm{A} 5 \% \mathrm{H}_{2} \mathrm{SO}_{4}$ solution was used for removal of stainless steel oxide scales at $74^{\circ} \mathrm{C}$.

\section{Organic Acid Electrolytes}

Representative operating parameters for acetylacetone-based electropolishing decontamination are as follows: electrolyte composed of acetylacetone plus $\mathrm{KBr}$ plus n-propanol, operating temperatures of 20 to $40^{\circ} \mathrm{C}$, electrode potential of 15 to $24 \mathrm{~V} \mathrm{dc}$, and current densities of $200 \mathrm{~mA} / \mathrm{cm}^{2}$. Typical decontamination times range from 40 to $100 \mathrm{~min}$, which corresponds to the removal of 1 to 2 mil ( 25 to $50 \mu \mathrm{m}$ ) of surface material at a current density of $200 \mathrm{~mA} / \mathrm{cm}^{2}$. It is usually important to move the anode contacts once during a cycle to decontaminate the area under the contacts [DOE].

There are three major advantages to using an acetylacetone-based electrolyte. First, acetylacetone has good $\mathrm{pH}$ stability and can resist changes caused by the formation of hydroxides. Second, the organic acid component can be destroyed, resulting in a nonacidic waste. Third, the radioactive contents of the electrolyte reach a steady state that is governed by the solubility of the acetylacetonate salts. This is beneficial where criticality is a concern and where radiation control is essential. The large salt crystal formed in this process can be removed from the bottom of the electropolishing vessel and isolated in a safe storage condition [DOE].

Studies performed at Kraftanlagen Aktiengesellschaft, Heidelberg, Germany, showed that an acetylacetone electrolyte could achieve a DF of 36 for components with generalized contamination consisting largely of ${ }^{137} \mathrm{Cs}$ and ${ }^{60} \mathrm{Co}$ [DOE]. 


\section{Foam and Gel Systems}

Radioactive installaticns are often decontaminated by spraying with aqueous solutions. These produce a large amount of effluent, and contact between the items to be decontaminated and the decontamination solution is of short duration. These drawbacks can be offset by applying the decontaminant in a foam- or gel-based medium.

In this sense, foamed or gelled solutions appear to be promising agents for obtaining satisfactory DFs with small amounts of decontaminants. The volume of liquid waste generated is only 1 to $2 \%$ of that obtained by soaking procedures. Gelled solutions are also satisfactory reagents for decontaminating hot spots or selected areas [DOE].

Various mixtures of chemicals have been developed for application to facility or component surfaces as gels, foams, and prastes. Generally speaking, the major disadvantage for foam and gel processes is lower DFs than similar aqueous-based systems.

\section{Foam}

Foam is used as a carrier of a chemical decontamination agent, not as the agent itself. Foam can be applied in a thin layer to a surface in any orientation, even to overhead surfaces. It can be sprayed onto component walls, or the component can be filled with the foam. The foam method can effectively decontaminate metallic walls and parts of complex components. By increasing dwell time, the foam better exploits the capability of the decontamination agent. Surfactants in the foaming agent enhance the effect by increasing contact with the surface. Repeated applications can give "several orders of magnitude reduction in surface contamination" [ORNL].

The advantages of foam decontamination are that it is effective for treating large components with complex shapes; it is a good process for internal in situ decontamination to eliminate smearable contamination before dismantlement; and it produces a low final waste volume. In addition, the process is readily applied remotely; thus it reduces operator exposure to and potential uptake of an acid decontamiration agent and/or radioactive materials. Recirculating the foam can increase its effectiveness.

The disadvantiages are that it is difficult to obtain a good DF using a one-time application (batch process). Fully controlled foaming times are needed. In addition, foam is difficult to recirculate when it is used to fill large cavities, and it is not appropriate for use on cracked surfaces or where there are deep or convoluted crevices [ORNL]. The technology itself is inexpensive, but more development and scale-up work is required.

Foam decontamination is well developed and widely used in the nuclear industry. It has been developed at DOE's Savannah River Site as a waste minimization tool [GUTHRIE]. Previous experience with foam decontaminants has shown a significant waste reduction (up to $70 \%$ ). This process was tested on a series of large valves with complex internal configurations [GUTHRIE]. The foam decontamination process also has been applied to contaminated walls at the West Valley Demonstration Project [MEIGS]. In this instance, results indicated that 
decontamination foams achieve better DFs on stainless steel surfaces than on carbon steel or painted concrete. The foam process is routinely used by Rockwell International Energy Systems Group in the decontamination of hot cells, glove boxes, and obsolete nuclear facilities. The process is most effective when the foam is applied hot and the surface is nonporous [HARRIS-1982].

When a closed system is used for making the foam, extreme caution is required. The system is pressurized to make the foam and force it out through a nozzle. A mixture of organic foam makers and decontaminating agent is forced through a chamber where air is added to make the foam. The hazards of this technique were experienced at the Savannah River Site when a large amount of organic foam maker was added to nitric acid (i.e., the decontamination agent) [DOE]. The resultant chemical reaction between the chemical foam maker and the acid had a constantly accelerating reaction rate. The volume of gas produced was greater than the pressure relief output, so the system overpressurized and ruptured.

A foam process called COMODIN was used to clean up five large heat exchangers from a French G2 reactor [COSTES]. The same process was used to clean another heat exchanger, but the foam was ozone-enriched. The COMODIN process relies on a foam that is created in a generator where reactants are mixed with gas and then continuously circulated through the heat exchangers from the bottom to the top. The foam flows out the top and is recirculated; the condensed foam is removed from the bottom and also recovered for reuse. Alkaline and acid foams are often used in turn for periods of $4 \mathrm{~h}$ each. Multiple washes are also performed. At the G 2 reactor, the alkaline foam contained $12 \% \mathrm{NaOH}$; the acidic foam contained $1 \mathrm{M} \mathrm{H}_{2} \mathrm{SO}_{4}$, $2.0 \mathrm{M} \mathrm{HNO}_{3}$, and $0.04 \mathrm{M} \mathrm{Ce}\left(\mathrm{SO}_{4}\right)_{2}$. A biodegradable surface active agent $(0.8 \%)$ was added to improve performance. The addition of ozone to the foam improved the rate of decontamination by $50 \%$. The presence of ozone was thought to regenerate $\mathrm{Ce}$ (IV) from $\mathrm{Ce}$ (III) directly in the foam. Overall DFs of 40 to 50 (for all six heat exchangers) were observed for this process. For the unit treated with ozone-enriched foam, the DF was nearly 160 . The liquid waste generated was $6280 \mathrm{~L}$ for processing six heat exchangers-each heat exchanger had a surface area of $232 \mathrm{~m}^{2}$.

\section{2. $\underline{\text { Gels }}$}

Glycerophthalic, glycerophosphoric, silica, and diopside gels are all compatible with most decontaminants. These chemical gels are used as carriers of chemical decontamination agents. Gels are sprayed onto a component wall, allowed to work, and then scrubbed, wiped, rinsed, or peeled off. An airless compressor can be used for spraying the gel and, with a change in heads, for rinsing.

A typical reagent combination is a nitric-hydrofluoric-oxalic acid mixture and a nonionic detergent mixed with a carboxymethycellulose gelling agent, with aluminum nitrate used as a fluoride chelating agent. Steps in the gel decontamination method of a hot cell include scraping and vacuuming the solid waste material, using a hot-water rinse as pretreatment, and spraying gel throughout the cell.

The French have been active in developing a Ce(IV) gel process. This system is discussed below. Some of the various gels [BOULITROP] used in decontamination are also described below. 


\section{a. Glycerophthalic Gel}

Glycerophthalic gel is used as an acid support medium. This medium can be used with sulfamic, oxalic, and sulfuric acids. Sulfamic acid, which is used mainly to decontaminate mild steel and iron (reduction of iron oxides), is added slowly, at 120 to $130^{\circ} \mathrm{C}$, to the glycerophthalic gel, which is made up beforehand by adding phthalic anhydride to glycerine at the same temperature. The compound has a viscosity of about $15 \mathrm{P}$. Oxalic acid, used for the pickling of stainless steels, is added hot to the glycerophthalic gel. Sulfuric acid is added to the gel in the proportion of $50 \mathrm{~mL}$ of concentrated acid per liter of gel.

\section{b. Glycerophosphoric Gel}

Phosphoric acid is added to substances that are used to decontaminate iron or mild and stainless steels. Glycerophosphoric gel is formed by dissolving concentrated phosphoric acid in glycerine. The solution is heated to $100^{\circ} \mathrm{C}$ for about $1 \mathrm{~h}$. Next, it is cooled, which causes gelling (viscosity of around $0.7 \mathrm{P}$ ). The decontamination reagent is completed by adding one or two moles per liter of phosphoric acid or $100 \mathrm{~mL} / \mathrm{L}$ of the phosphoric detergent Paracodine 120 to the gel.

\section{c. Silica (Sel}

Silica gel is used for decontamination, primarily as a support medium for nitric or sulfuric acids. Gellings occurs at ambient temperature after concentrated nitric acid is added slowly to a solution of $0.4 \underline{M}$ of sodium silicate. The silica gel thus formed has a viscosity of $1.3 \times 10^{3} \mathrm{P}$. The addition of 1.1 moles of concentrated nitric acid per liter of gel destroys the molecular structure of the gel and produces a colloidal suspension with a viscosity of about $0.5 \mathrm{P}$. Inclusion of 50 to $100 \mathrm{~mL}$ of concentrated sulfuric acid results in a compound with a viscosity of between 1 and $10 \mathrm{P}$. Silica gel containing sulfuric acid adheres well to stainless steel $\left(1500 \mathrm{mg} / \mathrm{dm}^{2}\right)$, although some residues remain after flushing with water (residual surface mass of $200 \mathrm{mg} / \mathrm{dm}^{2}$ ).

\section{d. Diopside Gel}

This gel is stable in an oxidizing, basic medium. Diopside gel is formed by adding sodium silicate to an equimolecular mixture of calcium nitrate and magnesium nitrate in the presence of sodium. It has a viscosity of around $2 \mathrm{P}$. Sodium hydroxide $(40 \mathrm{~g} / \mathrm{L}$ of gel) and potassium permanganate $(10 \mathrm{~g} / \mathrm{L}$ of gel) are added to the diopside gel, which decreases the viscosity to about $0.5 \mathrm{P}$.

A comparative decontamination study made it possible to select at least one compound yielding high DF; (in excess of 50) in the laboratory for mild steel, stainless steel, aluminum, copper and plexiglass. Some decontamination results [BOULITROP] with stainless steel are as follows: 
- The effectiveness of sulfuric acid in an aqueous solution was of the same order as when it was incorporated in glycerophthalic gel (DF $=102$ in aqueous solution; $\mathrm{DF}=165$ in the gel).

- The phosphating compounds, which are effective in decontaminating stainless steel by soaking (DFs of around 200), remained effective when incorporated in glycerophoric gel (DFs of 20 to 40).

- For nitric acid, the DF for fission products was approximately 50 in silica gel and about 400 in an aqueous solution.

- Glycerophosphoric gel in combination with a commercially available phosphate detergent, Paracodine 120 , and with a surface active agent based on nonylphenol polyglycol ether, Arkopal N 100, was as effective as silica gel with nitric acid and the surface active agent ( $D F=45)$.

- The presence of the surface active agent in glycerophoric gel resulted in substantial plutonium decontamination $(\mathrm{DF}=200)$. Sulfuric acid in glycerophthalic gel $(\mathrm{DF}=165)$ or in silica gel $(\mathrm{DF}=114)$ was a better decontaminant of plutonium than as a solution.

- Plutonium decontamination by sodium permanganate in combination with potassium permanganate was good in an aqueous solution $(\mathrm{DF}=50)$, and even more so in diopside gel ( $\mathrm{DF}=740$ ).

- In the case of fission products, the most effective decontamination was gel (DF $=125)$ made up of $2 \%$ isopropanol with the commercial products 20\% Mariox NP 109 (produced by adding alkylphenol and alkylene oxide) and 50\% Marlophen $86 \mathrm{~S}$ (ethoxyl alkylphenols).

- Chemical gels have been tested for decontamination of carbon dioxide cooling pipes from gas-cooled reactors. These pipes are made of ordinary ferritic steel. The following procedure was used in this project: soda gel spraying $(3 \mathrm{M} \mathrm{NaOH}), 30$-min contact time, rinsing, acid gel spraying ( $3 \mathrm{M} \mathrm{H}_{3} \mathrm{PO}_{4}, 3 \mathrm{M} \mathrm{H}_{2} \mathrm{SO}_{4}$, and $16 \%$ silica), and rinsing for 30 to $60 \mathrm{~min}$. The results indicated that gel spraying is an effective process for removal of $\beta / \gamma$ emitters on ferritic iron steel pipes with simple geometry. The process generated a low volume of secondary wastes. The secondary liquid wastes generated are $\sim 7.2 \mathrm{~L} / \mathrm{m}^{2}$ for 10 -meter length pipe [COURTOIS].

Owing to its suitability for remote use and the low production of secondary effluents, the gel decontamination process permits in situ decontamination of highly contaminated installations with no additional exposure of personnel. Gel decontamination has recently become the preferred treatment for equipment exteriors. Other advantages of the process are that it is effective for removing smearable contamination from large components in situ and it can achieve DFs as high as 100 . 
The disadvantages of gel decontamination are that it is a complex process, which generally requires at east two applications and rinses. Additional treatability studies are needed before the optimum compound composition and operating conditions are designed for specific sites [ORNL]. Reagent action is limited by the solution viscosity, which reduces the ion diffusion rate at the gel/surface interface. The amount of active reagents in the gel film must be kept low $\left(<10 \mathrm{~g} / \mathrm{m}^{2}\right)$.

The wiste generated from the chemical gel can be collected, neutralized, and treated using precipitation techniques [DOE]. On one occasion after spraying and rinsing the gel film two or three times, the volume of waste to be neutralized was four or five times less than that for decontamination of the same item by chemical solutions such as nitric acid. The acidic and basic wastes can be treated by phosphate precipitation, sulfate precipitation, simple neutralization, and addition of a preformed nickel ferrocyanide precipitate [HARRIS-1982].

\section{e. Ceriun (IV) Gel}

Frenck scientists have been active in evaluating $\mathrm{Ce}(\mathrm{IV})$ decontamination processes using both gels [MORSON] and foams [COSTES]. The gel process was used to decontaminate an empty, alpha-contaminated, stainless-steel-lined hot cell at the Commissariat à L'Energie Atomique facility in Marcoule. Decontamination factors of 100 were achieved after the first application; DFs up to 10100 were achieved after the second application. To clean the cell, the entire surface was first degreased by using an alkaline foam. The gel containing $0.5 \mathrm{M} \mathrm{Ce}(\mathrm{IV})$ and $10 \mathrm{M} \mathrm{HNO}_{3}$ was then applied at a rate of 500 to 1000 grams of gel per square meter at a rate of 1 to $2 \mathrm{~m}^{2} / \mathrm{min}$. After 2 to $2.5 \mathrm{~h}$, the gel was rinsed off by using a high-pressure water jet. Several applications of the gel were required. Several hot spots remained after treatment. These spots were cleaned with an electrochemical cell and mechanical grinding. The hot spots were mainly located on welding lines, corroded areas, and places damaged by the removal of equipment. Gel consumption was $2.2 \mathrm{~kg} / \mathrm{m}^{2}$, and $21 \mathrm{~L} / \mathrm{m}^{2}$ of liquid waste was generated. The liquid effluents from the gel process were treated by reducing the $\mathrm{Ce}$ (IV) to $\mathrm{Ce}$ (III) by using hydrogen peroxide followed by precipitation of the $\mathrm{Ce}(\mathrm{III})$ with oxalic acid. The solids were then removed by filtration, dried, and stored in drums. The filtrate vras further treated in an on-site treatment station. 


\section{RECOMMENDED DECONTAMINATION PROCESSES}

On the basis of the results of the literature survey, six decontamination processes were selected for further evaluation in the laboratory:

- Fluoroboric acid system

- Nitric plus hydrofluoric acid system

- Alkaline-persulfate/Citrox system

- $\mathrm{Ag}(\mathrm{II})$-persulfate-nitric acid system

- Oxalic acid-hydrogen peroxide-hydrofluoric acid system

- Electropolishing using a nitric acid electrolyte

All six treatments show promise for in situ use in the decontamination of decommissioned facilities, and all have been demonstrated in either laboratory or actual full-scale processes. None of the chosen processes used foams; however, it is possible that the chemical decontamination agents chosen could be used in a foam system. This will decrease the volume of waste generated and the DF of a single application.

The first agent selected, fluoroboric acid, is used to remove oxide and contamination layers by removing thin layers of the contaminated metal itself (chemical milling). Tests at the ICPP, ORNL, and Alaron Corporation showed fluoroboric acid to be very effective, with DFs in the range of 50 to 100. The DECOHA process (Alaron Corporation) was developed to decontaminate metal from commercial nuclear power plants. Reaction rates can easily be controlled by controlling the solution temperature. Typical removal rates for nickel alloys are 3 is $4 \mu \mathrm{m} / \mathrm{hr}$ at $80^{\circ} \mathrm{C}$ in a solution of $50 \% \mathrm{HBF}_{4}$. This technology generates metal waste as a result of surface removal. The acid can be electrolytically regenerated and recycled, and the radioactive waste can be plated out at the cathode and solidified in cement. Other waste treatment options are neutralization and precipitation followed by solidification in cement.

The second process selected is treatment with solutions of nitric and hydrofluoric acids. These solutions have been used to dissolve $\mathrm{PuO}_{2}$ and to remove oxide coatings from systems for decontamination purposes. Hydrofluoric acid is usually used in conjunction with nitric acid and is present in small amounts. The effectiveness of $\mathrm{HNO}_{3}-\mathrm{HF}$ solutions is primarily due to the removal of the stainless steel surface. Typical solution concentrations are $3.5 \mathrm{M} \mathrm{HNO}_{3}-0.04 \mathrm{M}$ HF. Decontamination factors of 1000 have been reported for BWR and PWR systems; DFs for other systems are typically much lower. Waste treatment typically consists of neutralization with $\mathrm{NaOH}$ or $\mathrm{CaO}$, or complexation of the fluoride, followed by distillation (or evaporation) to recover the $\mathrm{HNO}_{3}$.

The third process selected is the alkaline-persulfate/Citrox treatment. This two-step process uses a concentrated alkaline solution of potassium persulfate to pretreat the chromium-rich surface oxide and render it soluble in the Citrox (citric acid-oxalic acid). In the second step, Citrox dissolves the pretreated film, neutralizes residual alkaline solution from the first step, and complexes iron oxides. Decontamination factors greater than 10 were achieved on a CANDU reactor system 
with corrosion inhibitors in solution. Without these inhibitors, higher DFs are expected. Waste from this process can be treated using mixed-bed ion exchanger; the resins are disposed of as solid waste.

The fourth process selected is the $\mathrm{Ag}$ (II)-persulfate-nitric acid system. Both $\mathrm{Ag}(\mathrm{II})$ and $\mathrm{Ce}(\mathrm{IV})$ are powerful oxidizers, and both have been shown to be effective decontaminants. However, dissolution rates, and possibly DFs, are expected to be higher for $\mathrm{Ag}$ (II) than for $\mathrm{Ce}(\mathrm{IV})$ systems. The peroxydisulfate ion $\left(\mathrm{S}_{2} \mathrm{O}_{8}{ }^{2-}\right)$ serves as a means to oxidize $\mathrm{Ag}(\mathrm{I})$ to $\mathrm{Ag}(\mathrm{II})$. The optimum conditions for a system at Hanford were $0.5 \underline{\mathrm{M}} \mathrm{K}_{2} \mathrm{~S}_{2} \mathrm{O}_{8}, 0.2 \underline{\mathrm{M}} \mathrm{Ag}$, and $3 \underline{\mathrm{M}} \mathrm{HNO}_{3}$ at a temperature of $40^{\circ} \mathrm{C}$. For waste treatment, a process was developed at PNL that uses ascorbic acid $\left(\mathrm{C}_{6} \mathrm{H}_{8} \mathrm{O}_{6}\right)$ to reduce and precipitate silver from solution. The silver could then be recovered and reused in the process. This process has been successfully demonstrated under bench- and processscale conditions, but the cost of the silver to prepare decontamination solutions for a large-scale demonstration may be prohibitive.

The fifth process selected is an oxalic acid-hydrogen peroxide-hydrofluoric acid system. One solution recommended for the decontamination of stainless steel is a mixture of $0.4 \mathrm{M}$ oxalic acid, $0.1 \mathrm{M} \mathrm{HF}$, and up to $1.0 \mathrm{M}$ hydrogen peroxide. The efficiency (and corrosivity) can be increased by reducing the peroxide concentration to $0.01 \mathrm{M}$. The corrosivity can also be controlled by varying the concentration of fluoride ion. Decontamination factors in tests at ORNL were 70 to 200. Waste processing requires neutralization of the hydrofluoric acid followed by decomposition of the peroxide and oxalic ac $\mathrm{d}$.

The sixth process selected is electropolishing using a nitric acid electrolyte. Electropolishing can be used to remove contamination that is on or in metal surfaces by the controlled removal of a thin layer of surface metal, including corrosion films that would otherwise be difficult to remove. It can be applied in situ to the inside of tanks, pumps, and large pipes and the outside of large components. It can also be applied to relatively complex shapes. Decontamination factors of 10,000 have been measured for this system. Generation of hydrogen and nitrogen oxides can be problematic; however, it can be mitigated by proper selection of electrode material and electrolytes. Distillation to recover the nitric acid is one waste disposal method that could be used. Some development work may be required to identify other possible methods. Engineering this process for long runs of pipes, large tanks, and complex shapes will be a challenge; a uniform current density is vital to achieving high DFs.

In addition to these six processes, other decontamination methods show promise. These other systems are typically used in the decontamination of BWR and PWR systems, and modifications are required to improve their performance. These modifications may be as simple as eliminating corrosion inhibitors or increasing reagent concentrations, but additional developmental work is needed.

The six recommended chemical decontamination techniques are summarized in Table 2. 
Table 2. Recommended Decontamination Processes

\begin{tabular}{|c|c|c|}
\hline Process $^{\mathrm{a}}$ & Major Functions & Waste Disposal \\
\hline $\mathrm{HBF}_{4}$ System & $\begin{array}{l}\text { Strong scale dissolvant; removes oxide layer in controllable, } \\
\text { uniform efficient manner. }\end{array}$ & $\begin{array}{l}\text { DECOHA process regenerates } \mathrm{HBF}_{4} \text { for recycle, removes } \\
\text { scale components, and recovers } \mathrm{HBF}_{4} \text { in a single closed } \\
\text { loop. }\end{array}$ \\
\hline $\mathrm{HNO}_{3}$-HF System & $\begin{array}{l}\mathrm{HNO}_{3} \text { functions as both oxide film dissolver and oxidizing } \\
\text { reagent; } \mathrm{HF} \text { accelerates dissolution of oxide layers; effective } \\
\text { for } \mathrm{U}, \mathrm{Pu} \text {, and fission products. }\end{array}$ & $\begin{array}{l}\text { Nitric acid can be recycled by evaporation and acid recovery. } \\
\text { Spent solution can be treated by neutralization. }\end{array}$ \\
\hline $\begin{array}{l}\text { Alkaline-Persulphate/ } \\
\text { Citrox }{ }^{b} \text { System }\end{array}$ & $\begin{array}{l}\text { Persulfate is an extremely powerful oxidizing agent that } \\
\text { converts } \mathrm{Cr}(\mathrm{III}) \text { to the more soluble } \mathrm{Cr}(\mathrm{VI}) \text {. Citrox } \\
\text { dissolves film, neutralizes base, and complexes iron oxides. } \\
\text { The process has been used to decon from fission products } \\
{ }^{106} \mathrm{Ru},{ }^{144} \mathrm{Ce},{ }^{137} \mathrm{Cs},{ }^{60} \mathrm{Co} \text {, and }{ }^{65} \mathrm{Zn} \text {. }\end{array}$ & $\begin{array}{l}\text { The solution can be deionized by a mixed-bed demineralizer; } \\
\text { resins are disposed of as solid waste. }\end{array}$ \\
\hline $\mathrm{AgS}_{2} \mathrm{O}_{8}-\mathrm{HNO}_{3}$ System & $\begin{array}{l}\text { Developed for } \mathrm{PuO}_{2} \text { dissolution. Process has been used for } \\
\text { actinide decontamination. }\end{array}$ & $\begin{array}{l}\text { Silver can be recovered by precipitation with ascorbic acid } \\
\text { followed by filtration. }\end{array}$ \\
\hline $\mathrm{H}_{2} \mathrm{O}_{2}-\mathrm{H}_{2} \mathrm{C}_{2} \mathrm{O}_{4}$-HF System & $\begin{array}{l}\text { Decontamination for components contaminated with }{ }^{95} \mathrm{Zr} \text {, } \\
{ }^{95} \mathrm{Nb},{ }^{144} \mathrm{Ce},{ }^{144} \mathrm{Pr},{ }^{106} \mathrm{Ru},{ }^{106} \mathrm{Rh},{ }^{140} \mathrm{Ba},{ }^{140} \mathrm{La},{ }^{131} \mathrm{I} \text {, and } \\
{ }^{132} \mathrm{Te} \text {. }\end{array}$ & $\begin{array}{l}\mathrm{H}_{2} \mathrm{O}_{2} \text { can be decomposed easily; the spent solution can be } \\
\text { concentrated by boiling, with destruction of } \mathrm{H}_{2} \mathrm{O}_{2} \text { and } \\
\mathrm{H}_{2} \mathrm{C}_{2} \mathrm{O}_{4} \text {. }\end{array}$ \\
\hline $\begin{array}{l}\text { Electropolishing Using } \mathrm{HNO}_{3} \\
\text { Electrolytes }\end{array}$ & $\begin{array}{l}\text { Shown to remove radionuclides such as } \mathrm{Pu}, \mathrm{U}, \mathrm{Ra}, \mathrm{Co}, \mathrm{Sr} \text {, } \\
\mathrm{Cs} \text {, and Am by electrochemically milling the oxide layer and } \\
\text { the base metal. }\end{array}$ & $\begin{array}{l}\text { Gases generated can be controlled or eliminated. Volume of } \\
\text { wastes is low; will require chemical treatment. }\end{array}$ \\
\hline
\end{tabular}

${ }^{a}$ Processes are specified for stainless steel and are recommended for fuel reprocessing and related facilities, but may also be applicable to reactor-type facilities undergoing decommissioning and decontamination.

b Two-step process using a concentrated form of Citrox. 


\section{ACKNOWLEDGMENTS}

The funding for the In Situ Flushing Decontamination of Equipment Interiors program is being provided by the U.S. Department of Energy's EM-50 branch through the Westinghouse Hanford Company under TTP\# RL4-5-20-03.

The authors acknowledge George P. Miller, Westinghouse Hanford Company, for his support and advice in the prejaration of this report. 


\section{REFERENCES}

\section{ABRAMS}

C. S. Abrams and E. A. Salterelli, Decontamination of the Shippingport Atomic Power Station, Bettis Atomic Power Laboratory Report WAPD-299 (1966).

AEA

AEA Technology, Summary of AEA Technology Experience, personal communication (1995).

\section{ALLEN-1978}

R. P. Allen et al., Electropolishing as a Decontamination Technique-Process and Applications, Battelle Pacific Northwest Laboratory Report PNL-SA-6858 (1978).

\section{ALLEN-1984}

R. P. Allen, "Overview of Nonchemical Decontamination Technique," Decontamination of Power Reactors: The Cost, Benefits, and Consequences: Executive Conference, Springfield, VA, September 16-19, 1984.

\section{ALLEN-1985}

R. P. Allen, "Nonchemical Decontamination Techniques," Nuclear News, Vol. 28, No. 8, pp. 112-117, June 1985.

\section{ANON}

Anonymous, The Chemical Contouring of 18 Per Cent Nickel Maraging Steel Sheet, Bristol Aerojet and Westland Aircraft Ltd., Ministry of Technology, D. Mat. Report 143 (1967).

\section{ANSTINE}

L. D. Anstine, J. C. Blomgren, and P. J. Pettit, "Dilute Chemical Decontamination Program Review," in Decontamination and Decommissioning of Nuclear Facilities, M. M. Osterhout, Ed., Plenum Press, New York, pp. 305-316 (1979).

\section{AYRES}

J. A. Ayres, Decontamination of Water-Cooled Nuclear Reactors-Status and Future Research, Battelle Northwest Laboratory Report BNWL-CC-2184.

AYRES-1960

J. A. Ayres et al., Decontamination Studies for HAPO Water-Cooled Reactor Systems: Progress Report, U.S. Atomic Energy Commission Report HW-67937 (1960).

\section{AYRES-1962}

J. A. Ayres, Decontamination Studies for HAPO Water-Cooled Reactor Systems: Progress Report, U. S. Atomic Energy Commission Report HW-71259 (1962). 
AYRES-1967

J. A. Ayres, "Decontamination of Pressurized Water Reactor," Proceedings of the First International Symposium on the Decontamination of Nuclear Installations, Harwell, UK, pp. 101-102 (1967).

AYRES-1970A

J. A. Ayres, Decontamination Studies for N Reactor, Battelle Northwest Laboratory Report BNWL-CC-2659 (1970).

AYRES-1970B

J. A. Ayres, "Decortamination of Pressurized Water Reactors," in Decontamination of Reactors and Equipment, J. A. Ayres, Ed., Ronald Press, New York, pp. 468-578 (1970).

\section{AYRES-1971}

J. A. Ayres, Equipment Decontamination with Special Attention to Solid Waste Treatment-Survey Report, Battelle Northwest Laboratory Report BNWL-B-90 (1971).

AYRES-1979

J. A. Ayres, Decontamination of Water-Cooled Nuclear Reactors-Status and Future Research, Battelle Northwest Laboratory Report BNWL-SA-2460 (1979).

\section{BEAUJEAN}

H. W. Beaujean, J. Fiala-Goldiger, and J. Hanulil, "DECOHA at Chernobyl," Nuclear Engineering International, Vol. 36, No. 441, p. 30 (1991).

\section{BELL-1964A}

W. E. Bell, "Some Aspects of Corrosion and Chemistry in the Citrosolv Process-I," Combustion, 35, 23 (1964).

BELL-1964B

W. E. Bell, "Some Aspects of Corrosion and Chemistry in the Citrosolv Process-II," Combustion, 35, 26:1964).

\section{BENNETT}

M. R. Bennett, Electrodecontamination of Stainless Steel, Oak Ridge National Laboratory Report ORNL-1608 (1954).

\section{BERTHOLDT}

H. Willie and H. Bertholdt, "System Decontamination with CORD and Decontamination for Unrestricted Release," Proceedings of Nuclear Power Performance and Safety, Vienna, September 28-October 2, 1987, Vol. 5, pp. 179-191. 


\section{BLANCHARD}

D. L. Blanchard, J. E. Surma; D. L. Alexander, E. H. Shade, J. D. Matheson, T. E. Boyd, D. L. Cochran, and E. J. Wheelwright, Final Report: Recovery of Silver from CEPOD Anolyte Solutions, Battelle Pacific Northwest Laboratory Report PNL-10164 (1994).

\section{BOLER}

R. Boler, The Chemical Contouring of Corrosion Resisting Steels and of a Nickel Base Alloy, Ministry of Technology, Report D-Mat-144, London (1967).

\section{BOULITROP}

D. Boulitrop, J. P. Gauchon, and Y. Lecoffre, Specific Decontamination Methods: Water Lance, Erosion by Cavitation, Application of Gel-Based Decontaminants, Decommissioning of Nuclear Power Plants: Proceedings of a European Conference, Luxembourg, May 22-24, 1984, K. H. Schaller, Ed., pp. 177-189.

\section{BRADBURY}

D. Bradbury and W. J. Williams, "Decontamination of Magnox Boilers," Proceedings of International Conference on Decommissioning of Major Radioactive Facilities, Institute of Mechanical Engineers, pp. 131-138 (1988).

BRAY-1988A

L. Bray, Development of a Chemical Process Using Nitric Acid-Cerium(IV) for Decontamination of High-Level Waste Canisters, Battelle Pacific Northwest Laboratory Report PNL-6567 (1988).

\section{BRAY-1988B}

L. Bray and J. M. Seay, Development and Design Application of Cerium(IV) Decontamination Process, Battelle Pacific Northwest Laboratory Report PNL-15962 (1988).

BRAY-1992

L. Bray et al., Decontamination Testing of Radioactive-Contaminated Stainless Steel Coupons Using a Ce(IV) Solution, Battelle Pacific Northwest Laboratory Report PNL-8223 (1992).

\section{BREGANI-1987}

F. Bregani and P. Borroni, "Decontamination Studies Related to Garigliano BWR Decommissioning," International Decommissioning Symposium, Pittsburgh, PA, October 4, 1987, pp. IV86-IV100 (1987).

\section{BREGANI-1990}

F. Bregani and P. Borroni, Aggressive Chemical Decontamination Tests on Small Valves from the Garigliano BWR, Commission of the European Communities Report EUR 12878 (1990). 
BROOTHAERTS-1979A

J. Broothaerts et al., Industrial Experience Gained in the Decontamination and Partial Dismantling of a Shut-Down Reprocessing Plant, International Atomic Energy Agency Report IAEA-SM-234/40 (1979).

BROOTHAERTS-1979B

J. Broothaerts et al., Experience Gained with the Decontamination of a Shut-Down Reprocessing Plant, Iaternational Atomic Energy Agency Report IAEA-SM-234/39 (1979).

\section{CALIFORNIA}

University of Califonia and University of Chicago, Separation Process for Plutonium and Uranium, Report for Month Ending September 15, 1942, Oak Ridge National Laboratory Report CN-261 (194?).

\section{CAMPBELL}

D. O. Campbell, Decontamination of Homogeneous Reactor Experiment, Oak Ridge National Laboratory lReport ORNL-1839 (1955).

\section{CARLSON}

A. B. Carlson, "Low 'Temperature Water Cooled Reactors," in Decontamination of Nuclear Reactors and Equipment, J. A. Ayres, Ed., Ronald Press, New York, pp. 439-467 (1970).

\section{CHARLES}

J. Charles, Interim Report General Electric Project, General Electric Company Report HW-USCM-3 (1961).

\section{CHOPPIN}

G. R. Choppin, Litorature Review of Dilute Chemical Decontamination Processes of Water-Cooled Nuclear Reactors, Battelle Pacific Northwest Laboratory Report NP-1033 (1979).

\section{CLEGG}

J. W. Clegg and D. II. Foley, Uranium Ore Processing, Addison-Wesley, Boston (1958).

\section{CLEMMER}

R. G. Clemmer et al.. Pilot-Scale Decontamination Solution Test Results HGTP-93-070202, Battelle Pacific Northwest Laboratory Report PNL-8632 (1993).

\section{COMLEY}

G. C. W. Comley, "Coolant Circuit Contamination and Decontamination Experience at WSGHWR," Decontamination of Nuclear Facilities: International Joint Topical Meeting ANS-CNA, Niagara Falls, Canada, September 19-22, 1982, pp. 2-89-2-108 (1982). 
CONNER-1995A

C. Conner et al., Treatment of Plutonium Bearing Solutions: A Brief Survey of the DOE Complex, Argonne National Laboratory Report ANL-95/31 (1995).

CONNER-1995B

C. Conner et al., Equipment Decontamination: A Brief Survey of the DOE Complex, Argonne National Laboratory Report ANL-95/32 (1995).

\section{COSTES}

J. R. Costes and C. Le Goaller, "Decontamination of Stainless Steel Heat Exchangers with Ozone-Enriched Foam to Allow Steel Recycling," Waste Management '95, Tucson, AZ, 1995.

\section{COUEZ}

H. Couez and L. F. Picone, "Decontamination of a PWR Primary System, SENA Plant," Proceedings of the American Power Conference, 1971, Vol. 33, pp. 757-774 (1971).

\section{COURTOIS}

C. Courtois et al., "Decontamination Techniques for Dismantling," Decommissioning Policies for Nuclear Facilities, Proceedings of an International Seminar, Nuclear Energy Agency, Organization for Economic Cooperation and Development, Paris, October 2-4, 1991, pp. 67-75 (1992).

\section{DEMMER-1994A}

R. L. Demmer, Development of Simulated Contamination (SIMCON) and Miscellaneous Decontamination Scoping Tests, Westinghouse Idaho Nuclear Company Report WINCO-1188 (1994).

\section{DEMMER-1994B}

R. Demmer, Testing and Evaluation of Eight Decontamination Chemicals, Westinghouse Idaho Nuclear Company Report WINCO-1228 (1994).

\section{DEMMITT}

T. F. Demmitt et al., Decontamination Studies for HAPO Water-Cooled Reactor Systems: Progress Report, U.S. Atomic Energy Commission Report HW-62806 (1960).

\section{DETILLEUX}

E. Detilleux et al., Experience Gained with the Decontamination of Shutdown Reprocessing of Nuclear Facilities, International Atomic Energy Agency Report IAEA-SM-234/39 (1978).

\section{DIERCKS}

D. R. Diercks, Chemical Decontamination and Chemical Cleaning of LWR Components and Possible Interactions With Metallurgical Aging Effects, Argonne National Laboratory Report ANL-88-30 and NUREG/CR-5180 (1988). 
DNS-D1-034

Final Status Report jor The Chemical Cleaning DRESDEN-1, DNS-D1-034, DOE/ET 34205-33 (1981).

DOE

Department of Energy Office of Environmental Restoration, Decommissioning Handbook, Department of Energy Report DOE/EM-0142P (1994).

\section{EICKELPASCH}

N. Eickelpasch and M. Lasch, "In-situ Dekontamination von Teilen des KRB-Primakreises," Atomwirtsch. $\underline{24}, 247$ (1979).

ENDA

Masami Enda et al., Japanese KoKai Patent No. Hei 2[1990]-27298 (1990).

FARINELLI

U. Farinelli et al., Scme Experience and Study on Decommissioning Performed in Italy, International Atomic Jinergy Agency Report IAEA-SM-234/6 (1979).

FISHER

F. D. Fisher, G. S. Barney, T. D. Cooper, and M. J. Duchsherer, Silver-Catalyzed $\mathrm{PuO}_{2}$ Dissolution with Perizlfate, Westinghouse Hanford Company Report WHC-SA-1170-FP (1991).

GORODINSKY

S. M. Gorodinsky et c.1., Decontamination of Individual Protective Materials and Protective Coatings, Trans. of book published in Moscow, 1964.

\section{GRIGGS}

B. Griggs, The Decontamination of Reactors and Reactor Loops. A Literature Review, Battelle Pacific North west Laboratory Report HW-57642 (1958).

\section{GUTHRIE}

B. Guthrie, Foam Decontamination Technology Can Reduce Generated Waste by 70\%, D\&D Technologies, The Decommissioning and Decontamination Briefing, Kaiser Engineers Hanford Company, May 1, 1993.

\section{HANULIK}

J. D. Hanulik and Wr. T. Rippin, "Chemical Decontamination for Decommissioning with Application of DECCIHA Technology on Metal, Concrete, and Brickwork," Proceedings Institute of Mechanival Engineers Nuclear Decommissioning '92, Decommissioning of Radioactive Facilitie:; International Conference, London, 1992, pp. 105-112 (1992). 
HARMER-1979

D. E. Harmer and J. L. White, "Results to Date of the DRESDEN-1 Chemical Cleaning," in Decontamination and Decommissioning of Nuclear Facilities, M. M. Osterhout, Ed., Plenum Press, New York, pp. 269-280 (1979).

HARMER-1986

D. E. Harmer and J. L. White, Chemical Cleaning of Dresden-Unit 1: Final Report, Report DOE/ET/34205-34, Department of Energy (1986).

\section{HARMON}

H. D. Harmon, Dissolution of $\mathrm{PuO}_{2}$ with Cerium(IV) and Fluoride Promoters, Savannah River Laboratory Report DP-1371 (1975).

HARRIS-1982

J. M. Harris, J. R. Miller, R. S. Frazier, and J. H. Walter, “A Foam Process for Application of Decontamination Agents," Decontamination of Nuclear Facilities: International Joint Topical Meeting ANS-CNA, Niagara Falls, Canada, September 19-22, 1982, pp. 4-374-80 (1982).

HARRIS-1976

W. T. Harris, Chemical Milling, Clarendon Press, Oxford (1976).

HAYASHI

S. Hayashi et al., Experience in the Replacement of the Failed Acid Recovery Evaporator at the Tokai Reprocessing Facility, OECD, Paris, France (1980).

\section{HEITMANN}

H. G. Heitmann, "German Development in Acid Cleaning of High Pressure Boilers," J. Eng. Power $\underline{83}, 354$ (1961).

\section{HORNER}

D. E. Horner, D. J. Crouse, and J. C. Malen, Cerium-Promoted Dissolution of $\mathrm{PuO}$ and $\mathrm{PuO}_{2}-\mathrm{UO}_{2}$ in Nitric Acid, Oak Ridge National Laboratory Report ORNL/TM-4716 (1977).

IAEA-1985

International Atomic Energy Agency, Decontamination of Nuclear Facilities Operation, Inspection, Maintenance, Modification or Plan Decommissioning, International Atomic Energy Agency Technical Reports Series No. 249 (1985).

IAEA-1988

International Atomic Energy Agency, Decontamination and Demolition of Concrete and Metal Structures During the Decommissioning of Nuclear Facilities, International Atomic Energy Agency Technical Reports Series No. 286 (1988). 


\section{JOHNSON}

A. B. Johnson, A Siudy of Dilute Reagent Decontamination for Application in Boiling

Water Reactors, Battelle Pacific Northwest Laboratory Report NP-2960 (1983).

\section{JOHNSTON}

F. Johnston and J. Ka:z, Decontamination of Stainless Steel, Argonne National Laboratory Report ANL-4970 (1953).

\section{JUNG}

J. Jung et al., Chemical Aspects on Decontamination of PWR Components, Proceedings of the 3rd International Conference on Water Chemistry of Nuclear Systems, British Nuclear Energy Society, Lonclon, 1983, Vol. 2, pp. 93-101 (1983).

\section{$\mathrm{KOCH}$}

C. V. Koch and R. Gruner, "Decontamination During Decommissioning," Kerntechnik $\underline{6}$, 56 (1990).

KRATZER

W. K. Kratzer, "Desontamination of the Hanford N-Reactor in Support of Continued Operation," in Decontamination and Decommissioning of Nuclear Facilities, M. M. Osterhout, Ed., Plenum Press, New York, pp. 107-115 (1979).

KRASZNAI

J. Krasznai, "Pickering NGS Heat Transport System Decontamination Using the CANDECON Process," ] Jecontamination of Nuclear Facilities: International Joint Topical Meeting ANS-CNA, Niagara Falls, Canada, September 19-22, 1982, pp. 2-55-2-69 (1982).

\section{KRYSTOW}

P. E. Krystow and JM. Balicki, "Behavior of 18-8 Stainless Steel in 2 Normal Boiling Nitric and Sulfuric Acid Mixtures," Corrosion 12, 449 (1956).

\section{LACY}

C. S. Lacy and B. Montford, "Decontamination Experience in Ontario Hydro," in Decontamination and Decommissioning of Nuclear Facilities, M. M. Osterhout, Ed., Plenum Press, New York, pp. 93-105 (1979).

\section{LANGSTON}

H. C. Langston, P. C. Hoyle, and J. H. Adams, "Contour Etching of Steel," Airch. Prod., Lond. 22, 21\& (1960).

\section{LITVINOVA}

E. I. Litvinova, "Passivity of Steel in Nitroses," J. Applied Chemistry USSR 29, 1641 (1956). 


\section{LOUCKS}

C. M. Loucks, "Cleaning and Defilming Art in Industry," in Decontamination of Nuclear Reactors and Equipment, J. A. Ayres, Ed., Ronald Press, New York (1970).

\section{MANION}

W. J. Manion and T. S. LaGuardia, Decommissioning Handbook, Department of Energy Report DOE/EV/10128-1, RLO/SFM-80-3 (1980).

\section{MAFFEI}

H.P.Maffei, Descaling of Various Iron and Nickel Base Alloys, U.S. Atomic Energy Commission Report HW-79048 (1963).

\section{MCCORKLE}

K. H. McCorkle and W. R. Winsbro, Decontamination of the ORNL THOREX Pilot Plant, Oak Ridge National Laboratory Report ORNL-2058 (1956).

\section{McGREW}

J. W. McGrew, S. Frank, and T. Page, Autoclave Testing of Monel, Nickel, and Inconel, Martin Company, Nuclear Division, U.S. Atomic Energy Commission Report MND-E-2655 (1961).

\section{MCKINNELL}

W. P. Mckinnell, Jr. et al., "The Effect of $\mathrm{NO}, \mathrm{HNO}_{2}$, and $\mathrm{HNO}_{3}$ on Corrosion of Stainless Steel by $\mathrm{H}_{2} \mathrm{SO}_{4}$," Corrosion $\underline{14}, 9$ (1958).

\section{MEIGS}

R. A. Meigs, "Use of Foam Chemical for Decontamination," Proceedings of the International Decommissioning Symposium, Pittsburgh, Pennsylvania, October 4-8, 1987, pp. IV23-IV30 (1987).

MESERVEY-1963

A. B. Meservey, Peroxide-Inhibited Decontamination Solutions for Carbon Steel and Other Metals in the Gas-Cooled Reactor Program, Oak Ridge National Laboratory Report ORNL-3308 (1963).

\section{MESERVEY-1970}

A. B. Meservey, "Decontamination and Film Removal," in Decontamination of Nuclear Reactors and Equipment, J. A. Ayres, Ed., Ronald Press, New York, pp. 137-159 (1970).

\section{MORSON}

Robert Morson, Numatec, Inc., personal communication (1995). 


\section{MUNSON}

L. F. Munson et al., An Assessment of Chemical Processes for the Postaccident Decontamination of Reactor Coolant Systems, Battelle Pacific Northwest Laboratory Report NP-2866 (1983).

\section{NACE}

National Association of Corrosion Engineers, Task Group T-7D-7, "Procedures for Quantitative Removal of Oxide Scales Formed in High Temperature Water and Steam," Mater. Protect. $\underline{6}, 69$ (1967).

NEA

Report by an NEA Group of Experts, March 1981, private communication from Jan Arvesen to W. J. Marion, Reference JA/Eli, April 24, 1980.

NEI

"Pacific Nuclear Gains Experience with Dilute Chemical Processes," Nuclear Engineering International, $\underline{30}$, pp. 40-45 (1985).

NESBITT

J. F. Nesbitt, S. C. Slate and L. K. Fetrow, Decontamination of High-Level Waste Canisters, Battelle Pacific Northwest Laboratory Report PNL-3514 (1980).

$\mathrm{OH}$

Won Zih Oh et al., Decontamination and Decommissioning Technology Development of Nuclear Facilities, Korea Advanced Energy Research Institute Report KAERI/RR-798/88 (1988).

ONUMA-1990A

Tsutomu Onuma et a]., Japanese KoKai Patent No. Hei 2[1990]-22596 (1990).

ONUMA-1990B

Tsutomu Onuma et a.., Japanese KoKai Patent No. Hei 2[1990]-22597 (1990).

ORNL

Oak Ridge National Laboratory, Oak Ridge National Laboratory Technology Logic Diagram, Volume 2, Oak Ridge National Laboratory Report DE93016147 (1993).

PALMER

P. A. Palmer, Chemical Decontamination of Process Equipment Using Recyclable Chelating Agents, Department of Energy Report DOE/MC/30168-94/C0348 (1994).

PANCER

G. P. Pancer and J. L. Zegger, APPR-1 Research and Development Program, Alco Products, Inc. Report APAE 43, Vol. III (1959). 
PASCALI

R. Pascali, "Chemical and Electrochemical Decontamination," Decommissioning of Nuclear Power Plants: Proceedings of a European Conference, Luxembourg, May 22-24, 1984, K. H. Schaller, Ed., pp. 139-160 (1984).

\section{PAVLIK}

O. Pavlik, Decontamination of Nuclear Facilities by Electrochemical Methods, International Atomic Agency Report IAEA-IECDOC-511 (1989).

\section{PEACH}

M. J. Peach and R. L. Skelton, "Chemical Decontamination for Decommissioning," Proceedings of International Conference on Decommissioning of Major Radioactive Facilities, Institute of Mechanical Engineers, pp. 151-157 (1988).

PERRIGO-1967

L. D. Perrigo et al., "Plutonium Recycle Test Reactor Decontamination Following a MgO$\mathrm{PuO}_{2}$ Fuel Element Failure," Proceedings of the First International Symposium on the Decontamination of Nuclear Installations, H. J. Blythe, Ed., Cambridge University Press, pp. 129-141 (1967).

PERRIGO-1979

L. D. Perrigo and J. R. Devine, Decontamination Methods, Battelle Pacific Northwest Laboratories Report PNL-SA-7770 (1979).

PICK

M. E. Pick and M. G. Segal, "Chemical Decontamination of Water Reactors CEGB Developments and the International Scene," Nucl. Energy 22, 433 (1983).

PRWRA

The Puerto Rico Water Resources Authority and United Nuclear Corporation Boiling Nuclear Superheater Power Station Decommissioning Final Report, The Puerto Rico Water Resources Authority and United Nuclear Corporation Report WRA-B-70-500 (1970).

RANKIN-1982

W. N. Rankin, Decontamination of Savannah River Plant Waste Glass Canisters,

E. I. duPont de Nemours \& Company Report DP-MS-81-112 (1982).

RANKIN-1990

W. N. Rankin and J. F. McGlynn, Overview of Decontamination Technology, Westinghouse Savannah River Report WSRC-RP-89-1080 (1990).

RANKIN-1992

S. K. Rankin, Two-Step Chemical Decontamination Technology, Westinghouse Savannah River Laboratory Report WSRC-RP-92-998 (1992). 
ROLLOR-1992

M. A. Roller et al., Industrial-Scale Decontamination Using the DECOHA Process at

Chernobyl, Waste Management '92, Tucson, AZ, March 1-5, 1992, pp. 569-573 (1992).

ROLLOR-1995

M. A. Roller, Chemical Decontamination: The Roles of Process Control and Planning in

Waste Minimization, ? ?resented at Waste Management ‘95, Tucson, AZ, March 1995.

RYAN

Jack L. Ryan, L. A. Bray, E. J. Wheelwright, and G. H. Bryan, Catalyzed Electrolytic Plutonium Oxide (CEPOD)-The Past Seventeen Years and Future Potential, Battelle Pacific Northwest Laboratory Report PNL-SA-18018 (1990).

\section{SADOWSKI}

G. S. Sadowski, “Decontamination of Processing Plants,” Nucleonics $\underline{15}, 68$ (1957).

SCHENKER

E. Schenker, Fuel E'ement Defects and Decontamination of the Diorit Reactor, Part II, Eidgenoessisches Institute für Reaktorschung Report EIR-150 (1969).

\section{SKARPELOS}

J. M. Skarpelos and A. J. Lobsinger, Decontamination of H-Loop Following a Fuel Element Failure, US Atomic Energy Commission Report HW-42081 (1956).

\section{SHURTE}

E. A. Shurte and W. N. Rankin, "Evaluation of Commercially Available Decontamination Chemicals," Waste Nanagement '88, Tucson, AZ, Vol. 1, pp. 725-732 (1988).

SMEE

J. L. Smee, "Dissolution Characteristic of Metal Oxides in Water Cooled Reactors," in Decontamination and Decommissioning of Nuclear Facilities, M. M. Osterhout, Ed., Plenum Press, New York, pp. 281-292 (1979).

\section{SPEKKENS}

P. Spekkens, "Decontamination Solvent for PHWR Fueling Machines," Decontamination of Nuclear Facilities International Joint Topical Meeting ANS-CNA, Niagara Falls, Canada, September 17-22, 1982, pp. 2-21-2-33 (1982).

SPERANZINI-1990A

R. A. Speranzini, R. Voit, and M. Helms, "CAN-DECON Makes a Strong Comeback as CAN-DEREM," Nucl zar Engineering International 35, 52 (1990).

SPERANZINI-1990B

R. A. Speranzini, De:ontamination Effectiveness of Mixtures of Citric Acid, Oxalic Acid and EDTA, Atomic Entergy of Canada Limited Report AECL10109 (1990). 


\section{STEWART}

W. B. Stewart and T. S. Drolet, "Design Consideration for PHWR Decontamination," in Decontamination and Decommissioning of Nuclear Facilities, M. M. Osterhout, Ed., Plenum Press, New York, pp. 81-89 (1979).

\section{TOROK}

J. Torok, "An Oxidizing Pretreatment for the Decontamination of Austenitic Alloys by CAN-DECON," Decontamination of Nuclear Facilities: International Joint Topical Meeting ANS-CNA, Niagara Falls, Canada, September 19-22, 1982, pp. 3-37-3-56 (1982).

\section{TURNER}

A. D. Turner et al., Development of Remote Electrochemical Decontamination for Hot Cell Applications, Harwell Laboratory Report AERE-G5004 (1989).

\section{URIARTE}

A. L. Uriarte and R. H. Rainey, Dissolution of High-Density $\mathrm{UO}_{2}, \mathrm{PuO}_{2}$, and $\mathrm{UO}_{2}-\mathrm{PuO}_{2}$ Pellets in Inorganic Acids, Oak Ridge National Laboratory Report ORNL-3695 (1965).

UNGER-1973A

W. E. Unger et al., Aqueous Fuel Reprocessing Quarterly Report for Period Ending December 31, 1972, Oak Ridge National Laboratory Report ORNL-TM-4141 (1973).

UNGER-1973B

W. E. Unger et al., Aqueous Fuel Reprocessing Quarterly Report for Period Ending March 31, 1973, Oak Ridge National Laboratory Report ORNL-TM-4240 (1973).

UNGER-1973C

W. E. Unger et al., Aqueous Fuel Reprocessing Quarterly Report for Period Ending June 30, 1973, Oak Ridge National Laboratory Report ORNL-TM-4301 (1973).

\section{UNGER-1974}

W. E. Unger et al., Aqueous Fuel Reprocessing Quarterly Report for Period Ending September 30, 1973, Oak Ridge National Laboratory Report ORNL-TM-4394 (1974).

\section{VIEBROCK}

J. M. Viebrock, "Corrosion of Type 304 Stainless Steel in Mixed Anhydrous Nitric and Sulfuric Acids," Corrosion 25, 9 (1969).

\section{WATKINS}

R. M. Watkins, Development of Agents and Procedures for Decontamination of the Yankee Reactor Primary Coolant Systems, Westinghouse Power Department Report YAEC-117 (1959).

\section{WATSON}

C. D. Watson, A General Decontamination Manual for the Idaho Chemical Processing Facility, Department of Energy, Idaho Operations Office Report I00-26081 (1953). 
WEED-1962A

R. D. Weed, "Evalualion of Nuclear Reactor Decontaminants," Corrosion 18, 224t (1962).

WEED-1962B

R. D. Weed, "Decontamination of Pressurized-Water Systems," Master's Thesis, University of Washington, Sieattle, 1962.

WEED-1963

R. D. Weed, Decontcmination Experience with High Temperature In-Reactor Test Loops, Hanford Atomic Procucts Operation Report HW-SA-3021 (1963).

WEED-1968

R. D. Weed, Deconiamination of the Plutonium Recycle Test Reactor (PRTR) Primary System, Battelle Pacilic Northwest Laboratory Report BNWL-711 (1968).

WEED-1970

R. D. Weed, "Decontamination-Historical Survey," in Decontamination of Nuclear Reactors and Equipment, J. A. Ayres, Ed., Ronald Press, New York, pp. 24-33 (1970).

WHEELWRIGHT

E. J. Wheelwright, J. Ryan, L. Bray, G. Bryan, J. Surma, and J. Matheson, "The Use of Catalyzed Electrolyti: Plutonium Oxide Dissolution (CEPOD) for Waste Treatment," Battelle Pacific Northwest Laboratory Report PNL-DS-29739 (1991).

WILLIE

H. Willie and H. Bertholdt, System Decontamination with CORD and Decontamination for Unrestricted Release, Nuclear Power Performance and Safety, Vol. 5, IAEA-CN-48/158 (1988).

\section{WILSON}

A. S. Wilson, U.S. Patent 3,005,682 (October 24, 1961).

WOOD

C. Wood, "Developing Decon," Nuclear Engineering International, Vol. 29, No. 81, pp. 15-17 (1994).

ZEGGER-1959A

J. L. Zegger and G. P. Pancerr, APPR-1 Research and Development Program, Alco Products, Inc. Report APAE No.43, Vol. I (1959).

ZEGGER-1959B

J. L. Zegger and G. F'. Pancer, APPR-1 Research and Development Program, Alco Products, Inc. Report APAE No. 43, Vol. II (1959). 
ZEGGER-1960

J. L. Zegger and G. P. Pancer, "A Chemical Method for Nuclear Reactor Decontamination," Nuclear Engineering, Chemical Engineering Progress Symposium Series, No. 28, Vol. 56, pp. 66-71 (1960). 
Distribution for ANL-97/19

Internal:

J. Andrew

J. E. Helt

S. K. Bhattacharyya

J. J. Laidler

M. A. Sodaro

D. B. Chamberlain (30)

R. A. Leonard

M. J. Steindler

C. Conner

C. J. Mertz

D. M. Strachan

J. C. Cunnane

L. Nuñez

D. W. Green

J. Sedlet

G. F. Vandegrift

R. D. Wolson

J. E. Harmon

External:

DOE-OSTI (2)

ANL-E Library

ANL-W Library

Manager, Chicago Operations Office, DOE

R. Baker, DOE-CH

A. Bindokas, DOE-CH

J. C. Haugen, DOE-CH

A. L. Taboas, DOE-CH

Chemical Technology Division Review Committee Members:

H. U. Anderson, University of Missouri-Rolla, Rolla, MO

E. R. Beaver, Monsanto Company, St. Louis, MO

D. L. Douglas, Consultant, Bloomington, MN

R. K. Genung, Oak Ridge National Laboratory, Oak Ridge, TN

J. G. Kay, Drexel L"niversity, Philadelphia, PA

R. A. Osteryoung, INorth Carolina State University, Raleigh, NC

G. R. St. Pierre, Ohio State University, Columbus, $\mathrm{OH}$

G. T. Berlin, Westinghouse Hanford Company, Richland, WA (3)

S. Bossart, USDOE, Federal Energy Technology Center, Morgantown, WV

L. Chen, Naperville, $\mathrm{IL}$

L. Dworjahyn, Savannah River Technical Center, Aiken, SC

C. W. Frank, USDOE, Office of Technology Development, Washington, DC

D. Haley, ORNL, Martin Marietta Energy Systems, Inc., Oak Ridge, TN

P. Hart, USDOE, Federal Energy Technology Center, Morgantown, WV

J. M. Hyde, USDOE, Germantown, MD

S. C. Lien, USDOE, Office of Technology Development, Germantown, MD

G. J. Lumetta, Pacific Ncrthwest Laboratory, Richland, WA

C. P. McGinnis, Oak Ridge National Laboratory, Oak Ridge, TN

A. C. Muscatello, LATO Office, Rocky Flats Plant, Golden, CO

A. L. Olson, Lockheed Iclaho Technology Company, Idaho Falls, ID

M. Palmer, Los Alamos INational Laboratory, Los Alamos, NM

G. Pfennigworth, Martin Marietta Energy Systems, Oak Ridge, TN 
I. R. Tasker, Waste Policy Institute, Gaithersburg, MD

M. Thompson, Westinghouse Savannah River Company, Aiken, SC

T. A. Todd, Lockheed Idaho Technology Company, Idaho Falls, ID

E. V. Weiss, Westinghouse Hanford Company, Richland, WA

S. Yarbro, Los Alamos National Laboratory, Los Alamos, NM 